\title{
Firm-Specific Productivity Risk over the Business Cycle: Facts and Aggregate Implications
}

\author{
Ruediger Bachmann Christian Bayer*
}

April 8, 2009

\begin{abstract}
Is time-varying firm-level uncertainty a major cause or amplifier of the business cycle? This paper investigates this question in the context of a heterogeneous-firm RBC model with persistent firm-level productivity shocks and lumpy capital adjustment, where cyclical changes in uncertainty correspond naturally to cyclical changes in the cross-sectional dispersion of firm-specific Solow residual innovations. We use a unique German firm-level data set to investigate the extent to which firm-level uncertainty varies over the cycle. This allows us to put empirical discipline on our numerical simulations. We find that, while firmlevel uncertainty is indeed countercyclical, it does not fluctuate enough to significantly alter the dynamics of an RBC model with only first moment shocks. The mild changes we do find are mainly caused by a bad news effect: higher uncertainty today predicts lower aggregate Solow residuals tomorrow. This effect dominates the real option value effect of time-varying uncertainty, highlighted in the literature.
\end{abstract}

JEL Codes: E20, E22, E30, E32.

Keywords: Ss model, RBC model, lumpy investment, countercyclical risk, aggregate shocks, idiosyncratic shocks, heterogeneous firms, news shocks, uncertainty shocks.

\footnotetext{
${ }^{*}$ Respectively: University of Michigan; IGIER, Universitá Bocconi. We are grateful to seminar/meeting participants at the ASSA (San Francisco), Duke, Georgetown, Innsbruck, Michigan-Ann Arbor, Minneapolis FED, Universitá Ca'Foscari Venezia, Wisconsin-Madison and Zuerich for their comments. We thank the staff of the Research Department of Deutsche Bundesbank for their assistance. Special thanks go to Timm Koerting for excellent research assistance.
} 


\section{Introduction}

"Crises feed uncertainty. And uncertainty affects behaviour, which feeds the crisis. [...] But there is more at work. If you think that another Depression might be around the corner, better to be careful and save more."

IMF Chief Economist, Olivier Blanchard, in: The Economist, 29 January, 2009

Is time-varying firm-level uncertainty a major cause or amplifier of the business cycle? This paper investigates this question in the context of a heterogeneous-firm RBC model with persistent firm-level productivity shocks and lumpy capital adjustment. We make three contributions to the existing literature: first, we discipline the calibration of time-varying uncertainty as a driving force through a detailed analysis of the behavior of the cross-section of firms over the cycle, rather than through stock market data; secondly, we analyze the implications of timevarying uncertainty in the context of a general equilibrium framework and using the detailed unconditional and conditional second moment analysis of model-simulated aggregate time series that has become a standard tool in the business cycle literature; and, thirdly, we show a new mechanism through which uncertainty shocks have (mild) aggregate effects: a bad news effect, rather than the time-varying option value effect (wait-and-see) that has been highlighted thus far (Dixit and Pindyck, 1994, and, more recently, Bloom, 2009). We find the wait-and-see-effect to be dominated by the bad news effect.

In the aforementioned model context, cyclical changes in uncertainty correspond naturally to cyclical changes in the cross-section of firms - more specifically the dispersions of change rates of firm-level Solow residuals, real value added and real sales. Thus, using the balance sheet data set of Deutsche Bundesbank (USTAN) - a unique private sector, annual, firm-level data set that allows us to investigate 26 years of data (1973-1998), in which the cross-sections of the panel have over 30,000 firms per year on average, and which has a broad ownership, size and sectoral coverage -, we first show that the cross-sectional standard deviations of the firm-level innovations in the Solow residual, real value added and sales are indeed robustly and significantly countercyclical. This confirms U.S.-related findings by Bloom (2009) and Bloom et al. (2009) for the implied volatility of the stock market, for Compustat data on publicly traded firms and for sectoral data. We interpret these changes as countercyclical fluctuations in firm-specific productivity uncertainty. Second, we show that for our broad German cross-section of firms the volatility in uncertainty over the cycle is substantially lower than has been considered in the literature. These two results are robust to different choices for the cyclical indicator, to alternative calculations of the Solow residual, and to various changes in the sample selection criteria. Figure 1 illustrates the countercyclicality of firm-level risk. It displays for Germany the annual 
time series of the dispersion of firm-level Solow residual innovations, linearly detrended, and the cyclical component of GDP, as measured by log-HP(100) filtered aggregate output. ${ }^{1}$

Figure 1: Time Series of the Dispersion of Firm-Level Solow Residual Innovations (Normalized by the Average Dispersion) and the Cyclical Component of GDP

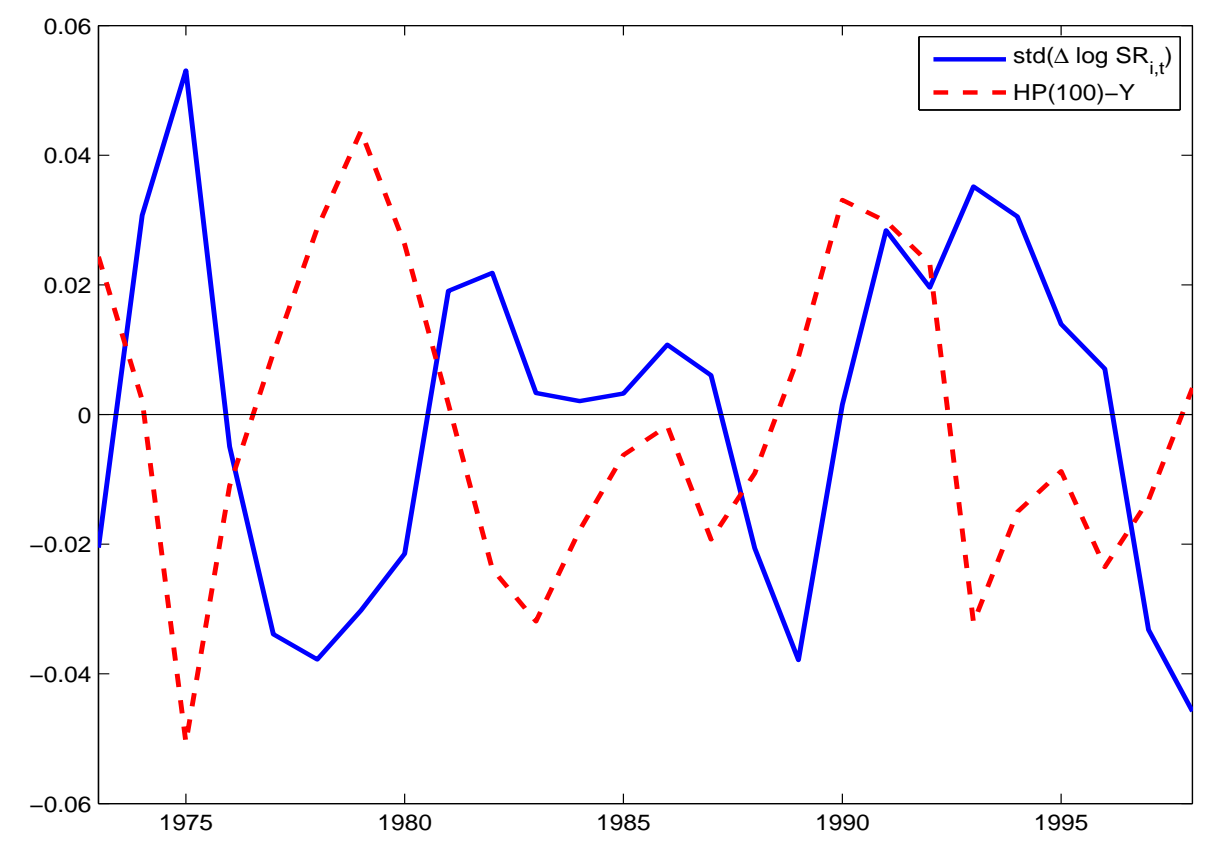

Notes: std: cross-sectional standard deviation, linearly detrended. $H P(\lambda)-Y$ : Cyclical component of GDP after HP-filtering using smoothing parameter $\lambda$.

We then explore the quantitative importance of these shocks to uncertainty in a heterogeneous-firm RBC model similar to the one in Khan and Thomas (2008) and Bachmann et al. (2008). We have developed the computational techniques to study time-varying uncertainty in general equilibrium in parallel with Bloom et al. (2009). We find that uncertainty shocks alone - if of a size in line with our empirical evidence - do not introduce quantitatively significant business cycle fluctuations. Moreover, purely uncertainty driven business cycles lead to counterfactual acyclicality of aggregate consumption.

Shocks to uncertainty nonetheless modestly alter the aggregate behavior of the model if they are introduced alongside standard first moment fluctuations in aggregate Solow residuals and compared to a model with only these first moment shocks (essentially the standard RBC model). Yet, this change does not come through the real options effect often associated with

\footnotetext{
${ }^{1}$ See Appendix B.1 for analogous figures for the time series of the dispersions of firm-level innovations to value added and sales, as well as scatter plots between dispersion measures and the cyclical component of GDP.
} 
time-varying uncertainty. Instead, we identify a new economic channel, by which fluctuations in uncertainty influence the business cycle that results only from their correlation with aggregate productivity. Since changes in uncertainty empirically correlate with future developments in the aggregate Solow residual, the former constitute news about the latter.

Specifically, we find that an increase in productivity risk essentially acts as a bad news shock. In general equilibrium, this means that households decrease their consumption and increase their labor supply, which we find to be consistent with the data. We also find a decrease in the real wage as a result of a shock to uncertainty not only in our model but again also in the impulse response function of the data. As a result of this decrease in wages, we find - again both in the data as well as in our model - an increase in economic activity at the moment of the uncertainty shock, followed by a recession, when the predicted downturn in productivity occurs. The effects of uncertainty shocks that we find in our model almost entirely operate through this channel.

Comparing a partial equilibrium version to our general equilibrium model in terms of the impulse response functions of investment with respect to shocks to uncertainty illustrates this mechanism further. While in partial equilibrium the bad news on impact causes aggregate investment activity to collapse, in general equilibrium, this effect is reversed by the decrease in the real interest rate, such that investment rates even expand on impact and only turn negative as lower productivity actually realizes. This shows that general equilibrium analysis is paramount in understanding the aggregate effects of firm-level uncertainty shocks.

The remainder of this paper is organized as follows: Section 2 describes our data set, the USTAN data, discusses briefly the selection of the final sample and details our empirical results. Section 3 explains the model. Section 4 describes its calibration and Section 5 discusses the numerical results. Appendices provide more details on the data set, give further robustness checks for the empirical findings as well as for the simulation results.

\section{Related Literature}

Over the last two decades, the economic literature has used models with fixed costs of capital adjustment or irreversibility as a natural starting point to study the effects of uncertainty on economic activity (see e.g. Dixit and Pindyck, 1994). More recently, Bloom (2009) and Bloom et al. (2009) document that increases in stock market volatility are correlated with a reduction in aggregate economic activity. The former in partial equilibrium, the latter in general equilibrium then provide a formal model qualitatively similar to the one used here, where an increase in uncertainty leads to a higher real option value of investment, letting more firms 'wait and see' after such an increase, which in turn leads to a fall in aggregate investment and employment. In a similar vein and also in general equilibrium, but in a different model context, Sim (2008) puts

forth a model that explains the cyclical patterns in firms' entry and exit with cyclical variations 
in uncertainty. Gilchrist et al. (2009) explore the implications of time-varying uncertainty for bond risk premia and via this channel for aggregate investment in a general equilibrium model. Finally, Alexopoulos and Cohen (2009) propose the 'number of New York Times articles on uncertainty and economic activity' as an alternative measure for uncertainty shocks and find in an empirical exercise that this measure of uncertainty is negatively correlated with aggregate activity.

None of the above draws its empirical evidence on broad-based cross-sectional firm data. The data that is typically used is stock market data or analyst data available only for a subset of large publicly traded companies or even sectoral data. Using stock market data to identify fluctuations in productivity, however, implies strong market efficiency assumptions (see for instance Shiller, 1981). We use firm-level balance sheet data instead. This links the empirical part of this paper most closely to a series of papers by Higson and Holly et al. (2002, 2004), Doepke and Holly et al. (2005, 2008), Doepke and Weber (2006), as well as Holly and Santoro (2008). Higson and Holly et al. (2002), using Compustat data, study empirically the cyclicality of the standard deviation, skewness and kurtosis of the sales growth rate distribution and find them to be countercyclical, countercyclical and procyclical, respectively. Higson and Holly et al. (2004) repeat this analysis for UK data on quoted firms, and Doepke and Holly et al. (2005) for Germany, using the USTAN database, with similar findings. Doepke and Weber (2006) study, again using USTAN data, the cyclicality of transitions between sales growth regimes in firm-level data. In contrast to these papers, we focus on the cyclicality of cross-sectional second moments only, but include real value added and Solow residuals into the analysis. These are arguably the right firm-level counterpart for GDP and aggregate Solow residuals, respectively.

The quantitative part of this paper draws heavily on the recent literature on heterogenousfirm RBC models, developed in Khan and Thomas (2008) as well as Bachmann et al. (2008). Finally, this paper is related to the work by Beaudry and Portier (2006), Jaimovich and Rebelo (2008), Sims (2008) as well as Schmidt-Grohe and Uribe (2008) on the impact of news shocks on business cycle dynamics. In a companion paper (Bachmann and Bayer, 2009), we focus on the implications of countercyclical dispersion in the firm-level Solow residual innovations for cross-sectional dynamics as opposed to aggregate dynamics. 


\section{The Facts}

In Section 2.1 we briefly describe the USTAN data set and the main sample selection criteria we use. Details are relegated to Appendix A.1. In Section 2.2 we present the baseline facts: the contemporaneous correlations of cyclical aggregate output and the cross-sectional standard deviations of log changes in firm-level Solow residuals, real value added and sales are negative, but the cyclical variations are small, at most 1.5 times the volatility of aggregate output. In Section 2.3 we perform extensive robustness checks and also show, how these facts depend on observable firm characteristics.

\subsection{A Brief Data Description}

\subsubsection{USTAN Data}

USTAN is a large annual firm-level balance sheet data base (Unternehmensbilanzstatistik) collected by Deutsche Bundesbank. It is unique in its size and coverage. It provides annual firm level data from 1971 to 1998 from the balance sheets and the profit and loss accounts of over 60,000 firms per year (see Stoess (2001), von Kalckreuth (2003) and Doepke et al. (2005) for further details). In the days when the discounting of commercial bills were one of the principal instruments of German monetary policy, Bundesbank law required the Bundesbank to assess the creditworthiness of all parties backing a commercial bill put up for discounting. The Bundesbank implemented this regulation by requiring balance sheet data of all parties involved. These balance sheet data were then archived and collected into a database.

Although the sampling design - one's commercial bill being put up for discounting - does not lead to a perfectly representative selection of firms in a statistical sense, the coverage of the sample is very broad. USTAN covers incorporated firms as well as privately-owned companies, which distinguishes it positively from Compustat data. ${ }^{2}$ Its sectoral coverage - while still somewhat biased to manufacturing firms - includes the construction, the service as well as the primary sectors. This makes it different from, for instance, the Annual Survey of Manufacturing (ASM) in the U.S. ${ }^{3}$ The following table 1 displays the sectoral coverage of our final baseline sample.

Moreover, while there remains a bias to somewhat larger and financially healthier firms, the size coverage is still fairly broad: $31 \%$ of all firms in our final baseline sample have less than 20 employees and 57\% have less than 50 employees (see Table 25 in Appendix A.1 for details).

\footnotetext{
${ }^{2}$ Davis et al. (2006) show that studying only publicly traded firms can lead to wrong conclusions, in particular when higher cross-sectional moments are concerned.

${ }^{3}$ An additional advantage of these data is easy access: while access is on-site, it is practically free for researchers, so that results derived from this data base can be easily tested and checked.
} 
Table 1: Sectoral Coverage

\begin{tabular}{lcc}
\hline \hline 1-digit Sector & Firm-year observations & Percentage \\
\hline Agriculture & 12,291 & 1.44 \\
Mining \& Energy & 4,165 & 0.49 \\
Manufacturing & 405,787 & 47.5 \\
Construction & 54,569 & 6.39 \\
Trade (Retail \& Wholesale) & 355,208 & 41.59 \\
Transportation \& Communication & 22,085 & 2.59 \\
\hline
\end{tabular}

Finally, the Bundesbank itself frequently uses the USTAN data for its macroeconomic analyses and for cross-checking national accounting data. We take this as an indication that the bank considers the data as sufficiently representative and of sufficiently high quality. This makes the USTAN data a uniquely suitable data source for the study of cross-sectional business cycle dynamics.

\subsubsection{Selection of the Baseline Sample}

From the original USTAN data, we select only firms that report complete information on payroll, gross value added and capital stocks. Moreover, we drop observations from East German firms to avoid a break of the series in 1990. In addition, we remove observations that stem from irregular accounting statements, e.g. when filing for bankruptcy or when closing operations. We deflate all but the capital and investment data by the implicit deflator for gross value added from the German national accounts.

Capital is deflated with one-digit sector- and capital-good specific investment good price deflators within a perpetual inventory method. Even though USTAN data can be considered as particularly high quality data, we cannot directly use capital stocks as reported. Tax motivated depreciation and price developments of capital goods lead to a general understatement of the stock of capital a firm holds. Thus, capital stocks have to be recalculated using a perpetual inventory method (see Appendix A.2, for details). Similarly, we recover the amount of labor inputs from wage bills, as information on the number of employees (as opposed to payroll data) is only updated infrequently for some companies (see Appendix A.3, for details). Finally, the firm-level Solow residual is calculated from data on gross value added and factor inputs.

We remove outliers according to the following procedure: we calculate log changes in real gross value added, the Solow residual, real capital and employment, as well as the firm-level investment rate and drop all observations where a change falls outside a three standard deviations 
interval around the year-specific mean. ${ }^{4}$ We also drop those firms for which we do not have at least five observations in first differences. This leaves us with a sample of 854,105 firm-year observations, which corresponds to observations on 72,853 firms, i.e. the average observation length of a firm in the sample is 11.7 years. The average number of firms in the cross-section of any given year is 32,850 . We perform numerous robustness checks with respect to each of the selection criteria and measurement choices: we use sectoral deflators for value added, an aggregate investment good price deflator, change the cut-off rule to 2.5 and 5 standard deviations and leave all firms in the sample with two and twenty observations in first differences, respectively. None of these choices change our baseline results (see Table 37 in Appendix B.1 for details).

\subsubsection{Solow Residual and Productivity Innovations}

We compute the firm-level Solow residual based on the following Cobb-Douglas production function in accordance with our model:

$$
y_{i, t}=z_{t} \epsilon_{i, t} k_{i, t}^{\theta} n_{i, t}^{v}
$$

where $\epsilon_{i, t}$ is firm-specific productivity, and $z_{t}$ is aggregate productivity. We assume that labor input $n_{i, t}$ is immediately productive, whereas capital $k_{i, t}$ is pre-determined and inherited from last period. In our main specification, we estimate the output elasticities of the production factors, $v$ and $\theta$, as median shares of factor expenditures over gross value added within each industry. ${ }^{5}$ We use log-differences in the Solow residual to capture Solow residual innovations, as the persistence of firm-level Solow residuals exhibits behavior close to a unit root. In order to check, whether our results are driven by measurement error in a difficult-to-measure driving force, we also study log-differences in outcome variables: firm-level real value added and sales. We remove firm fixed and sectoral-year ${ }^{6}$ effects from these first-difference variables to focus on idiosyncratic fluctuations that do not capture differences in sectoral responses to aggregate shocks or permanent ex-ante heterogeneity between firms. ${ }^{7}$ We focus on the cross-sectional

\footnotetext{
${ }^{4}$ This outlier removal is done after removing firm and sectoral fixed effects. Centering the outlier removal around the year mean is important to avoid artificial and countercyclical skewness of the respective distributions.

${ }^{5}$ To check the robustness of our results, we try alternative specifications with predefined elasticities common across sectors. We also change the timing assumption to include a predetermined employment stock, as well as immediate adjustment in both factors. All results are very robust to the alternative ways to generate the firmspecific Solow residual (see Table 30 Appendix B.1 for details).

${ }^{6}$ The sectoral fixed effects are essentially computed at the 2-digit level, see Table 24 in Appendix A.1 for details.

${ }^{7}$ Specifically, we decompose a variable observed of firm $i$ in sector $j$ at time $t$ into firm a fixed effect $\alpha_{i}$, a sectoral time effects $\gamma_{j t}$ and an idiosyncratic unpredictable error term $\varepsilon_{i j t}$, which are orthogonal to each other

$$
x_{i j t}=\alpha_{i}^{x}+\gamma_{j t}^{x}+\varepsilon_{i j t}^{x}
$$
}


dispersion of these three variables and measure the dispersion in terms of standard deviations. ${ }^{8}$ In a standard model with ex-ante homogenous firms, these standard deviations characterize the uncertainty or risk of a firm with regard to its idiosyncratic productivity growth. In line with this, the literature - e.g. Davis et al. (2006), Bloom et al. (2007), Sim (2008), Bloom et al. (2009), Bloom (2009) and Gilchrist et al. (2009) - has modeled fluctuations in idiosyncratic uncertainty as fluctuations in the standard deviation of firm-specific innovations in the Solow residual. We follow this view and study the quantitative aggregate importance of fluctuations in the crosssectional dispersion of productivity innovations.

\subsubsection{Macro data}

When combining this micro data with aggregate data, we have to take a stance on what sectoral aggregate we view as the empirical counterpart to our model. We chose to include firms from the following six sectors in our analysis: agriculture, mining and energy, manufacturing, construction, trade (both retail and wholesale) as well as the transportation and communication sector. This aggregate can be roughly characterized as the non-financial private business sector (NFPBS) in Germany. Whenever we use the term aggregate in the following, we mean this sector.

German national accounting data per one-digit sector (see Appendix A.1, Footnote 38, for a detailed description of the data sources used) allow us to compute real value added, investment, capital and employment data for this sectoral aggregate, and therefore also an aggregate Solow residual. Our USTAN sample captures on average $70 \%$ of sectoral value added and $78 \%$ of sectoral real gross output (sales).

In addition to representing a large part of the non-financial private business sector in Germany, USTAN also represents its cyclical behavior very well, as the following Table 2 shows: $^{9}$

Table 2: Cyclicality of Cross-Sectional Averages

\begin{tabular}{|c|c|}
\hline Cross-sectional Moment & $\rho(\cdot, H P(100)-Y)$ \\
\hline $\operatorname{mean}\left(\Delta \log \epsilon_{i, t}\right)$ & 0.592 \\
\hline $\operatorname{mean}\left(\Delta \log y_{i, t}\right)$ & 0.663 \\
\hline $\operatorname{mean}\left(\Delta \log\right.$ sales $\left._{i, t}\right)$ & 0.410 \\
\hline
\end{tabular}

Notes: mean: cross-sectional average, linearly detrended. $\rho$ : time series correlation coefficient. $H P(\lambda)-Y$ : Cyclical component of GDP after HP-filtering using smoothing parameter $\lambda$.

\footnotetext{
We then focus on the error term $\varepsilon_{i j t}$.

${ }^{8}$ The baseline within-transformed cross-sectional data for these dispersions can be found in Table 29 in Appendix A.5.

${ }^{9}$ We further illustrate the good representation properties of USTAN in Appendix A.1.
} 


\subsection{Main Facts}

\subsubsection{Idiosyncratic Productivity Risk: Large and Countercyclical}

Using the micro data from USTAN, we can compute the cross-sectional dispersions for innovations in firm-level Solow residuals, real value added and real sales. We analyze both their time-averaged long-run as well as their cyclical properties:

Table 3: Cyclicality and Volatility of Cross-Sectional Dispersion

\begin{tabular}{lccc}
\hline \hline Cross-sectional Moment & $s t d\left(\Delta \log \epsilon_{i, t}\right)$ & std $\left(\Delta \log y_{i, t}\right)$ & std $\left(\Delta \log\right.$ sales $\left._{i, t}\right)$ \\
\hline$c \nu(\cdot)$ & $2.67 \%$ & $3.73 \%$ & $3.82 \%$ \\
$\rho(\cdot, H P(100)-Y)$ & -0.481 & -0.450 & -0.405 \\
$\mu(\cdot)$ & 0.120 & 0.142 & 0.187 \\
\hline
\end{tabular}

Notes: std: cross-sectional standard deviation, linearly detrended. $c v$ : time series coefficient of variation. $\mu$ : time series average. See further notes to Table 2 .

Table 3 presents our main results:

- The time-averaged cross-sectional standard deviation of the log-changes in firm-level Solow residuals is large: $12 \%$, i.e. an order of magnitude larger than fluctuations in aggregate Solow residuals. For comparison, the volatility of the linearly detrended aggregate Solow residual is $2.06 \%$, the one for the linearly detrended cross-sectional average Solow residual $2.37 \%{ }^{10}$ This is also an order of magnitude larger than Kahn and Thomas (2008) as well as Bloom et al. (2009) - without the discipline of firm-level data - are using for the standard deviation of the innovations to firm-level Solow residuals in their models: $2.2 \%$ annually.

- The cross-sectional standard deviation of the innovations to firm-level Solow residuals is countercyclical with a correlation coefficient with HP-filtered aggregate GDP of - 0.481 . Table 4 shows that this countercyclicality is significant, as the $5 \%$ and $95 \%$ confidence bands from 10,000 parametric bootstrap simulations are both negative. ${ }^{11}$ The last column of Table 4 displays the fraction of positive correlations in these bootstrap simulations.

- The size of annual fluctuations in risk is relatively small, with a time-series coefficient of variation of $2.67 \%$.

\footnotetext{
${ }^{10}$ This order-of-magnitude difference also suggests that the fluctuations-in-uncertainty-story has to be likely one about idiosyncratic productivity, rather than aggregate productivity. Firms' policy functions are mainly determined by the idiosyncratic state given this difference, and fluctuations in anyway small aggregate risk do not seem to be a plausible candidate for business cycle fluctuations.

${ }^{11}$ We use a pairwise unrestricted VAR with one lag as the parametric model. The results from a nonparametric overlapping block bootstrap with a block size of four are similar to the parametric bootstrap.
} 
For comparison, Bloom et al. (2009) find a correlation of their stock market-based uncertainty index with GDP of -0.606 and Bloom (2009) considers a productivity process for monthly data, which exhibits a time-series coefficient of variation of the dispersion in annual productivity growth of roughly 17\%. Gourio (2008), using Compustat data, finds the correlation between GDP and the standard deviation of the innovation to a permanent productivity shock to be 0.56. ${ }^{12}$

One could be concerned that the Solow residual does not measure productivity well. For this reason, we provide evidence also from log-differences in endogenous outcome variables, namely real value added and real sales. As balance sheet items these are arguably less subject to measurement error. ${ }^{13}$ Using these indirect measures makes no difference: their cross-sectional dispersions are large on average, they are significantly countercyclical, but their business cycle fluctuations are small. In the next section we show that these findings are robust to specific choices we have made in generating the numbers in Table 3, as well as to subsamples stratified by observable firm characteristics, which means they are not a result of the sectoral or size composition of our sample.

Table 4: Cyclicality of Cross-Sectional Dispersion - Significance

\begin{tabular}{lcccc}
\hline \hline Cross-sectional Moment & $\rho(\cdot, H P(100)-Y)$ & $5 \%$ & $95 \%$ & Frac. w. opposite sign \\
\hline $\operatorname{std}\left(\Delta \log \epsilon_{i, t}\right)$ & -0.481 & -0.678 & -0.306 & 0.000 \\
$\operatorname{std}\left(\Delta \log y_{i, t}\right)$ & -0.450 & -0.675 & -0.196 & 0.005 \\
$\operatorname{std}\left(\Delta \log\right.$ sales $\left._{i, t}\right)$ & -0.405 & -0.711 & 0.042 & 0.065 \\
\hline
\end{tabular}

Notes: The columns 5\% and 95\% refer to the top and bottom 5-percentiles in a parametric bootstrap of the correlation coefficient. The last column displays the fraction of simulations with the opposite sign of the point estimate. See further notes to Tables 2 and 3.

\subsection{Robustness}

Obviously the question arises, whether these results are robust to the choice of the cyclical indicator and the dispersion measure used. Another question is to what extent they are driven by sample composition or cyclical sample selection.

\section{Cyclical Indicator and Dispersion Measure}

The following Table 5 shows that countercyclical idiosyncratic uncertainty as measured by the cross-sectional dispersion of firm-level Solow residual innovations is robust to the choice

\footnotetext{
${ }^{12}$ Interestingly, Comin and Mulani (2006), using also Compustat data, find procyclicality of a moving-standard deviation estimator of firm-level risk in real sales innovations.

${ }^{13}$ Bachmann and Bayer (2009) show that when looking at inputs, log-changes in firm-level employment are similarly countercyclical, firm-level investment rates are strongly and significantly procyclical.
} 
of the cyclical indicator (for $\operatorname{std}\left(\Delta \log y_{i, t}\right)$ and $\operatorname{std}\left(\Delta \log\right.$ sales $_{i, t}$ ) see Table 31 in Appendix B.1). The result stands irrespective of whether we choose as cyclical indicators output filtered using a smaller smoothing parameter for the HP filter, following Ravn and Uhlig (2002), apply a logdifference filter to output, or use the linearly detrended average cross-sectional investment rate, or the HP(100)-filtered aggregate employment, or aggregate Solow residuals.

Table 5: COUnTERCyCLICALITY OF IDIOSYNCRATIC UNCERTAinTY - ROBUSTNESS TO CyCLICAL INDICATOR

\begin{tabular}{lc}
\hline \hline Cyclical Indicator & $\rho\left(\operatorname{std}\left(\Delta \log \epsilon_{i, t}\right), \cdot\right)$ \\
\hline HP(6.25)-Y & -0.485 \\
Log-diff-Y & -0.583 \\
mean $\left(\Delta \log \epsilon_{i, t}\right)$ & -0.591 \\
Log-diff-N & -0.542 \\
Log-diff-Solow Residual & -0.465 \\
\hline
\end{tabular}

Notes: See notes to Tables 2 and 3. $N$ refers to aggregate employment.

Vice versa, as Table 6 shows, our three findings are also robust to the numerous choices we have made for the other part of the correlation, $s t d\left(\Delta \log \epsilon_{i, t}\right)$, for instance (for $s t d\left(\Delta \log y_{i, t}\right)$ and $\operatorname{std}\left(\Delta \log\right.$ sales $\left._{i, t}\right)$ see Table 32 in Appendix B.1). For instance, one can use the interquartile range (iqr) as the dispersion measure. Moreover, it is not the removal of firm-level and sectoral fixed effects that induces the countercyclicality, as row three of this table shows. Finally, the last two rows demonstrate that the results are neither driven by the German reunification, nor by the strong recession in 1975.

Table 6: More RoBustness

\begin{tabular}{lccc}
\hline \hline Cross-sectional Moment & $c v(\cdot)$ & $\rho(\cdot, H P(100)-Y)$ & $\mu(\cdot)$ \\
\hline $\operatorname{std}\left(\Delta \log \epsilon_{i, t}\right)_{\text {Baseline }}$ & $2.67 \%$ & -0.481 & 0.120 \\
\hline$i q r\left(\Delta \log \epsilon_{i, t}\right)$ & $4.56 \%$ & -0.386 & 0.130 \\
$\operatorname{std}\left(\Delta \log \epsilon_{i, t}\right)_{\text {raw }}$ & $2.90 \%$ & -0.449 & 0.126 \\
$\operatorname{std}\left(\Delta \log \epsilon_{i, t}\right)_{1973-1990}$ & $2.49 \%$ & -0.690 & 0.121 \\
$\operatorname{std}\left(\Delta \log \epsilon_{i, t}\right)_{1977-1998}$ & $2.50 \%$ & -0.320 & 0.119 \\
\hline
\end{tabular}

Notes: See notes to Tables 2 and 3. iqr stands for interquartile range, which is linearly detrended.

In any Solow residual calculation that is based on a simple Cobb-Douglas production function with only labor and capital, there is the potential problem of attributing optimal changes in utilization, hours per worker or effort to random productivity changes and therefore of overstating (average) firm-level risk. Therefore we focus in Table 7 on those firms who did not change 
the intensity of their material usage between two periods, assuming that observed changes in material usage are a good proxy for unobserved changes in utilization. These firms indeed exhibit a somewhat smaller productivity risk that fluctuates slightly more in relative terms than the productivity risk of the average firm in the sample. The measured countercyclicality of idiosyncratic uncertainty is smaller, ${ }^{14}$ but overall our results carry over to this group of firms.

Table 7: Results By Material Usage

\begin{tabular}{lccc}
\hline \hline Cross-sectional Moment & $c v(\cdot)$ & $\rho(\cdot, H P(100)-Y)$ & $\mu(\cdot)$ \\
\hline $\operatorname{std}\left(\Delta \log \epsilon_{i, t}\right)_{\text {Aggregate }}$ & $2.67 \%$ & -0.481 & 0.120 \\
$\operatorname{std}\left(\Delta \log \epsilon_{i, t}\right)_{\text {Material Intensity const. }}$ & $4.19 \%$ & -0.247 & 0.103 \\
\hline
\end{tabular}

Notes: See notes to Tables 2 and 3. Material Intensity const. refers to firms whose material expenditures over sales $\frac{m_{i, t}}{\text { sales }_{i, t}}$ have changed by less then one percentage point in absolute terms. Results for $\operatorname{std}\left(\Delta \log y_{i, t}\right)$ and $\operatorname{std}\left(\Delta \log\right.$ sales $\left._{i, t}\right)$ can be found in tables 33 in Appendix B.1.

\section{Sample Composition}

Table 8: RESULTS By SECTOR

\begin{tabular}{lccc}
\hline \hline Cross-sectional Moment & $c \nu(\cdot)$ & $\rho(\cdot, H P(100)-Y)$ & $\mu(\cdot)$ \\
\hline$s t d\left(\Delta \log \epsilon_{i, t}\right)_{\text {Aggregate }}$ & $2.67 \%$ & -0.481 & 0.120 \\
\hline$s t d\left(\Delta \log \epsilon_{i, t}\right)_{\text {AGR }}$ & $4.44 \%$ & -0.045 & 0.173 \\
$\operatorname{std}\left(\Delta \log \epsilon_{i, t}\right)_{\text {MIN/ENE }}$ & $11.46 \%$ & -0.166 & 0.116 \\
$\operatorname{std}\left(\Delta \log \epsilon_{i, t}\right)_{\text {MAN }}$ & $3.54 \%$ & -0.607 & 0.115 \\
$\operatorname{std}\left(\Delta \log \epsilon_{i, t}\right)_{\mathrm{CON}}$ & $4.56 \%$ & -0.483 & 0.112 \\
$\operatorname{std}\left(\Delta \log \epsilon_{i, t}\right)_{\mathrm{TRD}}$ & $2.68 \%$ & -0.192 & 0.124 \\
$\operatorname{std}\left(\Delta \log \epsilon_{i, t}\right)_{\mathrm{TRA} / \mathrm{COM}}$ & $3.28 \%$ & -0.036 & 0.136 \\
\hline
\end{tabular}

Notes: See notes to Tables 2 and 3. AGR: Agriculture; MIN/ENE: Mining \& Energy; MAN: Manufacturing; CON: Construction ; TRD: Trade (Retail \& Wholesale); TRA/COM: Transportation \& Communication.

USTAN is no random sample. Consequently, we need to check whether our findings are specific to certain sectors or types of firms overrepresented in this sample. Tables 8 to 10 show that this is not the case for $\operatorname{std}\left(\Delta \log \epsilon_{i, t}\right)$ (for $\operatorname{std}\left(\Delta \log y_{i, t}\right)$ and $\operatorname{std}\left(\Delta \log \operatorname{sales}_{i, t}\right.$ ) see Tables 34 to 36 in Appendix B.1). Table 8 displays the behavior of productivity risk for the six single-digit sectors in the USTAN sample. The relatively large idiosyncratic risk is obviously not specific to any sector, in fact the numbers are surprisingly uniform across sectors. When one disregards the small agricultural sector, average productivity uncertainty ranges from $11.2 \%$ in the

\footnotetext{
${ }^{14}$ The decline happens, irrespective of the cyclical measure used, but its magnitude is somewhat sensitive to the choice of the cyclical measure. For instance, had we used Log-diff-Y, the decline would have been from - 0.583 to -0.460 , and from -0.465 to -0.393 in the case of Log-diff-Solow Residual.
} 
construction sector to $13.6 \%$ in the transportation and communication sector. For the three sectors that comprise over $95 \%$ of all firms in the data - manufacturing, construction and trade - also the countercyclicality-of-uncertainty result is robust. ${ }^{15}$ Finally, also the result that risk fluctuations are not large is robust across sectors (again with the exception of the small mining and energy sector). Manufacturing and construction exhibit somewhat larger risk fluctuations, but the difference to both the trade sector and the aggregate is small.

The non random design of USTAN manifests itself not only in the sectoral but also the size composition of the sample. To understand the effect of this, we split the sample according to firm size, as measured by employment. Again this yields no different results. Table 9 shows that large firms exhibit a somewhat smaller average uncertainty that fluctuates more than the uncertainty of small firms, but overall the results are surprisingly uniform across size classes and invalidate the notion that large firms are just a collection of independently operating smaller units. ${ }^{16}$ Moreover, it shows that using data sets, which suffer from an even stronger overrepresentation of large firms, such as Compustat, may lead to an overstatement of the cyclical fluctuations in firm-level uncertainty.

Table 9: Results By Firm Size (EMPloyment)

\begin{tabular}{lccc}
\hline \hline Cross-sectional Moment & $c \nu(\cdot)$ & $\rho(\cdot, H P(100)-Y)$ & $\mu(\cdot)$ \\
\hline $\operatorname{std}\left(\Delta \log \epsilon_{i, t}\right)_{\text {Aggregate }}$ & $2.67 \%$ & -0.481 & 0.120 \\
\hline $\operatorname{std}\left(\Delta \log \epsilon_{i, t}\right)_{\text {SMALL33 }}$ & $2.01 \%$ & -0.341 & 0.137 \\
$\operatorname{std}\left(\Delta \log \epsilon_{i, t}\right)_{\text {SMALL75 }}$ & $2.42 \%$ & -0.441 & 0.125 \\
$\operatorname{std}\left(\Delta \log \epsilon_{i, t}\right)_{\text {SMALL95 }}$ & $2.62 \%$ & -0.474 & 0.121 \\
$\operatorname{std}\left(\Delta \log \epsilon_{i, t}\right)_{\text {LARGE05 }}$ & $5.55 \%$ & -0.508 & 0.098 \\
\hline
\end{tabular}

Notes: See notes to Tables 2 and 3. SMALL33 refers to the smallest 33\% firms in a given year, SMALL75 to the smallest $75 \%$, etc. if size is measured in employment.

\footnotetext{
${ }^{15}$ One could be concerned about the lower countercyclicality in the large trade sector, but again this difference is somewhat sensitive to the choice of the cyclical measure. For instance, had we used Log-diff-Y, the difference between the aggregate would have been from -0.583 versus -0.474 , and -0.465 versus -0.455 in the case of Log-diffSolow Residual.

${ }^{16}$ We tried alternative splits according to the stock of capital and real value added. The results are very similar, details can be found in Table 35 in Appendix B.1.
} 
Finally, Table 10 shows that the results are also robust across productivity classes.

Table 10: Results By Firm Productivity

\begin{tabular}{lccc}
\hline \hline Cross-sectional Moment & $c v(\cdot)$ & $\rho(\cdot, H P(100)-Y)$ & $\mu(\cdot)$ \\
\hline$\sigma\left(\Delta \log \epsilon_{i, t}\right)_{\text {Aggregate }}$ & $2.67 \%$ & -0.481 & 0.120 \\
\hline$s t d\left(\Delta \log \epsilon_{i, t}\right)_{\text {First Quartile }}$ & $2.48 \%$ & -0.751 & 0.127 \\
$\operatorname{std}\left(\Delta \log \epsilon_{i, t}\right)_{\text {Second Quartile }}$ & $2.63 \%$ & -0.400 & 0.113 \\
std $\left(\Delta \log \epsilon_{i, t}\right)_{\text {Third Quartile }}$ & $3.22 \%$ & -0.383 & 0.114 \\
$\operatorname{std}\left(\Delta \log \epsilon_{i, t}\right)_{\text {Fourth Quartile }}$ & $3.63 \%$ & -0.158 & 0.123 \\
\hline
\end{tabular}

Notes: See notes to Tables 2 and 3. First Quartile refers to the 25\% least productive firms in a given year, when measured in firm-level Solow residuals, Second Quartile to the firms with productivity in the $25 \%-50 \%$ range, etc.

\section{Cyclical Sample Selection}

So far we have focused on permanent misrepresentation of certain kinds of firms, like the bias towards manufacturing in USTAN. As we have shown, this can be dealt with by splitting the sample along observable characteristics. The possibility of systematic cyclical variation in sample selection, for instance through firm entry and exit, poses a more severe problem to our analysis.

Specifically, the USTAN sample is biased towards financially healthy firms and financial health can be expected to have cyclical fluctuations. However, this sample selection is important rather for the cross-sectional distribution of the levels of productivity, employment, and capital. Since we find close to unit-root behavior of these variables, however, levels have no predictive power for the first-differences on which our analysis focuses. Sample selection will thus depend on changes in productivity only insofar as these changes influence the level of productivity. For example, firms that have a lower average productivity-growth rate are more likely to drop out of the sample.

We check the importance of this effect in two ways, based on the dispersion of firm specific averages - the estimates of firm fixed effects. First, we check, how large the time-average dispersion of these fixed effects is. In order to be able to decompose the dispersion measure, we now use variances instead of standard deviations. The total cross-sectional variance of firm-level Solow residual innovations, $v a r_{\text {raw }}\left(\Delta \log \epsilon_{i, j, t}\right)$, at each point in time is composed of ex-ante heterogeneity due to differences in firm fixed effects, $\operatorname{var}_{\alpha}\left(\Delta \log \epsilon_{i}\right)$, ex-post heterogeneity due to sectoral differences, $\operatorname{var}\left(\Delta \log \epsilon_{j, t}\right)$ and idiosyncratic risk, $\operatorname{var}\left(\Delta \log \epsilon_{i, j, t}\right)$. Since the decomposition in Footnote 7 is orthogonal,

$$
v a r_{\text {raw }}\left(\Delta \log \epsilon_{i, j, t}\right)=v a r_{\alpha}\left(\Delta \log \epsilon_{i}\right)+\operatorname{var}\left(\Delta \log \epsilon_{j, t}\right)+\operatorname{var}\left(\Delta \log \epsilon_{i, j, t}\right)
$$


holds for all $t$ asymptotically in $i$. This decomposition holds analogously for $\Delta \log y_{i, t}$ and $\Delta \log$ sales $_{i, t}$. Table 11 shows that compared to within firm changes in productivity ('idiosyncratic risk'), fixed differences in productivity growth have little dispersion. At least $85 \%$ of the observed cross-sectional dispersion in innovations to Solow residuals, value added and sales is due to idiosyncratic uncertainty. This shows that our results are unlikely to be quantitatively driven by cyclical sample selection, as the margin this process could operate on is small to begin with.

Table 11: DeCOMposition OF OBSERVED CROSS-SECTIONAL DiSPERSION

\begin{tabular}{|c|c|c|c|c|c|c|}
\hline \multicolumn{2}{|c|}{$\begin{array}{l}\Delta \log \epsilon_{i, t} \\
\text { absolute average dispersion }\end{array}$} & $\Delta \log y_{i, t}$ & $\overline{\Delta \Delta \log \text { sales }_{i, t}}$ & \multicolumn{3}{|c|}{$\begin{array}{l}\log \epsilon_{i, t} \quad \Delta \log y_{i, t} \quad \Delta \log \text { sales }_{i, t} \\
\% \text { of average raw dispersion }\end{array}$} \\
\hline raw data, $v a r_{\text {raw }}$ & 1.582 & 2.354 & 3.960 & $100 \%$ & $100 \%$ & $100 \%$ \\
\hline fixed effects, $v a r_{\alpha}$ & 0.115 & 0.301 & 0.360 & $7.2 \%$ & $12.8 \%$ & $9.0 \%$ \\
\hline sectoral effects, $v a r_{\gamma}$ & 0.024 & 0.037 & 0.103 & $1.5 \%$ & $1.6 \%$ & $2.4 \%$ \\
\hline idiosyncratic risk, var & 1.444 & 2.013 & 3.497 & $91.3 \%$ & $85.6 \%$ & $88.4 \%$ \\
\hline
\end{tabular}

Notes: Cross-sectional variances, var, are multiplied by 100 . We display their time series averages.

Second, we decompose the variation of raw data heterogeneity in variations in the heterogeneity in fixed effects, sectoral effects and idiosyncratic innovations. If the set of firms in the sample was constant or the sample was a random collection of firms from the universe of all German firms, the dispersion in fixed effects would be constant over time. ${ }^{17}$

Table 12 demonstrates that compared to within-firm changes in productivity, fixed differences in productivity growth not only have a smaller steady state dispersion, but also fluctuate little in absolute terms (an order of magnitude lower), and only half in terms of the coefficient of variation (the left-hand panel of the table). Correspondingly, a decomposition of the time-series variation in heterogeneity in the raw data shows that the main source of these fluctuations - at least $72 \%$ - stems from variations in idiosyncratic within-firm uncertainty (the right-hand panel of the table). Therefore, it is unlikely that cyclical sample selection driven by cyclical entry and exit strongly affects our results.

As a final robustness check for cyclical sample attrition, we constrain our sample to those firms which we observe at least 20 times in the sample (see Table 13). The advantage of this sample is that its selection is by construction less subject to cyclical fluctuations. This sample

\footnotetext{
${ }^{17}$ We make use of the time-series decomposition

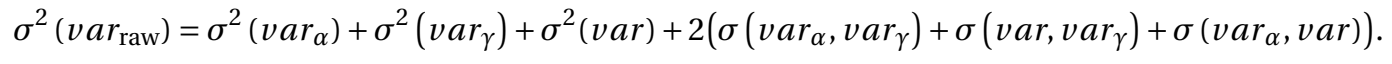

As we work with an unbalanced panel, this decomposition holds only approximately. 
Table 12: Decomposition of Fluctuations in ObSERved Cross-SECTIONAL Dispersion

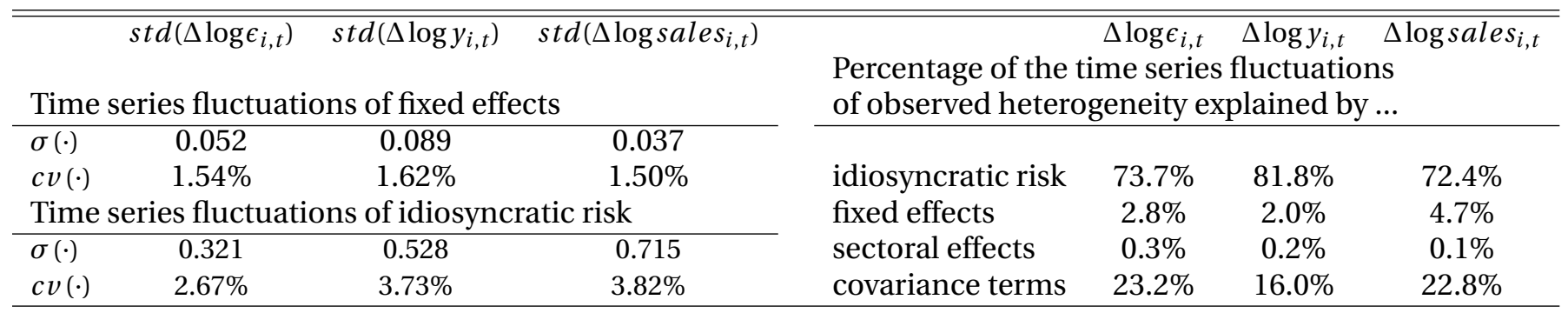

Notes: See notes to Tables 2 and 3. $\sigma$ is multiplied by 100 .

displays the same countercyclical pattern in productivity risk with a somewhat higher volatility of uncertainty. Yet, this increase partly reflects the stronger representation of large firms. On the basis of these three pieces of evidence - little importance of fixed differences in growth rates in explaining variations in heterogeneity and low volatility in these differences, as well as robustness of our results to a sample with surviving firms - we conclude that cyclical sample attrition is not central to our findings.

Table 13: Cyclicality and Volatility of Cross-Sectional DisPersion FOR Firms With AT LEAST 20 OBSERVATIONS

\begin{tabular}{lccc}
\hline \hline Cross-sectional Moment & $c \nu(\cdot)$ & $\rho(\cdot, H P(100)-Y)$ & $\mu(\cdot)$ \\
\hline std $\left(\Delta \log \epsilon_{i, t}\right)_{\text {Aggregate }}$ & $2.67 \%$ & -0.481 & 0.120 \\
std $\left(\Delta \log \epsilon_{i, t}\right)_{\text {Longer in sample }}$ & $4.61 \%$ & -0.341 & 0.106 \\
\hline std $\left(\Delta \log y_{i, t}\right)_{\text {Aggregate }}$ & $3.73 \%$ & -0.450 & 0.142 \\
std $\left(\Delta \log y_{i, t}\right)_{\text {Longer in sample }}$ & $7.00 \%$ & -0.383 & 0.120 \\
\hline std $\left(\Delta \log \text { sales }_{i, t}\right)_{\text {Aggregate }}$ & $3.82 \%$ & -0.405 & 0.187 \\
std $\left(\Delta \log \text { sales }_{i, t}\right)_{\text {Longer in sample }}$ & $7.90 \%$ & -0.466 & 0.149 \\
\hline
\end{tabular}

Notes: See notes to Tables 2 and 3.

In Table 37 in Appendix B.1 we provide further robustness checks for our results. In all these robustness checks we find a strongly countercyclical productivity risk with small cyclical fluctuations in this risk. Next, we explore the quantitative implications of our three findings: large idiosyncratic uncertainty, countercyclical fluctuations in and low volatility of this uncertainty, in a heterogeneous firm dynamic stochastic general equilibrium model with fixed cost of capital adjustment 


\section{The Model}

In this section we describe our model economy. We start with the firm's problem, followed by a brief description of the households and the definition of equilibrium. We conclude with a sketch of the equilibrium computation. Our model follows closely Khan and Thomas (2008) and Bachmann et al. (2008). Since there the model set up is discussed in detail, we will be rather brief here.

The main departure from either papers is the introduction of a second exogenous aggregate state. Following Bloom (2009) we assume that firms today observe the standard deviation of the distribution of idiosyncratic productivity shocks tomorrow, $\sigma\left(\epsilon^{\prime}\right)$. Following Khan and Thomas (2008), we approximate this now bivariate aggregate state process with a discrete Markov chain.

\subsection{Firms}

The economy consists of a unit mass of small firms. We do not model entry and exit decisions. There is one commodity in the economy that can be consumed or invested. Each firm produces this commodity, employing its pre-determined capital stock $(k)$ and labor $(n)$, according to the following Cobb-Douglas decreasing-returns-to-scale production function $(\theta>0, v>0, \theta+v<$ 1):

$$
y=z \epsilon k^{\theta} n^{v}
$$

where $z$ and $\epsilon$ denote aggregate and firm-specific (idiosyncratic) technology, respectively.

The idiosyncratic technology process has autocorrelation $\rho_{I}$. It follows a Markov chain, whose transition matrix depends on the aggregate state of its time-varying standard deviation, $\sigma\left(\epsilon^{\prime}\right)$. In contrast, its support is independent of the aggregate state. To also capture observed excess kurtosis in the idiosyncratic productivity shocks, we use a mixture of two Gaussian distributions in the Tauchen-approximation algorithm instead of the usual normal distribution. ${ }^{18}$

We denote the trend growth rate of aggregate productivity by $(1-\theta)(\gamma-1)$, so that aggregate $y$ and $k$ grow at rate $\gamma-1$ along the balanced growth path. From now on we work with $k$ and $y$ (and later $C$ ) in efficiency units. The linearly detrended logarithm of aggregate productivity levels as well as linearly detrended $\sigma(\epsilon)$ evolve according to a VAR(1) process, with normal innovations $v$ that have zero mean and covariance $\Omega$ :

$$
\left(\begin{array}{c}
\log z^{\prime} \\
\sigma\left(\epsilon^{\prime \prime}\right)-\bar{\sigma}(\epsilon)
\end{array}\right)=\varrho_{A}\left(\begin{array}{c}
\log z \\
\sigma\left(\epsilon^{\prime}\right)-\bar{\sigma}(\epsilon)
\end{array}\right)+v
$$

\footnotetext{
${ }^{18}$ Tauchen (1986). For details, see Section 4.
} 
where $\bar{\sigma}(\epsilon)$ denotes the steady state standard deviation of idiosyncratic productivity innovations. $^{19}$

Productivity innovations at different aggregation levels are independent. Also, idiosyncratic productivity shocks are independent across productive units. In contrast, we do not impose any restrictions on $\Omega$ or $\varrho_{A} \in \mathbb{R}^{2 \times 2}$.

Each period a firms draws from a time-invariant distribution, $G$, its current cost of capital adjustment, $\xi \geq 0$, which is denominated in units of labor. $G$ is a uniform distribution on $[0, \bar{\xi}]$, common to all firms. Draws are independent across firms and over time, and employment is freely adjustable.

At the beginning of a period, a firm is characterized by its pre-determined capital stock, its idiosyncratic productivity, and its capital adjustment cost. Given the aggregate state, it decides its employment level, $n$, production and depreciation occurs, workers are paid, and investment decisions are made. Then the period ends.

Upon investment, $i$, the firm incurs a fixed cost of $\omega \xi$, where $\omega$ is the current real wage rate. Capital depreciates at a rate $\delta$. We can then summarize the evolution of the firm's capital stock (in efficiency units) between two consecutive periods, from $k$ to $k^{\prime}$, as follows:

\begin{tabular}{ccc}
\hline \hline & Fixed cost paid & $\gamma k^{\prime}$ \\
\hline$i \neq 0:$ & $\omega \xi$ & $(1-\delta) k+i$ \\
\hline$i=0:$ & 0 & $(1-\delta) k$ \\
\hline
\end{tabular}

Given the i.i.d. nature of the adjustment costs, it is sufficient to describe differences across firms and their evolution by the distribution of firms over $(\epsilon, k)$. We denote this distribution by $\mu$. Thus, $\left(z, \sigma\left(\epsilon^{\prime}\right), \mu\right)$ constitutes the current aggregate state and $\mu$ evolves according to the law of motion $\mu^{\prime}=\Gamma\left(z, \sigma\left(\epsilon^{\prime}\right), \mu\right)$, which firms take as given.

Next we describe the dynamic programming problem of each firm. We will take two shortcuts (details can be found in Khan and Thomas, 2008). First, we state the problem in terms of utils of the representative household (rather than physical units), and denote by $p=p\left(z, \sigma\left(\epsilon^{\prime}\right), \mu\right)$ the marginal utility of consumption. Second, given the i.i.d. nature of the adjustment costs, continuation values can be expressed without explicitly taking into account future adjustment costs.

Let $V^{1}\left(\epsilon, k, \xi ; z, \sigma\left(\epsilon^{\prime}\right), \mu\right)$ denote the expected discounted value-in utils—of a firm that is in idiosyncratic state $(\epsilon, k, \xi)$, given the aggregate state $\left(z, \sigma\left(\epsilon^{\prime}\right), \mu\right)$. Then the expected value prior

\footnotetext{
${ }^{19}$ Specifying this process in terms of $\log (\sigma(\epsilon))$, in order to avoid negativity of the standard deviation of idiosyncratic productivity shocks is - given its high steady state value and relatively low variability - an unnecessary precaution that does not change the results. Simulation results are available upon request.
} 
to the realization of the adjustment cost draw is given by:

$$
V^{0}\left(\epsilon, k ; z, \sigma\left(\epsilon^{\prime}\right), \mu\right)=\int_{0}^{\bar{\xi}} V^{1}\left(\epsilon, k, \xi ; z, \sigma\left(\epsilon^{\prime}\right), \mu\right) G(d \xi) .
$$

With this notation the dynamic programming problem is given by:

$$
V^{1}\left(\epsilon, k, \xi ; z, \sigma\left(\epsilon^{\prime}\right), \mu\right)=\max _{n}\left\{\mathrm{CF}+\max \left(V_{\mathrm{no} \mathrm{adj}}, \max _{k^{\prime}}\left[-\mathrm{AC}+V_{\mathrm{adj}}\right]\right)\right\}
$$

where CF denotes the firm's flow value, $V_{\text {no adj }}$ the firm's continuation value if it chooses inaction and does not adjust, and $V_{\text {adj }}$ the continuation value, net of adjustment costs $A C$, if the firm adjusts its capital stock. That is:

$$
\begin{aligned}
\mathrm{CF} & =\left[z \epsilon k^{\theta} n^{v}-\omega\left(z, \sigma\left(\epsilon^{\prime}\right), \mu\right) n\right] p\left(z, \sigma\left(\epsilon^{\prime}\right), \mu\right), \\
V_{\text {no adj }} & =\beta \mathrm{E}\left[V^{0}\left(\epsilon^{\prime},(1-\delta) k / \gamma ; z^{\prime}, \sigma\left(\epsilon^{\prime \prime}\right), \mu^{\prime}\right)\right], \\
A C & =\xi \omega\left(z, \sigma\left(\epsilon^{\prime}\right), \mu\right) p\left(z, \sigma\left(\epsilon^{\prime}\right), \mu\right), \\
V_{\text {adj }} & =-i p\left(z, \sigma\left(\epsilon^{\prime}\right), \mu\right)+\beta \mathrm{E}\left[V^{0}\left(\epsilon^{\prime}, k^{\prime} ; z^{\prime}, \sigma\left(\epsilon^{\prime \prime}\right), \mu^{\prime}\right)\right],
\end{aligned}
$$

where both expectation operators average over next period's realizations of the aggregate and idiosyncratic shocks, conditional on this period's values, and we recall that $i=\gamma k^{\prime}-(1-\delta) k$. Also, $\beta$ denotes the discount factor of the representative household.

Taking as given $\omega\left(z, \sigma\left(\epsilon^{\prime}\right), \mu\right)$ and $p\left(z, \sigma\left(\epsilon^{\prime}\right), \mu\right)$, and the law of motion $\mu^{\prime}=\Gamma\left(z, \sigma\left(\epsilon^{\prime}\right), \mu\right)$, the firm chooses optimally labor demand, whether to adjust its capital stock at the end of the period, and the optimal capital stock, conditional on adjustment. This leads to policy functions: $N=N\left(\epsilon, k ; z, \sigma\left(\epsilon^{\prime}\right), \mu\right)$ and $K=K\left(\epsilon, k, \xi ; z, \sigma\left(\epsilon^{\prime}\right), \mu\right)$. Since capital is pre-determined, the optimal employment decision is independent of the current adjustment cost draw.

\subsection{Households}

We assume a continuum of identical households that have access to a complete set of statecontingent claims. Hence, there is no heterogeneity across households. Moreover, they own shares in the firms and are paid dividends. We do not need to model the household side in detail (see Khan and Thomas (2008) for the details), and concentrate instead on the first-order conditions to determine the equilibrium wage and the marginal utility of consumption.

Households have a standard felicity function in consumption and (indivisible) labor:

$$
U\left(C, N^{h}\right)=\log C-A N^{h}
$$


where $C$ denotes consumption and $N^{h}$ the household's labor supply. Households maximize the expected present discounted value of the above felicity function. By definition we have:

$$
p\left(z, \sigma\left(\epsilon^{\prime}\right), \mu\right) \equiv U_{C}\left(C, N^{h}\right)=\frac{1}{C\left(z, \sigma\left(\epsilon^{\prime}\right), \mu\right)},
$$

and from the intratemporal first-order condition:

$$
\omega\left(z, \sigma\left(\epsilon^{\prime}\right), \mu\right)=-\frac{U_{N}\left(C, N^{h}\right)}{p\left(z, \sigma\left(\epsilon^{\prime}\right), \mu\right)}=\frac{A}{p\left(z, \sigma\left(\epsilon^{\prime}\right), \mu\right)} .
$$

\subsection{Recursive Equilibrium}

A recursive competitive equilibrium for this economy is a set of functions

$$
\left(\omega, p, V^{1}, N, K, C, N^{h}, \Gamma\right)
$$

that satisfy

1. Firm optimality: Taking $\omega, p$ and $\Gamma$ as given, $V^{1}\left(\epsilon, k ; z, \sigma\left(\epsilon^{\prime}\right), \mu\right)$ solves (4) and the corresponding policy functions are $N\left(\epsilon, k ; z, \sigma\left(\epsilon^{\prime}\right), \mu\right)$ and $K\left(\epsilon, k, \xi ; z, \sigma\left(\epsilon^{\prime}\right), \mu\right)$.

2. Household optimality: Taking $\omega$ and $p$ as given, the household's consumption and labor supply satisfy (7) and (8).

3. Commodity market clearing:

$$
C\left(z, \sigma\left(\epsilon^{\prime}\right), \mu\right)=\int z \epsilon k^{\theta} N\left(\epsilon, k ; z, \sigma\left(\epsilon^{\prime}\right), \mu\right)^{v} d \mu-\iint_{0}^{\bar{\xi}}\left[\gamma K\left(\epsilon, k, \xi ; z, \sigma\left(\epsilon^{\prime}\right), \mu\right)-(1-\delta) k\right] d G d \mu
$$

4. Labor market clearing:

$$
N^{h}\left(z, \sigma\left(\epsilon^{\prime}\right), \mu\right)=\int N\left(\epsilon, k ; z, \sigma\left(\epsilon^{\prime}\right), \mu\right) d \mu+\iint_{0}^{\bar{\xi}} \xi \mathscr{J}\left(\gamma K\left(\epsilon, k, \xi ; z, \sigma\left(\epsilon^{\prime}\right), \mu\right)-(1-\delta) k\right) d G d \mu
$$

where $\mathscr{J}(x)=0$, if $x=0$ and 1 , otherwise.

5. Model consistent dynamics: The evolution of the cross-section that characterizes the economy, $\mu^{\prime}=\Gamma\left(z, \sigma\left(\epsilon^{\prime}\right), \mu\right)$, is induced by $K\left(\epsilon, k, \xi ; z, \sigma\left(\epsilon^{\prime}\right), \mu\right)$ and the exogenous processes for $z, \sigma\left(\epsilon^{\prime}\right)$ as well as $\epsilon$.

Conditions 1, 2, 3 and 4 define an equilibrium given $\Gamma$, while step 5 specifies the equilibrium condition for $\Gamma$. 


\subsection{Solution}

As is well-known, (4) is not computable, since $\mu$ is infinite dimensional. Hence, we follow Krusell and Smith $(1997,1998)$ and approximate the distribution $\mu$ by its first moment over capital, and its evolution, $\Gamma$, by a simple log-linear rule. In the same vein, we approximate the equilibrium pricing function by a log-linear rule discrete - aggregate state by discrete aggregate state:

$$
\begin{aligned}
\log \bar{k}^{\prime} & =a_{k}\left(z, \sigma\left(\epsilon^{\prime}\right)\right)+b_{k}\left(z, \sigma\left(\epsilon^{\prime}\right)\right) \log \bar{k} \\
\log p & =a_{p}\left(z, \sigma\left(\epsilon^{\prime}\right)\right)+b_{p}\left(z, \sigma\left(\epsilon^{\prime}\right)\right) \log \bar{k}
\end{aligned}
$$

where $\bar{k}$ denotes aggregate capital holdings. Given (8), we do not have to specify an equilibrium rule for the real wage. As usual with this procedure, we posit this form and check that in equilibrium it yields a good fit to the actual law of motion. We use this simple forecasting rule because it is much less computationally involved than a rule that includes higher moments of the capital distribution. In models without second moment shocks, it has been extensively shown that the first moment suffices. Unfortunately, we show here that the pure $R^{2}$ goodness-of-fit metric does not favor the simple rule $(9 a): R^{2}$ below 0.9 are possible, as we shall see in Section 5.2. However, we show for our baseline calibration that the aggregate dynamics of the economy are hardly affected, when higher moments of the capital distribution are included and the $R^{2}$ are pushed closer to unity (see Bachmann et al. (2008) for a similar observation). Therefore, we prefer the increase in computational speed and report our results, unless otherwise noted, with the first moment only as a state variable.

Combining these assumptions and substituting $\bar{k}$ for $\mu$ into (4) and using (9a)-(9b), we have that (4) becomes a computable dynamic programming problem with policy functions $N=N\left(\epsilon, k ; z, \sigma\left(\epsilon^{\prime}\right), \bar{k}\right)$ and $K=K\left(\epsilon, k, \xi ; z, \sigma\left(\epsilon^{\prime}\right), \bar{k}\right)$. We solve this problem via value function iteration on $V^{0}$.

With these policy functions, we can then simulate a model economy without imposing the equilibrium pricing rule (9b), but rather solve for it along the way. We simulate the model economy for 1,600 time periods and discard the first 100 observations, when computing any statistics. This procedure generates a time series of $\left\{p_{t}\right\}$ and $\left\{\bar{k}_{t}\right\}$ endogenously, with which assumed rules (9a)-(9b) can be updated via a simple OLS regression. The procedure stops when the updated coefficients $a_{k}\left(z, \sigma\left(\epsilon^{\prime}\right)\right)$ and $b_{k}\left(z, \sigma\left(\epsilon^{\prime}\right)\right)$, as well as $a_{p}\left(z, \sigma\left(\epsilon^{\prime}\right)\right)$ and $b_{p}\left(z, \sigma\left(\epsilon^{\prime}\right)\right)$ are sufficiently close to the previous ones. We skip the details of this procedure, as this has been outlined elsewhere - see Khan and Thomas (2008) and Bachmann et al. (2008). 


\section{Calibration}

\subsection{Baseline}

The model period is a year - in congruence with the data frequency in USTAN. The following parameters have standard values: $\beta=0.98$ and $\delta=0.094$, which we compute from German national accounting data for the sectoral aggregate that the USTAN sample corresponds to: the non-financial private business sector. Given this depreciation rate, we pick $\gamma=1.014$, in order to match the time-average aggregate investment rate of 0.108 . This number is also consistent with German long-run growth rates. The log-felicity function features an elasticity of intertemporal substitution (EIS) of one. The disutility of work parameter, $A$, is chosen to generate an average time spent at work of 0.33: $A=2$ for the baseline calibration.

We set the output elasticities of labor and capital to $v=0.5565$ and $\theta=0.2075$, respectively, which correspond to the measured median labor and capital shares in manufacturing in the USTAN data base (see Appendix A.4). While our data also include a considerable amount of firms from other sectors, any weighted average or median of these shares would still be close to the manufacturing values, which is why we decided to use them in our baseline calibration. We discuss robustness to this parameter choice in Tables 41 and 42 in Appendix B.2. ${ }^{20}$

Next, we have to choose the parameters of the two-state aggregate shock process. Here we simply estimate a bivariate, unrestricted VAR with the linearly detrended natural logarithm of the aggregate Solow residual ${ }^{21}$ and the linearly detrended $\sigma(\epsilon)$-process from the USTAN data. ${ }^{22}$ The parameters of this VAR are as follows: ${ }^{23}$

$$
\varrho_{A}=\left(\begin{array}{cc}
0.4474 & -3.7808 \\
0.0574 & 0.7794
\end{array}\right) \quad \Omega=\left(\begin{array}{ll}
0.0146 & 0.1617 \\
0.1617 & 0.0023
\end{array}\right)
$$

This process is discretized on a [5×5]-grid, using the bivariate analog of Tauchen's procedure. We measure the steady state standard deviation of idiosyncratic technology innovations as $\bar{\sigma}(\epsilon)=0.1201$. Since these innovations also exhibit mild excess kurtosis -4.4480 on average

\footnotetext{
${ }^{20}$ If one views the DRTS assumption as a mere stand-in for a CRTS production function with monopolistic competition, than these choices would correspond to an employment elasticity of the underlying production function of 0.7284 and a markup of $\frac{1}{\theta+v}=1.31$. Given the regulated product markets in Germany, this is a reasonable value. The implied capital elasticity of the revenue function, $\frac{\theta}{1-v}$ is 0.47 .

${ }^{21}$ We use again $v=0.5565$ and $\theta=0.2075$ in these calculations.

${ }^{22}$ After firm-level and sectoral fixed effects have been removed.

${ }^{23}$ With a slight abuse of notation, but for the sake of readability, $\Omega$ displays standard deviations on the main diagonal and correlations on the off diagonal. We also estimate a seemingly unrelated regressions (SUR) specification of this bivariate VAR and use it for simulation. This specification mitigates somewhat the obvious problems with estimating a bivariate VAR with 7 independent parameters from $2 \times 26$ data points. We show that both the actual estimates of the remaining VAR parameters as well as the implications for our simulation results are remarkably robust. Results can be seen in Table 43 in Appendix B.2.
} 
over our time horizon,$-{ }^{24}$ and since the adjustment cost parameter $\bar{\xi}$ will be identified by the kurtosis of the firm-level investment rate (next to its skewness), we want to avoid attributing excess kurtosis in the firm-level investment rate to nonlinearities in the adjustment technology, when the driving force itself has kurtosis. Hence, we incorporate the measured excess kurtosis into the discretization process for the idiosyncratic technology state. ${ }^{25}$ Finally, we set $\rho_{I}=0.95$, in accordance with the high persistence of Solow residual innovations we find in the data. This process is discretized on a 19-state-grid, using the Tauchen's procedure with mixed Gaussian normals.

Given the aforementioned set of parameters $\left(\beta, \delta, \gamma, A, v, \theta, \varrho_{A}, \Omega, \bar{\sigma}(\epsilon), \rho_{I}\right)$, we then calibrate the adjustment costs parameter $\bar{\xi}$ to minimize a quadratic form in the logarithmic differences between the time-average firm-level investment rate skewness produced by the model and the data, as well as the time-average firm-level investment rate kurtosis:

$$
\begin{aligned}
\min _{\bar{\xi}} \Psi(\bar{\xi}) \equiv 0.5 \cdot\left[\left(\log \left(\frac{1}{26} \sum_{t} \operatorname{skewness}\left(\frac{I_{i, t}}{0.5 *\left(K_{i, t}+K_{i, t+1}\right)}\right)(\bar{\xi})-1.6645\right)\right)^{2}+\right. \\
\left.\left(\log \left(\frac{1}{26} \sum_{t} \operatorname{kurtosis}\left(\frac{I_{i, t}}{0.5 *\left(K_{i, t}+K_{i, t+1}\right)}\right)(\bar{\xi})-19.1046\right)\right)^{2}\right] .
\end{aligned}
$$

As can be seen from (11), the distribution of firm-level investment rates exhibits both substantial positive skewness - 1.6645 - as well as excess kurtosis - 19.1046. Caballero et al. (1995) document a similar fact for U.S. manufacturing plants. They also argue that non-convex capital adjustment costs are an important ingredient to explain such a strongly non-Gaussian distribution, given a close-to-Gaussian shock process. We therefore use the deviation from Gaussianity in firm-level investment rates to identify $\bar{\xi}$.

Table 14: Calibration of Adjustment Costs $-\bar{\xi}$

\begin{tabular}{lcccc}
\hline$\overline{\bar{\xi}}$ & Skewness & Kurtosis & $\Psi(\bar{\xi})$ & $\begin{array}{c}\text { Adj. costs/ } \\
\text { Unit of Output }\end{array}$ \\
\hline 0.01 & 0.7840 & 5.0383 & 1.0824 & $1.5 \%$ \\
0.05 & 1.5155 & 7.6443 & 0.6511 & $4.2 \%$ \\
0.10 & 1.9329 & 9.3329 & 0.5175 & $6.8 \%$ \\
$0.25(\mathrm{BL})$ & 2.5590 & 12.1591 & 0.4411 & $13.3 \%$ \\
0.5 & 3.0683 & 14.7695 & 0.4692 & $23.3 \%$ \\
1 & 3.5927 & 17.8153 & 0.5463 & $43.3 \%$ \\
\hline
\end{tabular}

Table 14 demonstrates identification of $\bar{\xi}$, as cross-sectional skewness and kurtosis of the

\footnotetext{
${ }^{24}$ We find no skewness.

${ }^{25}$ We achieve this by using a mixture of two Gaussian distributions: $N(0,0.0777)$ and $N(0,0.1625)-$ the standard deviations are $0.1201 \pm 0.0424$ - with a weight of 0.4118 on the first distribution.
} 
firm-level investment rates are both monotonically increasing in $\bar{\xi}$. The minimum of the distance measure $\Psi$ is achieved for $\bar{\xi}=0.25$, our baseline case. ${ }^{26}$ This implies costs conditional on adjustment equivalent to $13.3 \%$ of annual firm-level output on average, which is well in line with estimates from the U.S. (see Bloom, 2009).

\subsection{Variants of the Driving Processes}

The empirical analysis has shown a negative comovement between the dispersion of firm-level Solow residual innovations and aggregate Solow residuals. The dynamics of this comovementas in (2) and (10) - imply that one variable conveys information about the future development of the other. In other words, a shock to idiosyncratic uncertainty affects aggregate activity not only through the option value channels highlighted by Bloom (2009) and Bloom et al. (2009), but also as a news shock in the spirit of Beaudry and Portier (2006), Jaimovich and Rebelo (2008), Sims (2008) as well as Schmidt-Grohe and Uribe (2008). Upon observing an increase in idiosyncratic uncertainty today, households and firms rationally expect a future decrease in productivity ceteris paribus.

To disentangle the effects from the news about productivity contained in movements in idiosyncratic uncertainty, we solve a variant of our model where the actual risk that firms face remains constant over time at $\bar{\sigma}(\epsilon)=0.1201$, but firms still observe a time-varying state, $s$, as a variable without further economic content that nonetheless contains information about future productivity as in (2). The parameters that describe the law of motion of $s$ are the same as in (2) and (10), i.e. as in the model with time-varying uncertainty. More generally, we can reparameterize the model for the standard deviation of idiosyncratic productivity shocks, $\sigma(\epsilon)$, as follows:

$$
\sigma(\epsilon)=\bar{\sigma}(\epsilon)+\vartheta(s-\bar{\sigma}(\epsilon))
$$

For $\vartheta=0$, idiosyncratic uncertainty remains constant and in the following we use the term 'News Model' to describe this parametrization. The second state no longer influences actual risk, but only the conditional expectation of future aggregate Solow residuals, $z^{\prime}$. The baseline specification in which idiosyncratic uncertainty fluctuates as well is termed 'Full Model', $\vartheta=1$. Using an $\vartheta>1$ we can scale up the fluctuations in idiosyncratic uncertainty without changing the underlying dynamics of the exogenous state variables, i.e. keeping the news content of $s$ constant. Moreover, for comparison we consider a model with a standard univariate AR(1) process for the aggregate Solow residual, 'RBC Model', and a specification, where the only driving force of business cycles are shocks to idiosyncratic uncertainty, 'Risk Model'. ${ }^{27}$

\footnotetext{
${ }^{26}$ We searched over a much finer grid of $\bar{\xi}$ than displayed in the table, in order to find the optimal $\bar{\xi}$.

${ }^{27}$ The estimated autocorrelation of the aggregate Solow residual is 0.5259 and the standard deviation of its innovations 0.0182 . The corresponding moments for the univariate risk process are: 0.5685 and 0.0028 .
} 


\section{Results}

\subsection{Baseline Results}

Our main set of quantitative results can be summarized as follows: 1) Fluctuations in idiosyncratic uncertainty alone do not produce business cycle dynamics as observed in the data. 2) Adding orthogonal shocks to idiosyncratic uncertainty into a model with first-moment shocks to aggregate Solow residuals hardly changes the business cycle dynamics of the model. 3) Adding shocks to idiosyncratic uncertainty that comove with aggregate Solow residuals in a way observed in the data produces mild changes in the business cycle dynamics of the model, which we attribute to the bad news effect that uncertainty shocks have for aggregate productivity in the future. This bad news effect is embodied in the negative VAR coefficient (see 10) of tomorrow's (but known today) firm-level uncertainty on tomorrow's aggregate Solow residual.

\section{Risk Model}

Table 15: Aggregate Business Cycle Statistics for the Pure 'Risk Model’

\begin{tabular}{lcccc}
\hline \hline Moment/Aggregate Quantity & $Y$ & $C$ & $I$ & $N$ \\
\hline Volatility & $0.30 \%(2.30 \%)$ & $0.23 \%(1.79 \%)$ & $2.01 \%(4.37 \%)$ & $0.41 \%(1.80 \%)$ \\
Volatility relative to $Y$ & 1 & $0.77(0.78)$ & $6.72(1.90)$ & $1.37(0.78)$ \\
Persistence & $0.55(0.48)$ & $0.51(0.67)$ & $0.29(0.42)$ & $0.26(0.61)$ \\
Correlation with $Y$ & 1 & $0.03(0.66)$ & $0.84(0.83)$ & $0.78(0.68)$ \\
\hline
\end{tabular}

Notes:

Business cycle statistics of aggregate output, $Y$, consumption $C$, investment $I$ and employment $N$. $N$ in the model includes the amount of labor used to adjust the firms' capital stocks. All variables are logged and then HP-filtered with a smoothing parameter of 100 . The first numbers in a column refer to a simulation of the model over $T=$ 1500 periods. Numbers in brackets refer to German aggregate NFPBS data (see Appendix A.1, Footnote 38, for a detailed description of sources). Volatility is percentage standard deviation. Persistence refers to the first order autocorrelation.

Table 15 shows that the pure 'Risk Model', in which the only driving force of business cycles is fluctuations in uncertainty, yields little fluctuations. Output fluctuations are almost eight times smaller than in the data, investment fluctuations just below $50 \%$ of the volatility in the data. The uncertainty fluctuations in the data are simply too small - with a time series coefficient of variation of $2.67 \%$ - to generate realistic business fluctuations. We also note that general equilibrium price movements are partly responsible for this low volatility, as the volatility of output, investment and employment increases, respectively, to $0.63 \%, 4.28 \%$ and $0.63 \%$, i.e. more than doubles in a simulation, where we fix real wages and real interest rates to their 
average value from the general equilibrium simulation. ${ }^{28}$ This shows that general equilibrium is important for understanding the aggregate implications of idiosyncratic uncertainty innovations. Finally, in terms of contemporaneous correlations with output, pure uncertainty shocks lead to a counterfactual de-coupling of consumption and output, which is accompanied by a lack of comovement between consumption and investment, whose correlation coefficient is 0.52 in the baseline calibration. We conclude that uncertainty shocks alone cannot produce business cycles in an RBC model, augmented with persistent idiosyncratic productivity shocks and fixed capital adjustment costs.

Table 16: Aggregate Business Cycle Statistics for the Pure 'Risk Model' - Double Volatility $(\vartheta=2)$

\begin{tabular}{lcccc}
\hline \hline Moment/Aggregate Quantity & $Y$ & $C$ & $I$ & $N$ \\
\hline Volatility & $0.60 \%(2.30 \%)$ & $0.45 \%(1.79 \%)$ & $4.01 \%(4.37 \%)$ & $0.81 \%(1.80 \%)$ \\
Volatility relative to $Y$ & 1 & $0.76(0.78)$ & $6.71(1.90)$ & $1.36(0.78)$ \\
Persistence & $0.56(0.48)$ & $0.52(0.67)$ & $0.30(0.42)$ & $0.27(0.61)$ \\
Correlation with $Y$ & 1 & $0.03(0.66)$ & $0.84(0.83)$ & $0.79(0.68)$ \\
\hline
\end{tabular}

Notes: See notes to Table 15.

Table 16 shows that doubling the uncertainty fluctuations $(\vartheta=2)$ leads to an almost linear increase in all volatilities of the pure 'Risk Model', whereas persistence and correlations with output are practically unchanged. This is a perhaps surprising finding: just as with first moment shocks, increasing the volatility of idiosyncratic shocks essentially amounts to re-scaling the model generated fluctuations. Consequently, we would need to observe uncertainty fluctuations that are roughly eight times as large as the fluctuations we observe in the data, in order for fluctuations in idiosyncratic uncertainty alone to produce realistic output volatility. This number would then be close to the volatility of uncertainty that based on stock market data has been suggested by Bloom (2009) for the U.S.: roughly $17 \%$. However, it is unlikely that we underestimate the risk fluctuations by such an order of magnitude. None of our different sample splits or robustness checks find an increase in the volatility of uncertainty by more than a factor of two relative to the baseline specification. In fact, as Table 8 in Section 2.3 shows, the service sector - still underrepresented in the USTAN data - exhibits less volatile uncertainty fluctuations than the goods-producing industries. Thus we should expect to have over- rather than underestimated the volatility of uncertainty fluctuations for the overall economy. Moreover, in comparison with U.S. evidence, it is well-known that the tertiary sectors comprise a much larger share of aggregate output and employment in the U.S., compared to Germany.

\footnotetext{
${ }^{28}$ These numbers are not reported in a table. A systematic second moment analysis for the partial equilibrium case is available on request.
} 


\section{Risk Model and RBC Model}

Table 17: Aggregate Business Cycle Statistics for the Pure ‘Risk Model’ and the 'RBC MODEL'

\begin{tabular}{|c|c|c|c|c|}
\hline & $\begin{array}{c}\text { RBC-Risk } \\
\text { Combination }\end{array}$ & $\begin{array}{l}\text { RBC- } \\
\text { Model }\end{array}$ & $\begin{array}{c}\text { Risk } \\
\text { Model }\end{array}$ & Data \\
\hline $\begin{array}{l}\text { Volatility } \\
\text { of Output }\end{array}$ & $3.20 \%$ & $3.18 \%$ & $0.30 \%$ & $2.30 \%$ \\
\hline \multicolumn{5}{|c|}{ Volatility of aggregate variables relative to output volatility } \\
\hline Consumption & 0.44 & 0.38 & 0.77 & 0.78 \\
\hline Investment & 4.29 & 4.38 & 6.72 & 1.90 \\
\hline Employment & 0.69 & 0.70 & 1.37 & 0.78 \\
\hline \multicolumn{5}{|l|}{ Persistence } \\
\hline Output & 0.32 & 0.31 & 0.55 & 0.48 \\
\hline Consumption & 0.65 & 0.54 & 0.51 & 0.67 \\
\hline Investment & 0.23 & 0.25 & 0.29 & 0.42 \\
\hline Employment & 0.22 & 0.25 & 0.26 & 0.61 \\
\hline \multicolumn{5}{|c|}{ Contemporaneous Correlation with Aggregate Output } \\
\hline Consumption & 0.81 & 0.86 & 0.03 & 0.66 \\
\hline Investment & 0.95 & 0.97 & 0.84 & 0.83 \\
\hline Employment & 0.92 & 0.96 & 0.78 & 0.68 \\
\hline
\end{tabular}

Notes: See notes to Table 15. 'RBC-Risk Combination' refers to a simulation, where we simply combine the two univariate processes for aggregate Solow residuals and idiosyncratic uncertainty, as specified in Footnote 27.

Although we do not find realistic business cycles caused by uncertainty fluctuations alone, they might well alter more standard first-moment-driven cycles. Therefore, as a next step, we briefly compare the 'Risk Model' with the simple 'RBC Model', ${ }^{29}$ and include a specification, where we mechanically combine the two univariate processes for aggregate Solow residuals and idiosyncratic uncertainty, as specified in Footnote 27. This variant is referred to as 'RBC-Risk Combination'. It gives a first indication, whether second-moment shocks as found in firm-level data can alter the aggregate dynamics of a standard 'RBC Model'. Table 17 shows that this is not the case: the 'RBC Model' displays second-moment statistics very similar to the combined one:

\footnotetext{
${ }^{29}$ Note that we keep the calibrated adjustment costs fixed across the variants for the driving process. This is justified, since they were calibrated to the steady state investment rate distribution, which is at least numerically invariant to the specification of the driving process. That means, by the 'RBC Model' we really mean a model with fixed capital adjustment costs and shocks to aggregate Solow residuals only. De facto, however, the calibrated adjustment cost level is so low that our baseline model is in the neutrality range that has been explored by Khan and Thomas (2008).
} 
'RBC-Risk Combination'. Put differently, the characteristic features of the Risk model vanish as soon as uncertainty shocks are combined with standard aggregate Solow residual innovations.

Perhaps somewhat surprisingly, the overall volatility of the 'RBC Model' is too high, relative to the data. In Table 20 in Section 5.2 we show that fixing the excess volatility of the model by rescaling the volatility of the first-moment shock - to give the second moment shock maximum chance - so as to match the observed volatility of aggregate output does not change our main results.

Otherwise, the 'RBC Model' displays the well-known and typical failures: low persistence, too high contemporaneous correlations with output and the wrong mix between relative consumption and investment volatility, the former being too low, the latter too high. What matters here that neither the 'Risk Model' alone nor, as we shall see, in combination with first-moment shocks fixes these failures in a satisfying manner. Of course, there are well-known additions to the 'RBC Model', such as quadratic adjustment costs for capital on top of the fixed ones, or simply higher fixed adjustment costs, that would help to ameliorate its performance, but we aim here for cleanliness of exposition and view these issues as mainly orthogonal to the question, whether shocks to idiosyncratic uncertainty matter for aggregate dynamics.

\section{Full Model and News Model}

Integrating our empirical findings a bit further into the model simulations, we extend the driving process (2) such that it incorporates the correlation structure between firm-level uncertainty and aggregate Solow residuals found in the data. We proceed in three steps. First, we introduce in the 'RBC Model' the aggregate driving process estimated in the data, (10), but set $\vartheta=0$, i.e. $s$ has no actual implications for firm-level uncertainty. Also, we allow firms' policy functions to depend only on aggregate productivity $z$. We call this specification 'Naive Model', because firms could actually use $s$ to get better forecasts about aggregate productivity. Second, we lift the latter assumption and allow firms to condition their optimal policy on $s$ as well as $z$. The state $s$ still has no implications for firm-level uncertainty, it merely helps to forecast aggregate productivity tomorrow. This variant - the aforementioned 'News Model' - adds the news character of uncertainty fluctuations to the model. Third, we explore the effect of uncertainty fluctuations, setting $\vartheta=1$. This specification is called 'Full Model'.

Comparing 'Full Model' and 'RBC Model', we find that the standard business cycle statistics, volatilities, autocorrelations and correlations, change only modestly, see Table 18. As for autocorrelations, most of the change is mechanically due to the different driving process, as the persistence improvements happen, even when agents do not use the news content of uncertainty shocks ('Naive Model'). The same holds partially true for the increase in the volatility of aggregate output. ${ }^{30}$ In other words, the excess volatility in output, featured in the 'RBC Model',

\footnotetext{
${ }^{30} \mathrm{Of}$ course, in general equilibrium this change is not purely mechanical, because the change in aggregate dy-
} 
Table 18: Aggregate Business CyCle Statistics for the 'Full Model' and 'News Model'

\begin{tabular}{|c|c|c|c|c|c|}
\hline & $\begin{array}{c}\text { Full } \\
\text { Model }\end{array}$ & $\begin{array}{l}\text { News } \\
\text { Model }\end{array}$ & $\begin{array}{l}\text { Naive } \\
\text { Model }\end{array}$ & $\begin{array}{l}\text { RBC- } \\
\text { Model }\end{array}$ & Data \\
\hline of Output & $4.05 \%$ & $4.25 \%$ & $3.73 \%$ & $3.18 \%$ & $2.30 \%$ \\
\hline
\end{tabular}

Volatility of aggregate variables relative to output volatility

$\begin{array}{llllll}\text { Consumption } & 0.31 & 0.30 & 0.40 & 0.38 & 0.78 \\ \text { Investment } & 4.74 & 4.79 & 4.34 & 4.38 & 1.90 \\ \text { Employment } & 0.75 & 0.76 & 0.69 & 0.70 & 0.78\end{array}$

$\begin{array}{llllll}\text { Persistence } & & & & & \\ \text { Output } & 0.42 & 0.46 & 0.47 & 0.31 & 0.48 \\ \text { Consumption } & 0.67 & 0.66 & 0.64 & 0.54 & 0.67 \\ \text { Investment } & 0.34 & 0.41 & 0.42 & 0.25 & 0.42 \\ \text { Employment } & 0.33 & 0.40 & 0.42 & 0.25 & 0.61\end{array}$

\begin{tabular}{lccccc} 
Contemporaneous & Correlation with & Aggregate Output \\
Consumption & 0.83 & 0.85 & 0.85 & 0.86 & 0.66 \\
Investment & 0.98 & 0.98 & 0.97 & 0.97 & 0.83 \\
Employment & 0.97 & 0.98 & 0.95 & 0.96 & 0.68 \\
\hline
\end{tabular}

Notes: See notes to Table 15. The 'Naive Model' is a simulation, where the realized aggregate shock process is the same as in the 'News Model', but we allow agents only to condition their policy functions on aggregate Solow residuals.

is actually exacerbated when introducing the further state $s$. However, not all differences are mechanic to the driving process. We can see that agents using the information content of the second underlying state leads to altered relative volatilities, which is marked by the change from the 'Naive Model' to the 'News Model'. Yet only in the case of the relative volatility of employment, the 'Full Model' actually brings improvement over the 'RBC Model'. However, the overall change from the 'RBC Model' to the 'Full Model' is not due to the specific nature of the second state being time-varying uncertainty and thus generating time-varying option values, but rather due to its news character for aggregate productivity: changes in uncertainty alter the conditional expectations of aggregate productivity. Hence, an increase in risk acts as a (bad) news shock. This bad news is embodied in the negative VAR coefficient of tomorrow's (but known today) firm-level uncertainty on tomorrow's aggregate Solow residual, see (10). ${ }^{31}$ Finally, the namics alters the Krusell-Smith rules (9a)-(9b), and therefore there is an indirect effect of news on agent's decisions.

${ }^{31}$ We also estimate a SUR specification of this bivariate VAR and use it for simulation. We show that most of the changes between the 'RBC Model' and the 'Full/News Model' are mainly due to the interaction effect between 
last panel of Table 18 shows almost no changes in the contemporaneous output correlations. In particular, there is no decrease in the notoriously too high 'RBC Model' correlation coefficients, something that one might have hoped for with the introduction of a second aggregate shock.

In summary, there is little difference between the 'Full Model' and the 'News Model'. Figure 2 illustrates this further by simply plotting a time series trajectory of aggregate output simulations from both models for an identical bivariate shock series. Both time series look very similar.

Figure 2: Comparison of the 'Full Model' and the'News Model'

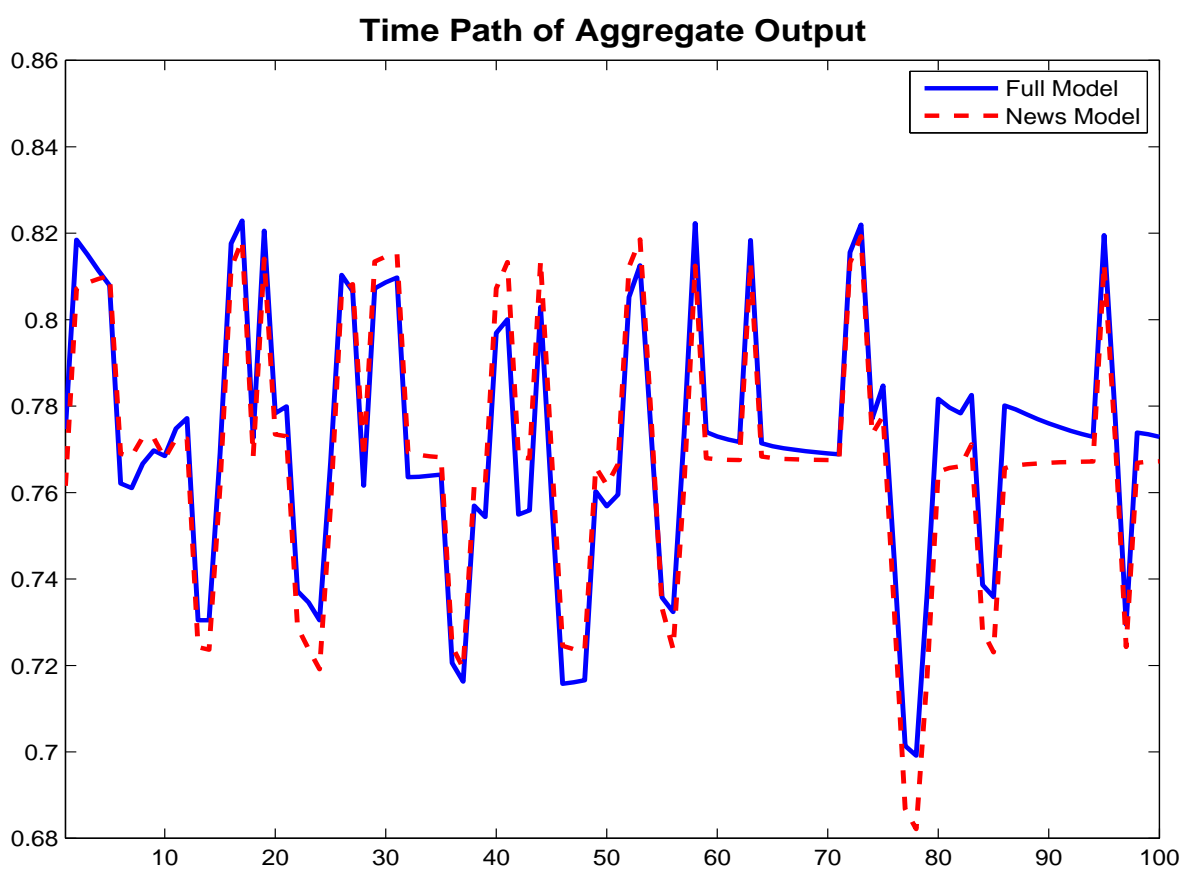

Notes: Raw aggregate output from simulations of the 'Full Model' and the'News Model'.

\section{Uncertainty Shocks as News Shocks}

To further understand the mechanisms behind the effect of shocks to idiosyncratic uncertainty, we run a series of trivariate SVARs with one lag, where we augment the aggregate Solow residual (ordered first) and the idiosyncratic uncertainty (ordered second) by a third variable: aggregate output, the aggregate investment rate, aggregate consumption, aggregate employment and hours as well as the real wage. ${ }^{32}$ We estimate these SVARs both from the actual data

aggregate Solow residuals and firm-level uncertainty. Results can be seen in Table 43 in Appendix B.2

${ }^{32}$ We use a simple Cholesky decomposition, assuming the aggregate Solow residual has an instantaneous effect on idiosyncratic uncertainty but not vice versa. This is to identify a pure innovation in contemporaneous uncertainty. Notice that studying SVARs in this context is really studying and comparing an interesting summary statistic between data and models. There is nor claim on causal empirical identification. 
for 1973 - 1998 and for 60 independent $T=26$-samples from simulations of both 'Full Model' and 'News Model'. With a series of impulse response functions, we show first that 'Full Model' and 'News Model' are practically indistinguishable in their conditional responses to shocks to idiosyncratic uncertainty. ${ }^{33}$ Secondly, we also show that - for the most part - model and data impulse responses look very much alike, i.e. our model replicates the empirical aggregate dynamics resulting from a shock to uncertainty. Finally, and most importantly, these impulse responses are exactly the way the impulse responses to a bad news shock are predicted to be in a standard RBC model with King-Rebelo-Plosser preferences (see Beaudry and Portier (2006), Jaimovich and Rebelo (2008) and Sims (2008) for a discussion of this issue): output and investment increase, consumption decreases. The intertemporal wealth effect increases employment and this labor supply shift depresses the real wage.

Figure 3: Impulse Response of Aggregate Output to a Shock in Idiosyncratic Uncertainty

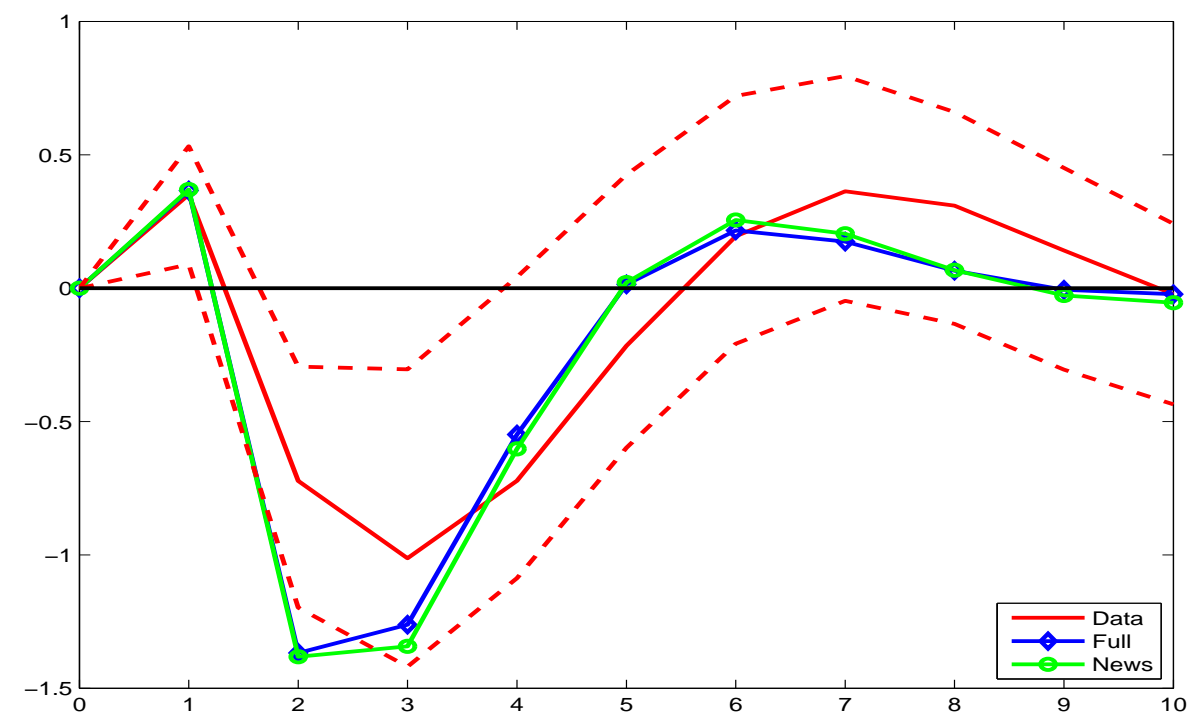

Notes: Impulse response functions from SVAR estimations of the linearly detrended aggregate Solow residual (ordered first), the linearly detrended idiosyncratic uncertainty (ordered second) and HP(100)-filtered aggregate output (ordered third). The dotted lines reflect $95 \%$ confidence bounds for the estimates from the data from 10,000 bootstrap replications. Estimates from data are in red, estimates from simulated data in blue ('Full Model') and green ('News Model'), respectively. Estimates from simulated data are the average of 60 impulse response functions estimated on 60 independent time series of $T=26$, the length of our sample.

Figure 3 displays the impulse response of aggregate output to a shock to idiosyncratic uncertainty. On impact, output goes up after an increase in uncertainty (larger dispersion of firm-

\footnotetext{
${ }^{33}$ The impulse responses with respect to a first-moment shock, i.e. an innovation to the aggregate Solow residual, for the same aggregate variables are displayed in Figures 14 and 15 in Appendix B.2. Except for the general excess volatility that our baseline calibration suffers from, data and model impulse responses are very similar and theoretically reasonable. We take this as an encouraging sign that our impulse responses with respect to a secondmoment shock are also estimated reasonably well despite the short sample problems.
} 
level productivity innovations in the following period), both in the model and in the data. So, rather than causing an immediate recession, as has been argued in the literature on uncertainty shocks thus far, a shock in idiosyncratic uncertainty causes a boom in output on impact. Then the bad news is realized and the economy goes into a recession.

Figure 4: Impulse Response of the Aggregate Investment Rate and Aggregate Consumption to a Shock in Idiosyncratic Uncertainty
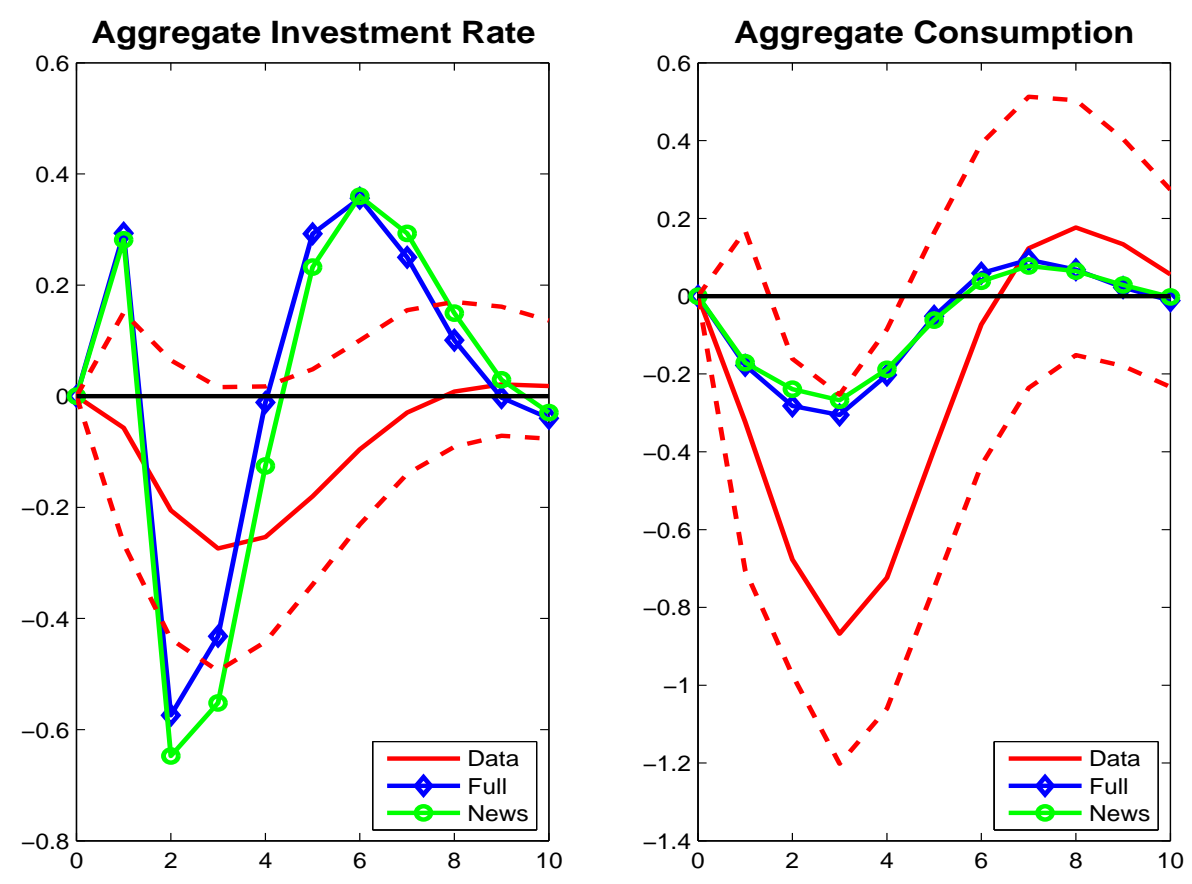

Notes: See notes to Figure 3. In this figure, the linearly detrended aggregate investment rate and HP(100)-filtered consumption, respectively, are ordered third. The aggregate investment rate is the sum of NFPBS investment divided by the average of the beginning-of-period and end-of-period aggregate capital stocks in NFPBS.

The left-hand panel of Figure 4 shows a similar expansion in the model aggregate investment rate as a response to an uncertainty shock, which is at least qualitatively consistent with the data, given the wide confidence bands around the downward sloping point estimate. ${ }^{34}$ Of course, the impulse response of aggregate investment features the excess volatility we have discussed above. In contrast, the right-hand panel of Figure 4 illustrates that the opposite is true for the undershooting impulse response of aggregate consumption, which declines after a shock to idiosyncratic uncertainty, because agents anticipate through it lower aggregate productivity and therefore wealth in the future. One can (re-)interpret the quote by Blanchard from the introduction in this context: higher uncertainty leads to a fall in consumption through a wealth

\footnotetext{
${ }^{34}$ An SVAR with aggregate investment instead of the aggregate investment rate shows a positive point estimate with similarly wide confidence bands.
} 
effect, which in turn shifts the supply of funds curve outward, lowering the real interest rate and thus causing an investment increase on impact (of course in the current situation the economy has arguably been hit also by contemporaneous negative first moment shocks, which is why we would not necessarily observe this investment increase). Notice, however, that this is a very different mechanism from the wait-and-see interpretation of uncertainty increases that has been proposed in the literature and that operates through time-varying real option values.

Figure 5: Impulse Response of the Aggregate Employment and Aggregate Hours to a Shock in Idiosyncratic Uncertainty
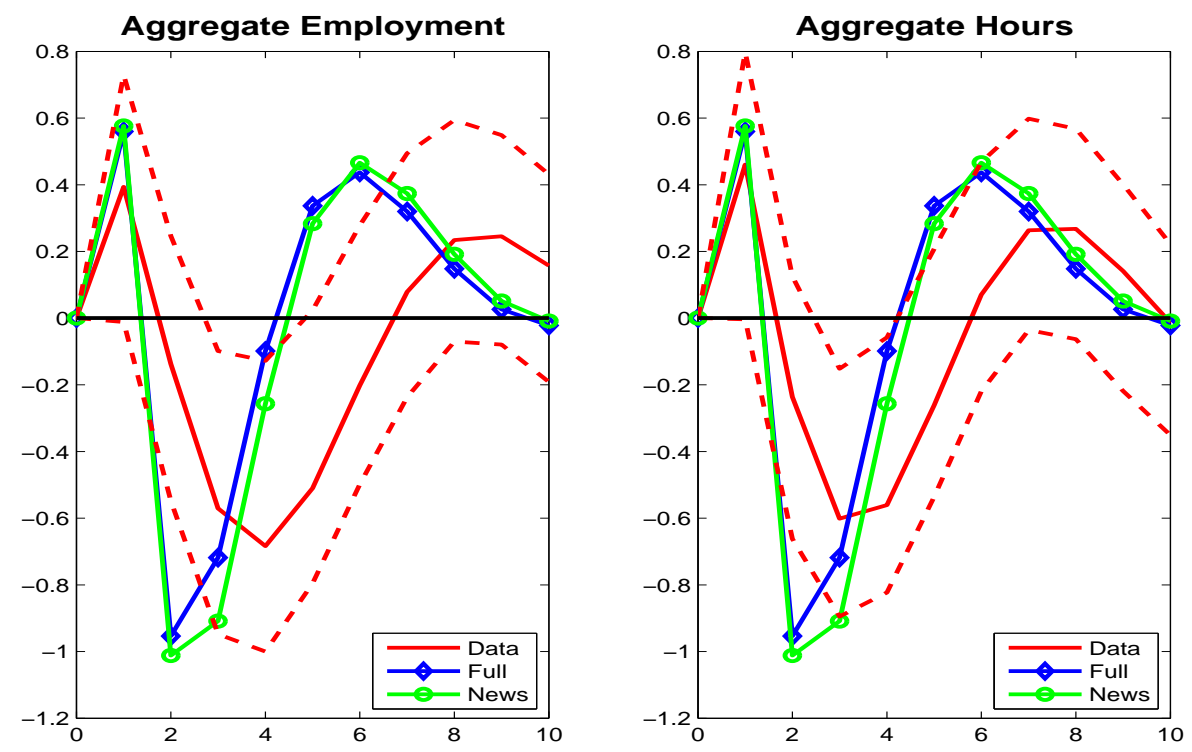

Notes: See notes to Figure 3. In this figure, HP(100)-filtered aggregate employment and HP(100)-filtered aggregate total hours, respectively, are ordered third. Employment in the model includes the amount of labor used to adjust the firms' capital stocks.

Consistently with the wealth effect both the data and the model impulse responses display an increase in aggregate employment, whether it is measured in the data by number of workers or aggregate hours (since the model features indivisible labor, this distinction is meaningless for the model). This increase in aggregate labor inputs - and the output boom that is entailed is made possible by a decline in the real wage. The labor market response, which is typical for a bad news shocks under standard preferences, is shown in Figures 5 and 6, respectively.

The final piece of the chain of arguments is displayed in Figure 7, which demonstrates that the expansion in the aggregate investment rate as a response to a shock to idiosyncratic uncertainty is a general equilibrium effect. The increase in investment is absent in partial equilibrium, where we hold constant both wages and interest rates at their average level from the general equilibrium simulation. With no increase in aggregate saving and thus a decrease in the 
Figure 6: Impulse Response of the Real Wage to a Shock in Idiosyncratic Uncertainty

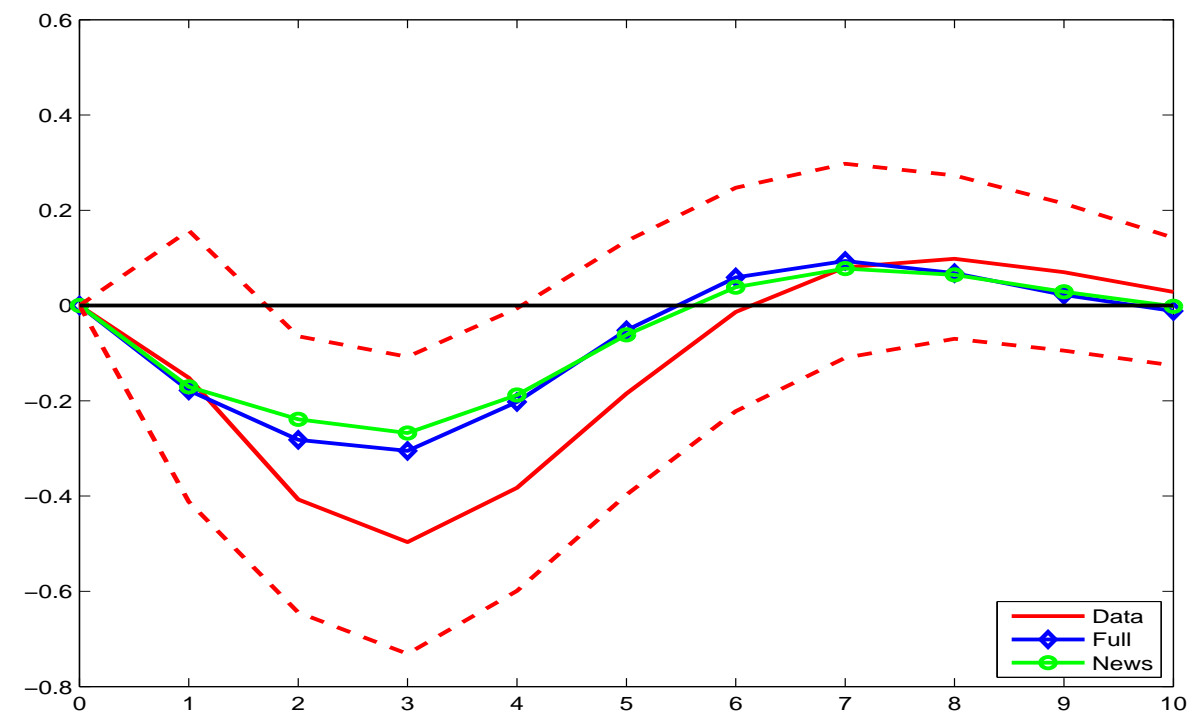

Notes: See notes to Figure 3. In this figure, the HP(100)-filtered real wage is ordered third. The real wage is aggregate real payroll divided by the number of workers.

real interest rate, the expectation of lower future productivity drives down the expected return on capital and hence investment.

Figure 7: Impulse Response of the Aggregate Investment Rate to a Shock in Idiosyncratic Uncertainty - GE vs. PE

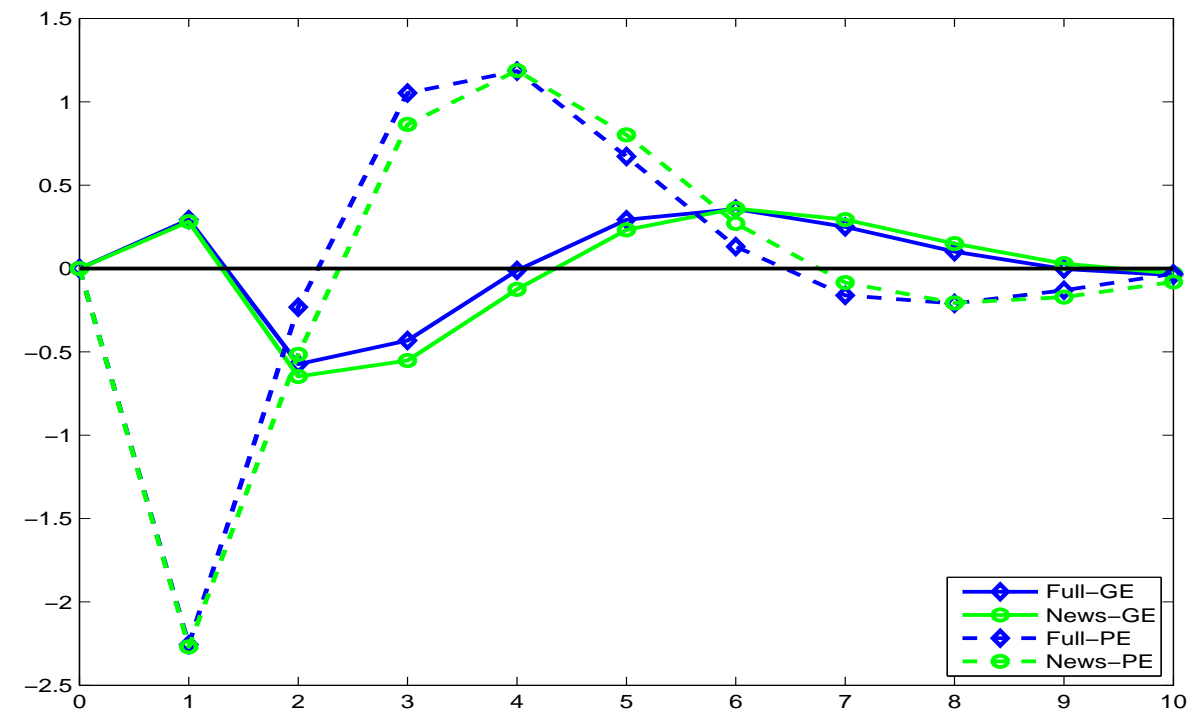

Notes: See notes to Figures 3 and 4. 'GE' stands for general equilibrium and means a model simulation with market clearing wages and interest rates. 'PE' stands for partial equilibrium and means a model simulation, where wages and interest rates are held constant at the average level in the 'GE'-simulation. 
To summarize: quantitatively realistic uncertainty shocks have bad news effects in general equilibrium, and it is this news effect that dominates the time-varying real option value effect. This shows again that general equilibrium is paramount to understanding the aggregate implications of shocks to idiosyncratic uncertainty.

\subsection{Robustness Checks}

In this subsection we provide robustness checks for our simulation results along three dimensions. First, we double the volatility of firm-level uncertainty, while keeping its steady state value fixed at 0.1201 . This amounts to setting $\vartheta=2$. Bloom (2009) uses a roughly seven times more volatile firm-level uncertainty measure than we. While our empirical results are not consistent with $\vartheta=7$, they are consistent with a doubling of the volatility of uncertainty. We explore this here. Second, we re-scale the volatility of the aggregate Solow residual so that the cyclical component of aggregate output in the model matches roughly the volatility of aggregate output in the data, in order to make sure that our results are not driven by the general excess volatility generated by the baseline specification. In particular, it could be that we falsely place too much weight on first-moment shocks by overestimating their volatility. Notice, that this is a conservative approach, because the excess volatility might actually at least in part be due to measurement error in the volatility of the uncertainty shocks as well. Finally, we check whether a quadrupling of the adjustment costs parameter, $\bar{\xi}$, changes our results. Figure 8 - at the end of this subsection - shows graphically with the help of simple time series plots of model generated aggregate output that none of these changes overturn our result. Other robustness checks with respect to choices for the risk aversion parameter, $\bar{\sigma}(\epsilon), \rho_{I}, v$ and $\theta$ are relegated to Appendix B.2.

If we increase the fluctuations in uncertainty, setting $\vartheta=2$, the difference between 'Full Model' and the 'News Model' becomes somewhat larger, see Table 19. Interestingly, the overall volatility of the model decreases, while the relative standard deviations are fairly robust to $\vartheta$. This is a result of the mechanism highlighted in Bloom et al. (2007): when uncertainty increases firms react less to first moment shocks. The performance of the 'Full Model' in terms of persistence is actually slightly worsened, while the contemporaneous correlation of consumption

and output drops to a more realistic 0.77. Finally, notice that the 'News Model' is completely (up to numerical error) invariant to $\vartheta$. This is not surprising, as the news content of firm-level uncertainty for the aggregate Solow residual is independent of its volatility. 
Table 19: Aggregate Business Cycle Statistics for the 'Full Model' and 'News Model' - Double Volatility of UnCertainty $(\vartheta=2)$

\begin{tabular}{|c|c|c|c|c|c|}
\hline & $\begin{array}{c}\text { Full } \\
\text { Model } \\
\vartheta=1\end{array}$ & $\begin{array}{c}\text { Full } \\
\text { Model } \\
\vartheta=2\end{array}$ & $\begin{array}{c}\text { News } \\
\text { Model } \\
\vartheta=1\end{array}$ & $\begin{array}{c}\text { News } \\
\text { Model } \\
\vartheta=2\end{array}$ & Data \\
\hline $\begin{array}{l}\text { Volatility } \\
\text { of Output }\end{array}$ & $4.05 \%$ & $3.86 \%$ & $4.25 \%$ & $4.25 \%$ & $2.30 \%$ \\
\hline \multicolumn{6}{|c|}{ Volatility of aggregate variables relative to output volatility } \\
\hline Consumption & 0.31 & 0.36 & 0.30 & 0.30 & 0.78 \\
\hline Investment & 4.74 & 4.70 & 4.79 & 4.79 & 1.90 \\
\hline Employment & 0.75 & 0.74 & 0.76 & 0.76 & 0.78 \\
\hline \multicolumn{6}{|l|}{ Persistence } \\
\hline Output & 0.42 & 0.36 & 0.46 & 0.46 & 0.48 \\
\hline Consumption & 0.67 & 0.68 & 0.66 & 0.66 & 0.67 \\
\hline Investment & 0.34 & 0.25 & 0.41 & 0.41 & 0.42 \\
\hline Employment & 0.33 & 0.23 & 0.40 & 0.40 & 0.61 \\
\hline \multicolumn{6}{|c|}{ Contemporaneous Correlation with Aggregate Output } \\
\hline Consumption & 0.83 & 0.77 & 0.85 & 0.85 & 0.66 \\
\hline Investment & 0.98 & 0.97 & 0.98 & 0.98 & 0.83 \\
\hline Employment & 0.97 & 0.95 & 0.98 & 0.98 & 0.68 \\
\hline
\end{tabular}

Notes: See notes to Table 15.

The next robustness check concerns re-scaling the volatility of the aggregate Solow residual by a factor of 0.6 in the 'Full Model', in order to approximately match the observed volatility of cyclical aggregate output in the data. We keep this re-scaling factor the same for the 'News Model' and the 'RBC Model'. Despite the reduced importance of the first-moment shock both the absolute and the relative volatilities of the 'Full Model' and the 'News Model' remain very similar. As before in the case of an increased volatility of the firm-level uncertainty - which is essentially a weakening of the first-moment shock from the other side-, we see a deterioration (with the exception of consumption) in the persistence numbers, but an improvement in the contemporaneous correlation of consumption and output in the 'Full Model' compared to the data. 
Table 20: Aggregate Business Cycle Statistics - Re-scaled Volatility of the Aggregate SOLOW RESIDUAL

\begin{tabular}{|c|c|c|c|c|}
\hline & $\begin{array}{c}\text { Full } \\
\text { Model }\end{array}$ & $\begin{array}{l}\text { News } \\
\text { Model }\end{array}$ & $\begin{array}{l}\text { RBC- } \\
\text { Model }\end{array}$ & Data \\
\hline Volatility & $2.35 \%$ & $2.55 \%$ & $1.91 \%$ & $2.30 \%$ \\
\hline \multicolumn{5}{|c|}{ Volatility of aggregate variables relative to output volatility } \\
\hline Consumption & 0.34 & 0.30 & 0.38 & 0.78 \\
\hline Investment & 4.61 & 4.67 & 4.32 & 1.90 \\
\hline Employment & 0.74 & 0.76 & 0.70 & 0.78 \\
\hline \multicolumn{5}{|l|}{ Persistence } \\
\hline Output & 0.38 & 0.46 & 0.31 & 0.48 \\
\hline Consumption & 0.68 & 0.66 & 0.54 & 0.67 \\
\hline Investment & 0.28 & 0.41 & 0.26 & 0.42 \\
\hline Employment & 0.26 & 0.40 & 0.25 & 0.61 \\
\hline \multicolumn{5}{|c|}{ Contemporaneous Correlation with Aggregate Output } \\
\hline Consumption & 0.80 & 0.85 & 0.86 & 0.66 \\
\hline Investment & 0.98 & 0.99 & 0.98 & 0.83 \\
\hline Employment & 0.96 & 0.98 & 0.96 & 0.68 \\
\hline
\end{tabular}

Notes: See notes to Table 15. The re-scaling factor is 0.6. 
Table 21: Aggregate Business Cycle Statistics - Higher Adjustment Costs $(\bar{\xi}=1)$

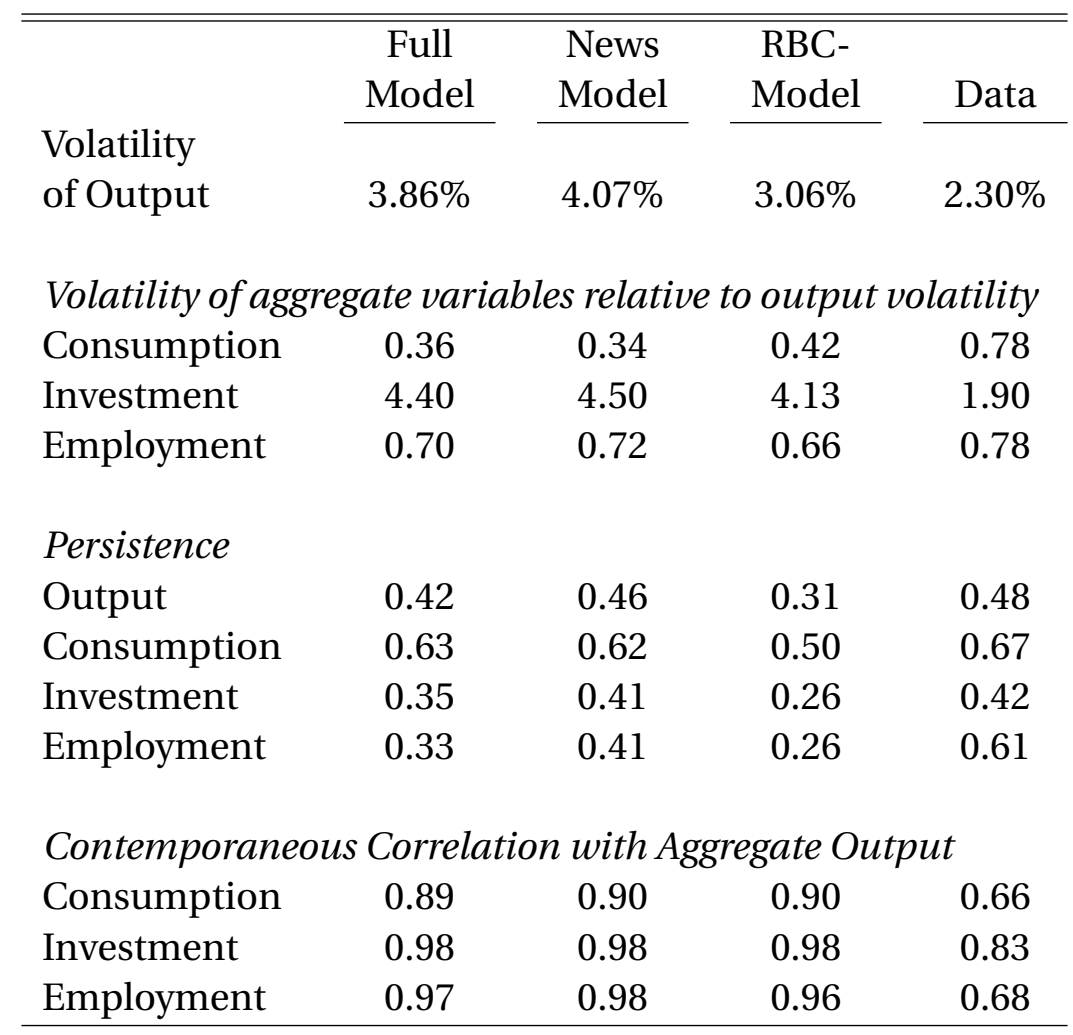

Notes: See notes to Table 15.

Figure 8: Comparison of the 'Full Model' and the'News Model' - Robustness
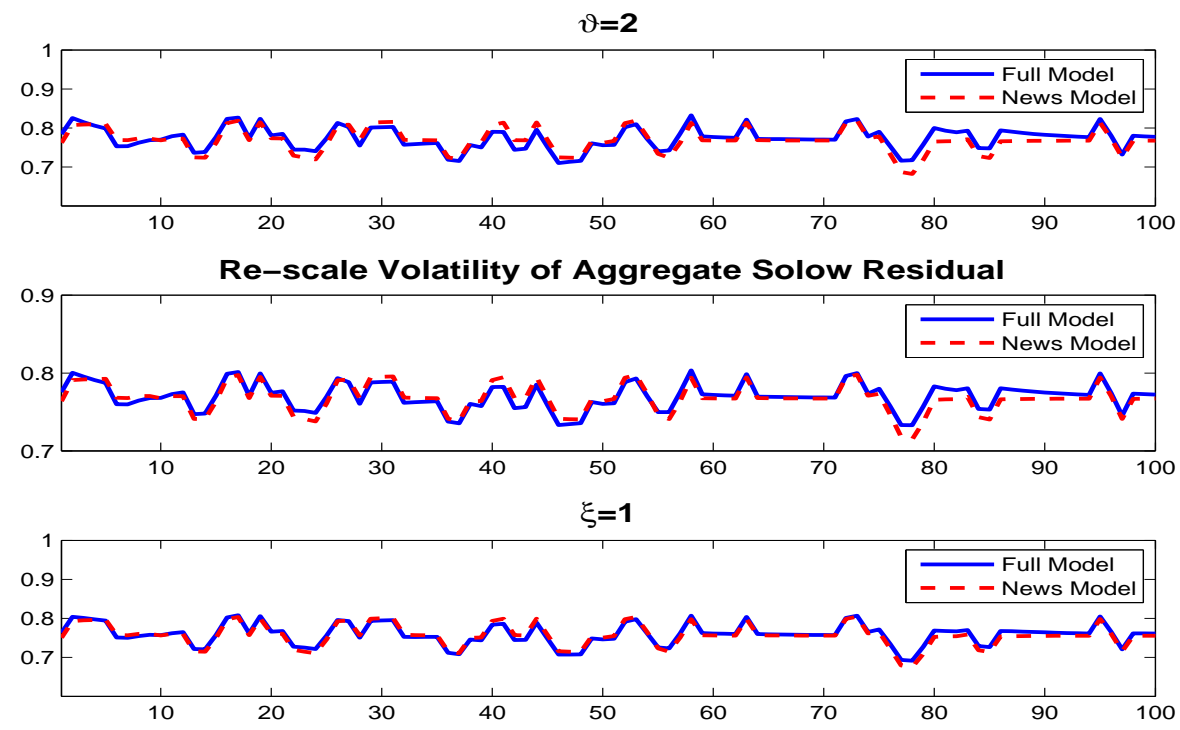

Notes: Raw aggregate output from simulations of the 'Full Model' and the'News Model'. First panel: double volatility of uncertainty. Second panel: re-scaled volatility of the aggregate Solow residual to roughly match the volatility of the cyclical component of GDP in the data (re-scaling factor is 0.6 ). Third panel: higher adjustment costs, $\bar{\xi}=1$. 


\section{Higher Moments in the Krusell and Smith Rules}

It remains to be shown that our results are not driven by the choice of only the average capital stock in the Krusell and Smith rules (9a) and (9b). While it is the case that in the presence of countercyclical second-moment shocks the conventional $R^{2}$-measure is fairly low for the 'Full Model' - at least in some combinations of the discrete aggregate states, the minimum is 0.8718 -, and while it is also true that including the skewness of the capital distribution in the Krusell and Smith rules of the 'Full Model'35 leads to an average increase of the $R^{2}$ for the capital regressions from 0.9383 to 0.9899 and for the marginal utility of consumption regressions from 0.9963 to 0.9987 , the aggregate behavior of the 'Full Model' is essentially unchanged. Better forecasts do not necessarily induce the agents to behave differently (see Bachmann et al. (2008) for a similar finding).

Table 22: Aggregate Business Cycle Statistics - Higher Moments

\begin{tabular}{|c|c|c|c|c|}
\hline & $\begin{array}{c}\text { Full } \\
\text { Model } \\
\text { MEAN }\end{array}$ & $\begin{array}{c}\text { Full } \\
\text { Model } \\
\text { SKEWNESS }\end{array}$ & $\begin{array}{l}\text { News } \\
\text { Model } \\
\text { MEAN }\end{array}$ & $\begin{array}{c}\text { News } \\
\text { Model } \\
\text { SKEWNESS }\end{array}$ \\
\hline Volatility & $4.05 \%$ & $4.07 \%$ & $4.25 \%$ & $4.23 \%$ \\
\hline \multicolumn{5}{|c|}{ Volatility of aggregate variables relative to output volatility } \\
\hline Consumption & 0.31 & 0.31 & 0.30 & 0.30 \\
\hline Investment & 4.74 & 4.68 & 4.79 & 4.72 \\
\hline Employment & 0.75 & 0.75 & 0.76 & 0.76 \\
\hline \multicolumn{5}{|l|}{ Persistence } \\
\hline Output & 0.42 & 0.44 & 0.46 & 0.46 \\
\hline Consumption & 0.67 & 0.65 & 0.66 & 0.65 \\
\hline Investment & 0.34 & 0.39 & 0.41 & 0.40 \\
\hline Employment & 0.33 & 0.39 & 0.40 & 0.40 \\
\hline \multicolumn{5}{|c|}{ Contemporaneous Correlation with Aggregate Output } \\
\hline Consumption & 0.83 & 0.84 & 0.85 & 0.85 \\
\hline Investment & 0.98 & 0.98 & 0.98 & 0.98 \\
\hline Employment & 0.97 & 0.97 & 0.98 & 0.98 \\
\hline
\end{tabular}

Notes: See notes to Table 15. MEAN refers to a simulation, where only the aggregate capital stock is used in the Krusell-Smith rules (9a)-(9b). SKEWNESS refers to a simulation, where also the skewness of the firm-level capital stock distribution is used in the Krusell-Smith rules (9a)-(9b), plus an analogous rule to (9a) for skewness itself.

\footnotetext{
${ }^{35}$ The 'News Model' features high $R^{2}$ over 0.9999 on any aggregate state with the average capital stock only. Including the standard deviation of capital does not yield any significant improvements in $R^{2}$. The average $R^{2}$ over all discrete states for the skewness regression that is analogous to (9a) is 0.9397 .
} 


\section{Final Remarks}

This paper, to the best of our knowledge, is the first to jointly study the cyclical behavior of the second moments of the cross-sections of firm-level innovations to Solow residuals, real value added and real sales. We show that firm-specific Solow residual innovations (likewise innovations in value added and sales) are more disperse in recessions than in booms. Thus, firm-level uncertainty is significantly and robustly countercyclical in the way Bloom (2009) finds this for U.S. stock market and Compustat data. We also show that the volatility of uncertainty is much lower than has been previously found in this U.S. data.

We then explore the quantitative importance of these uncertainty fluctuations in an otherwise standard heterogeneous-firm dynamic stochastic general equilibrium model in the spirit of Khan and Thomas (2008) and Bachmann et al. (2008). We find that empirically realistic fluctuations in uncertainty about productivity growth on their own are not sufficient to generate realistic business cycles. Adding the second moment shocks to a model that has standard first moment shocks, we find that some aspects of the cyclical behavior of the model are altered. For the size of uncertainty fluctuations that we find in German firm-level data, we attribute these changes largely to the (bad) news uncertainty shocks carry about future aggregate productivity, rather than to the wait-and-see-effect of such fluctuations. In this context, we also find that general equilibrium price dynamics are paramount in understanding the aggregate effects of firm-level uncertainty shocks.

In a companion paper (Bachmann and Bayer, 2009), using cross-sectional firm dynamics, we provide further indirect evidence that the magnitude of uncertainty shocks over the business cycle cannot be too large. We document there that the firm-level investment rates display significantly and robustly procyclical dispersion. We explain this fact through a procyclical extensive margin effect caused by lumpy capital adjustment. However, we also demonstrate there that merely doubling the volatility of firm-level uncertainty mitigates this procyclical extensive margin effect, driving down the procyclicality of investment dispersion well below the level found in the data.

Since we base our results on German data, we leave open the possibility that shocks to uncertainty are a major driving force for the business cycle in the U.S. and encourage future research in this cross-country dimension. We also leave open the possibility that the dispersion shocks we measure in the data can be a source of aggregate fluctuations in a significantly altered model environment; for instance one, where the stock market and its volatility is more explicitly modeled. We thus view future research into the precise interaction between cross-sectional dynamics and aggregate dynamics as desirable and this paper as merely the beginning of a new research program. 


\section{References}

[1] Alexopoulos, M. and J. Cohen (2009). “Uncertain Times, Uncertain Measures”, mimeo.

[2] Bachmann, R. and C. Bayer (2009). "The Cross-section of Firms over the Business Cycle: New Facts and a DSGE Exploration", mimeo.

[3] Bachmann, R., Caballero, R. and E. Engel (2008). "Aggregate Implications of Lumpy Investment: New Evidence and a DSGE Model”, mimeo.

[4] Beaudry, P. and F. Portier (2006). “Stock Prices, News, and Economic Fluctuations,” American Economic Review, 96, 1293-1307.

[5] Blanchard, O. (2009). “(Nearly) Nothing to Fear but Fear Itself”, The Economist, 29 January 2009.

[6] Bloom, N. (2009). “The Impact of Uncertainty Shocks”, Econometrica, forthcoming.

[7] Bloom, N., Bond, S. and Van Reenen, J.(2007), "Uncertainty and Investment Dynamics”, Review of Economic Studies, 74, 391-415.

[8] Bloom, N., M. Floetotto and N. Jaimovich (2009). "Really Uncertain Business Cycles", incomplete draft.

[9] Caballero, R., E. Engel and J. Haltiwanger (1995). "Plant-Level Adjustment and Aggregate Investment Dynamics”, Brookings Paper on Economic Activity, 1995, (2), 1-54.

[10] Comin, D., and S. Mulani (2006). "Diverging Trends in Macro and Micro Volatility: Facts”, The Review of Economics and Statistics, 88/2, 374-383.

[11] Davis, S., J. Haltiwanger and S. Schuh (1996)."Job Creation and Destruction”, Cambridge, MA: MIT Press.

[12] Davis, S., J. Haltiwanger, R. Jarmin and J. Miranda (2006). "Volatility and Dispersion in Business Growth Rates: Publicly Traded and Privately Held Firms”, NBER Macroeconomics Annual.

[13] Dixit, Avinash K. and Robert S. Pindyck (1994). "Investment under Uncertainty”, Princeton University Press, Princeton, New Jersey.

[14] Doepke, J. and S. Weber (2006). “The Within-Distribution Business Cycle Dynamics of German Firms", Discussion Paper Series 1: Economic Studies, No 29/2006. Deutsche Bundesbank. 
[15] Doepke, J., M. Funke, S. Holly and S. Weber (2005). “The Cross-Sectional Dynamics of German Business Cycles: a Bird's Eye View”, Discussion Paper Series 1: Economic Studies, No 23/2005. Deutsche Bundesbank.

[16] Doepke, J., M. Funke, S. Holly and S. Weber (2008). "The Cross-Section of Output and Inflation in a Dynamic Stochastic General Equilibrium Model with Sticky Prices”, CWPE 0853.

[17] Gilchrist, S., J. Sim and E. Zakrajsek (2009). "Uncertainty, Credit Spreads and Aggregate Investment", mimeo.

[18] Gourio, F. (2008). “Estimating Firm-Level Risk”, mimeo.

[19] Higson, C., S. Holly and P. Kattuman (2002). "The Cross-Sectional Dynamics of the US Business Cycle: 1950-1999”, Journal of Economic Dynamics and Control, 26, 1539-1555.

[20] Higson, C., S. Holly, P. Kattuman and S. Platis (2004): “The Business Cycle, Macroeconomic Shocks and the Cross Section: The Growth of UK Quoted Companies”, Economica, 71/281, May 2004, 299-318.

[21] Holly, S. and E. Santoro (2008). "Financial Fragility, Heterogeneous Firms and the CrossSection of the Business Cycle”, CWPE 0846.

[22] Jaimovich, N. and S. Rebelo (2009). "Can News About the Future Drive the Business Cycle?", American Economic Review, forthcoming.

[23] von Kalckreuth, U. (2003). "Exploring the Role of Uncertainty for Corporate Investment Decisions in Germany", Swiss Journal of Economics, Vol. 139(2), 173-206.

[24] Khan, A. and J. Thomas, (2008). "Idiosyncratic Shocks and the Role of Nonconvexities in Plant and Aggregate Investment Dynamics”, Econometrica, 76(2), March 2008, 395-436.

[25] Krusell, P. and A. Smith (1997). "Income and Wealth Heterogeneity, Portfolio Choice and Equilibrium Asset Returns”, Macroeconomic Dynamics 1, 387-422.

[26] Krusell, P. and A. Smith (1998). "Income and Wealth Heterogeneity in the Macroeconomy", Journal of Political Economy, 106 (5), 867-896.

[27] Schmidt-Grohe, S. and M. Uribe (2008). “What's News in Business Cycles”, mimeo.

[28] Shiller, R. (1981)."Do Stock Prices Move Too Much to be Justified by Subsequent Changes in Dividends?", American Economic Review, 71, 421-436. 
[29] Sim, J.W. (2008). “Uncertainty Driven Business Cycle”, mimeo.

[30] Sims, E. (2008). “Expectations Driven Business Cycles: An Empirical Evaluation”, mimeo.

[31] Stoess, E. (2001). “Deutsche Bundesbank's Corporate Balance Sheet Statistics and Areas of Application", Schmollers Jahrbuch: Zeitschrift fuer Wirtschafts- und Sozialwissenschaften (Journal of Applied Social Science Studies), 121, 131-137.

[32] Ravn, M. and H. Uhlig (2002). "On Adjusting the Hodrick-Prescott Filter for the Frequency of Observations", The Review of Economics and Statistics, 84 (2), 371-380.

[33] Tauchen, G. (1986). "Finite State Markov-Chain Approximations To Univariate and Vector Autoregressions”, Economics Letters 20, 177-181. 


\section{A Appendix A - Data Appendix}

\section{A.1 Description of the Sample}

The Bundesbank's corporate balance sheet database (Unternehmensbilanzstatistik, USTAN henceforth) has been originally created as a by-product of the bank's rediscounting activities, an important instrument of monetary policy before the introduction of the Euro. When a commercial bank wished to pledge a commercial bill of exchange to the Bundesbank, the commercial bank had to prove the creditworthiness of the bill. For that purpose the bank had to provide the Bundesbank with balance sheet information of all parties who backed the bill of exchange. By law, the Bundesbank could only accept bills backed by at least three parties known to be creditworthy. This procedure allowed the Bundesbank to collect a unique dataset of information stemming from the balance sheets and the profit and loss accounts of firms (see Stoess (2001), von Kalckreuth (2003) and Doepke et al. (2005) for further details).

Quality standards of the data are particularly high. All mandatory data collected for USTAN have been double-checked by Bundesbank staff. Hence, the data should contain unusually few errors for a micro-data set. One drawback of USTAN is that with the introduction of the EURO, the Bundesbank stopped buying commercial bills and collected firm balance sheet data only irregularly and from publicly available sources. Therefore, the data set stops being useful in 1999. Therefore, we only use data from 1971 to 1998, which because of lagging and firstdifferencing leaves us with essentially 26 year observations from 1973 to 1998.

The coverage of the sample is broad, although it is technically not a representative sample due to the non-random sample design. It was also more common to use bills of exchange in manufacturing and for incorporated companies, which biases our data somewhat towards these kinds of firms. And, of course, the Bundesbank would only rediscount bills with a good rating, so that the set of firms in USTAN is also somewhat biased to financially healthy and larger firms.

Nevertheless, USTAN covers a wide range of firms, since short-term financing through commercial bills of exchange was common practice for many German companies across all business sectors (see Table 24 below for the detailed sectoral composition of our final sample). USTAN also has a broad ownership coverage ranging from incorporated firms as well as privately owned companies, which distinguishes it from the Compustat data. Within the former group USTAN covers both untraded corporations (e.g. limited liability firms, $\mathrm{GmbH}$ ) as well as publicly held companies $(A G)$. Finally, USTAN features also a relatively broad size coverage, as we will show in Table 25 below for our final sample, the creation of which we describe in some detail now.

We start out with the universe of observations in the USTAN data, merging the files for 1971-1986 and 1987-1998. In a first pass, we then drop all balance sheets that are irregular, 
e.g. bankruptcy or closing balance sheets, or stem from a holding (Konzernbilanz). This leaves us with only regular balance sheets (Handelsbilanz or Steuerbilanz). We also drop all firms with missing payroll data and missing or negative sales data, which are basically non-operating firms. A small amount of duplicate balance sheets is removed as well. And finally, we drop the following sectors: hospitality (hotels and restaurants), which has only a small amount of firms in the database, financial and insurance institutions, the mostly public health and education sectors, as well as other public companies like museums, etc. and some other small service industries, such as hair cutters, dry cleaners and funeral homes; ${ }^{36}$ or when sectoral information was missing. The sectoral aggregate we are studying can be roughly characterized as the nonfinancial private business sector in Germany. This leaves us with an initial data set of 1,764,846 firm-year observations and 259,614 firms. The average number of firms per year is 63,030.

From this initial data set we remove step-by-step more observations, in order to get an economically reasonable data set. We first drop observations from likely East German firms to avoid a break of the series in 1990. We identify a West German firm as a firm that has a West German address or has no address information but enters the sample before 1990. Then we recompute capital stocks with a modified perpetual inventory method (PIM) and employment levels. In the modified PIM we drop a small amount of observations from the top and bottom of the distribution of correction factors for the initial capital stock, see Appendix A.2. Extreme correction factors indicate that constant depreciation is not a good approximation for this particular firm. Such a firm will have had an episode of extraordinary depreciation (e.g. fire, a natural disaster, etc.) and the capital stocks by PIM will be a bad measure of the actual capital after the disaster. We remove observations that do not have a log value added and a log capital stock after PIM. Another large part is removed due to not featuring changes in log firm-level employment, capital and real value added, which obviously requires us to observe firms two years in a row. Then we remove outliers in factor changes and real value added changes. Specifically, we identify as outliers in our sample a firm-year in which the firm level investment rate or log changes in firm-level real value added, employment and capital stock fall outside a three standard deviations band around the firm and sectoral-year mean. Then we compute firm-level Solow residuals (see Appendix A.4 for details) and similarly remove observations with missing log changes in Solow residuals as well as outliers therein. We finally remove - before and after each step of the outlier removal - firms that have less than five observations in firm-level Solow residual changes. We conduct extensive robustness checks of our results to the choices for the outlier and observation thresholds (see Appendix B.1). Table 23 summarizes, how much observations are dropped in each step.

\footnotetext{
${ }^{36}$ The number of firms from the public sector and these small industries is tiny to begin with, as they did not use commercial bills as a financing instrument. We left out financial and insurance institutions, as they arguably have a very different production function and investment behavior.
} 
Table 23: SAMPLE CREATION

\begin{tabular}{lr}
\hline \hline Criterion & Drops of Firm-Year Observations \\
\hline East Germany & 104,299 \\
Outliers in PIM & 7,539 \\
Missing log value added & 1,349 \\
Missing log capital & 31,819 \\
Missing log-changes in N, K, VA & 161,668 \\
Outliers in factor and VA log-changes & 41,453 \\
Missing log-changes in Solow residual & 126,086 \\
Outliers in Solow residual log-changes & 18,978 \\
Not enough observations & 417,550 \\
\hline Total & 910,741
\end{tabular}

The final sample then consists of 854,105 firm-year observations, which amounts to observations on 72,853 firms and the average observation length of a firm in the sample is 11.7 years. The average number of firms per year is 32,850. The following Tables 24 and 25 as well as 26 show the average sectoral ${ }^{37}$ and the size distributions in our sample, as well as the distributions over the number of observations, respectively.

Table 24: SECTORAL Distribution

\begin{tabular}{llrrr}
\hline \hline & & & Fraction of \\
ID & Sector & Observations & Observations & WZ 2003 \\
\hline 10 & Agriculture & 12,291 & $1.44 \%$ & A, B \\
20 & Energy \& Mining & 4,165 & $0.49 \%$ & C, E \\
31 & Chemical Industry, Oil & 14,721 & $1.72 \%$ & DF, DG \\
32 & Plastics, Rubber & 23,892 & $2.80 \%$ & DH \\
33 & Glass, Ceramics & 28,623 & $3.35 \%$ & DI \\
34 & Metals & 30,591 & $3.58 \%$ & DJ \\
35 & Machinery & 162,407 & $19.01 \%$ & DK, DL, DM, DN \\
36 & Wood, Paper, Printing & 61,672 & $7.22 \%$ & DD, DE \\
37 & Textiles, Leather & 46,173 & $5.41 \%$ & DB, DC \\
38 & Food, Tobacco & 37,708 & $4.41 \%$ & DA \\
40 & Construction & 54,569 & $6.39 \%$ & F \\
61 & Wholesale Trade & 213,071 & $24.95 \%$ & G51 \\
62 & Retail Trade \& Cars & 142,137 & $16.64 \%$ & G50, G51 \\
70 & Transportation \& Communication & 22,085 & $2.59 \%$ & I \\
\hline & Total & 854,105 & &
\end{tabular}

\footnotetext{
${ }^{37}$ WZ 2003 is the industry classification from 2003 that the German national accounting system (Volkswirtschaftliche Gesamtrechnung, VGR) uses.
} 
Table 25: SizE Distributions OF FiRMS

\begin{tabular}{|c|c|c|c|c|c|c|c|c|c|}
\hline $\begin{array}{l}\text { Number of } \\
\text { Employees }\end{array}$ & $1-4$ & $5-9$ & $10-14$ & $15-19$ & $20-49$ & $50-99$ & $100-249$ & $250-499$ & $500+$ \\
\hline Fraction & $6.14 \%$ & $9.46 \%$ & $8.24 \%$ & $7.30 \%$ & $26.28 \%$ & $17.04 \%$ & $14.37 \%$ & $5.68 \%$ & $5.49 \%$ \\
\hline $\begin{array}{l}\text { Capital Stock } \\
\text { (in } 1000 \text { 1991-Euro) }\end{array}$ & $0-299$ & $300-599$ & $600-999$ & $1,000-1,499$ & $1,500-2,499$ & $2,500-4,999$ & $5,000-9,999$ & $10,000-24,999$ & $25,000+$ \\
\hline Fraction & $8.23 \%$ & $9.01 \%$ & $9.67 \%$ & $9.36 \%$ & $13.08 \%$ & $17.71 \%$ & $13.87 \%$ & $11.08 \%$ & $7.99 \%$ \\
\hline $\begin{array}{l}\text { Real Value Added } \\
\text { (in } 1000 \text { 1991-Euro) }\end{array}$ & $0-299$ & $300-499$ & $500-749$ & $750-999$ & $1,000-2,499$ & $2,500-4,999$ & $5,000-9,999$ & $10,000-24,999$ & $25,000+$ \\
\hline
\end{tabular}

Table 26: OBSERVATION Distribution

\begin{tabular}{crrrcrrr}
\hline \hline Obs. per Firm & Firms & Percent & Cum. & Obs. per Firm & Firms & Percent & Cum. \\
\hline 5 & 8,973 & 12.32 & 12.32 & 16 & 2,487 & 3.41 & 78.10 \\
6 & 7,592 & 10.42 & 22.74 & 17 & 2,225 & 3.05 & 81.16 \\
7 & 6,609 & 9.07 & 31.81 & 18 & 2,024 & 2.78 & 83.93 \\
8 & 5,724 & 7.86 & 39.67 & 19 & 1,849 & 2.54 & 86.47 \\
9 & 4,901 & 6.73 & 46.39 & 20 & 1,619 & 2.22 & 88.69 \\
10 & 4,338 & 5.95 & 52.35 & 21 & 1,479 & 2.03 & 90.72 \\
11 & 3,960 & 5.44 & 57.78 & 22 & 1,351 & 1.85 & 92.58 \\
12 & 3,528 & 4.84 & 62.63 & 23 & 1,446 & 1.98 & 94.56 \\
13 & 3,134 & 4.30 & 66.93 & 24 & 988 & 1.36 & 95.92 \\
14 & 3,006 & 4.13 & 71.05 & 25 & 892 & 1.22 & 97.14 \\
15 & 2,647 & 3.63 & 74.69 & 26 & 2081 & 2.86 & 100 \\
\hline
\end{tabular}

How well does the USTAN aggregate represent the non-financial private business sector (NFPBS) in Germany? USTAN represents on average $70 \%$ of the value added of the NFPBS and $78 \%$ of its gross output. ${ }^{38}$

\footnotetext{
${ }^{38}$ To compute these statistics we only average over the data from 1973 to 1990, because from then on German national accounting does no longer report West and East Germany separately. For the business cycle statistics we use the post-reunification data, but filter separately before and after this structural break. NFPBS value added is taken from Bruttowertschoepfung in jeweiligen Preisen, table 3.2.1 of VGR, deflated year-by-year by the implicit deflator for aggregate value added, table 3.1.1 of VGR (we apply the same deflator to USTAN data). The base year is always 1991. We experiment also with implicit sector-specific deflators for value added from table 3.2.1 and 3.2.2 of $V G R$, and results are robust to this. NFPBS gross output is taken from Produktionswerte in jeweiligen Preisen, table 3.2.3 of $V G R$, deflated year-by-year by the implicit deflator for aggregate gross output, gathered from table 3.2.6 of VGR. NFPBS investment is Bruttoanlageinvestitionen in jeweiligen Preisen from table 3.2.8.1, deflated with the implicit sector-specific investment price deflators given by Bruttoanlageinvestitionen - preisbereinigt, a chain index, from table 3.2.9.1, VGR. NFPBS capital is Nettoanlagevermoegen in Preisen von 2000 from table 3.2.19.1, VGR, re-chained to 1991 prices. In both the computation of investment and capital data for USTAN in the PIM we use the implicit sector and capital good specific (equipment and non-residential structures) deflators for investment: tables 3.2.8.2, 3.2.9.2., 3.2.8.3 and 3.2.9.3., VGR. We also experiment with deflating USTAN data with a uniform
} 
Figure 9 shows that except for a certain overrepresentation of manufacturing (at least, when measured in value added) and a certain underrepresentation of the transportation and communication sector, USTAN represents the sectoral composition in NFPBS rather well.

Figure 9: Sectoral Composition in USTAN and NFPBS
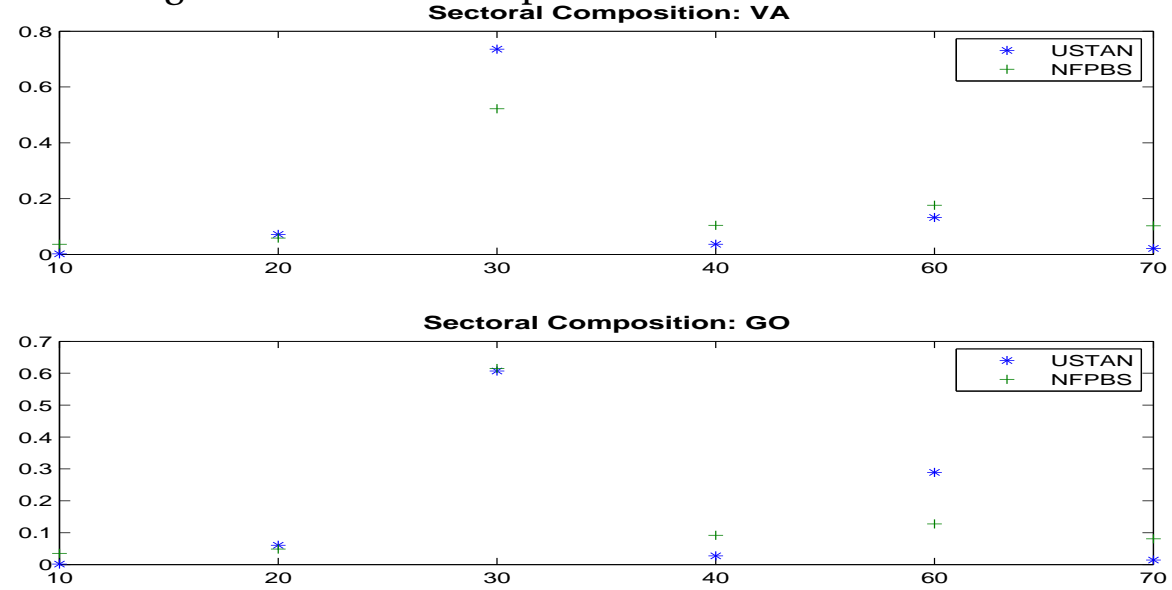

Notes: Graphs display the fraction of the sum of real value added and gross output respectively, over all firms by 1-digit sector within the USTAN sample over the NFPBS aggregate.

Figure 10 demonstrates that also the cyclical behavior of USTAN and NFPBS is close. The correlation of the cyclical components of value added is 0.7671 and for gross output it is $0.6049 .^{39}$

\section{A.2 Capital Stocks}

In order to obtain economically meaningful stocks of capital series for each firm, we have to re-calculate capital stocks in a Perpetual Inventory Method (PIM). The first step is to compute firm-level investment series, $i_{i, t}$, from the corporate balance sheets, which contain data only on accounting capital stocks, $k_{i, t}^{a}$, and accounting total depreciation, $d_{i, t}^{a}$. The following accumulation identity allows to back out nominal firm-level investment: ${ }^{40}$

investment price deflator, the Preisindex der Investitionsgueterproduzenten, source: GP-X002, Statistisches Bundesamt. NFPBS employment is number of employed, Arbeitnehmer, from table 3.2.13, VGR. Payroll is taken from Arbeitnehmerentgelt, table 3.2.10., VGR, deflated by the same general implicit deflator for aggregate value added that we use to deflate value added numbers. Aggregate total hours comes from Geleistete Arbeitsstunden der Arbeitnehmer, table 2.9, VGR. Finally, real private consumption data are private Konsumausgaben, a chain index with base year in 1991, from table 3.2 in the VGR.

${ }^{39}$ We take first differences of log value added as well as gross output and then take out for both a deterministic linear trend to remove the growth of the USTAN sample over time. The correlation between only the first differences in log value added is still 0.5348, and 0.4966, when an HP(100)-filter is applied.

${ }^{40}$ Specifically, $k_{i, t}^{a}$ is the sum of balance sheet items ap65, Technische Anlagen und Maschinen, and ap66, Andere Anlagen, Betriebs-und Geschaeftsausstattung, for equipment; and balance sheet item ap64, Grundstuecke, Bauten, for structures. Since balance sheet data are typically end-of-year stock data, notice that $k_{i, t}^{a}$ is the end-of-period capital stock in year $t-1 . d_{i, t}^{a}$ is profit and loss account item ap156, Abschreibungen auf Sachanlagen und imma- 
Figure 10: Cyclical Behavior in USTAN and NFPBS
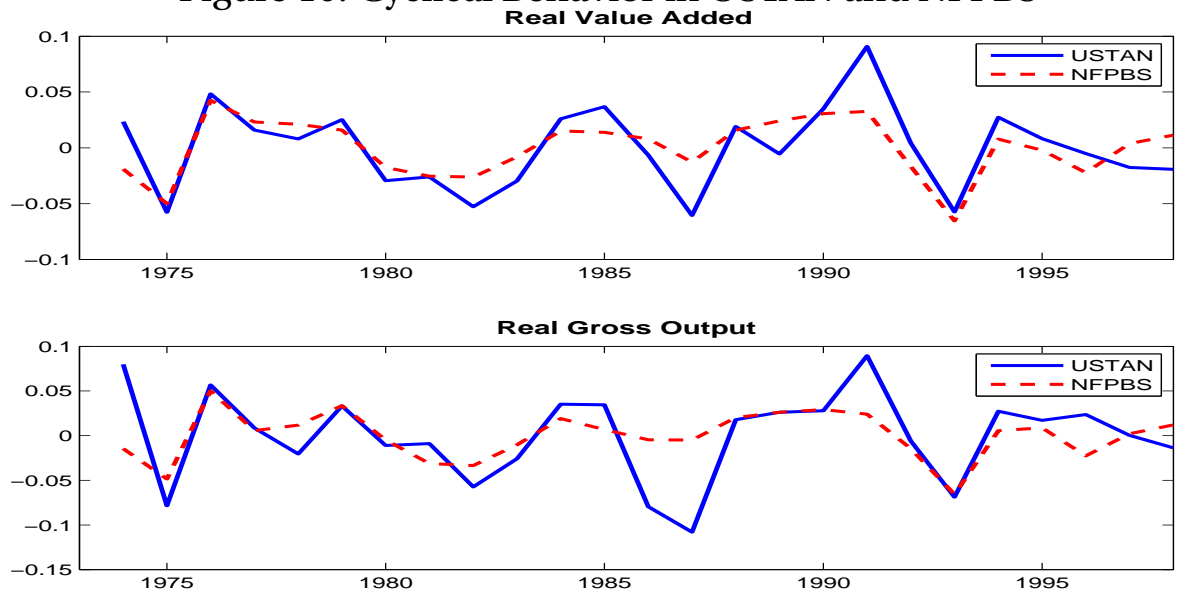

Notes: Upper panel: time series for the sum of real value added over all firms in the USTAN sample and NFBS after detrending with logarithmic first differences and a deterministic linear trend. Lower panel: time series for the sum of real gross output over all firms in the USTAN sample and NFBS after detrending with logarithmic first differences and a deterministic linear trend.

$$
k_{i, t+1}^{a}=k_{i, t}^{a}-d_{i, t}^{a}+p_{t}^{I} i_{i, t} .
$$

The next step is to recognize that capital stocks from corporate balance sheets are not directly usable for economic analysis for two reasons: 1 ) accounting depreciation, $d_{i, t}^{a}$, in corporate balance sheets is often motivated by tax reasons and typically higher than economic depreciation, $\delta_{i, t}^{e}$, expressed as a rate; 2 ) accounting capital stocks are reported at historical prices. Both effects would lead to an underestimation of the real firm-level capital stock, if one were to simply deflate the current accounting capital stock, $k_{i, t}^{a}$, with a current investment price deflator, $p_{t}^{I}$ (assuming that $p_{t}^{I}$ increases over time). We therefore apply a Perpetual Inventory Method (PIM) to compute economic real capital stocks:

$$
\begin{aligned}
k_{i, 1}^{(1)} & =k_{i, 1}^{a} \cdot \\
k_{i, t+1}^{(1)} & =\left(1-\delta_{t}^{e}\right) k_{i, t}^{(1)}+\frac{p_{t}^{I}}{p_{1991}^{I}} i_{i, t} .
\end{aligned}
$$

$k_{i, 1}^{a}$ is the accounting capital stock in prices of 1991 at the beginning of an uninterrupted sequence of firm observations - if for a firm-year we have a missing investment observation, the PIM is started anew, when the firm appears again in the data set. We estimate $\delta_{t}^{e}$ for each

terielle Vermoegensgegenstaende des Anlagevermoegens. In contrast to $k_{i, t}^{a}, d_{i, t}^{a}$ is not given for each capital good separately. For the solution of this complication, see below. 
year from national accounting data, $V G R$, separately for equipment and non-residential structures (table 3.1.3, VGR, Nettoanlagevermoegen nach Vermoegensarten in jeweiligen Preisen, Ausruestungen und Nichtwohnbauten; table 3.1.4, VGR, Abschreibungen nach Vermoegensarten in jeweiligen Preisen, Ausruestungen und Nichtwohnbauten). VGR contains sectoral and capital good specific depreciation data only after 1991, which is why we decided to use only capital good specific depreciation rates for the entire time horizon. For the data sources for investment price deflators see footnote 38. The drawback of this procedure is that we do not observe directly capital-good specific $d_{i, t}^{a}$ in the balance sheets (differently from $k_{i, t}^{a}$ ), so that (12) is not directly applicable for the two types of capital goods separately. We therefore split up $d_{i, t}^{a}$ according to the fraction that each capital good accounts for in the book value of total capital, weighting each capital good by its VGR depreciation rate. Creating a capital series for both capital goods this way is mainly meant to provide a better estimate for total capital for each firm, because we finally aggregate up both types of capital into a single capital good at the firm-level.

There is a final complication, which comes through relying on $k_{i, 1}^{a}$ as the starting value of the PIM. It is typically not a good estimate of the productive real capital stock of the firm at that time. Therefore, we calculate the time-average factor $\phi$ (for each sector), by which $k_{i, t}^{(1)}$ is larger than $k_{i, t}^{a}$, and replace $k_{i, 1}^{a}$ by $\phi k_{i, 1}^{a}$ in the perpetual inventory method. We do this iteratively, until $\phi$ converges, i.e. we calculate:

$$
\begin{aligned}
k_{i, t+1}^{(n)} & =\left(1-\delta_{t}^{e}\right) k_{i, t}^{(n)}+\frac{p_{t}^{I}}{p_{1991}^{I}} i_{i, t} \\
k_{i, 1}^{(n)} & =\phi^{(n-1)} k_{i, 1}^{(n-1)} \\
\phi^{(n)} & =(N T)^{-1} \sum_{i, t} \frac{k_{i, t}^{(n)}}{k_{i, t}^{(n-1)}}
\end{aligned}
$$

where $k_{i, t}^{(0)}=k_{i, t}^{a}, \phi^{(0)}=1$. We stop when for each sector and each capital good category $\phi<1.1$.

Since for our purposes we want to compute economic, i.e. productive, capital stocks, we then - as a final step - add to the capital stock series from this iterative PIM the net present value of the real expenditures for renting and leasing equipment and structures. ${ }^{41}$

\footnotetext{
${ }^{41}$ Specifically, we take item ap161, Miet- und Pachtaufwendungen, from the profit and loss accounts, deflate it by the implicit investment good price deflator, which we compute, in turn, from tables 3.2.8.1 and 3.2.9.1 from VGR, and then divide it by a measure of the user cost of capital. The latter is simply the sum of real interest rates for a given year, which - courtesy of the Bundesbank - we compute from nominal interest rates on corporate bonds and ex-post CPI inflation data (the series is available from the authors upon request), and the time-average, accounting capital-good weighted depreciation rate per firm.
} 


\section{A.3 Labor Inputs}

A more particular difficulty with USTAN data is that information on the number of employees is only updated infrequently for some companies, as it is not taken directly from balance sheets, but sampled from supplementary company information. Being no balance sheet item, the employment data is not constrained by legal accounting rules and did not undergo consistency checks by Bundesbank staff. However, in order to compute firm-level Solow residuals, we need some measure of employment.

We base this measure on the payroll data ( wagebill $_{i, t}$ ) from the profit and loss statements (item ap154, Personalaufwand). Payroll data is regulated by accounting standards and is checked for consistency by the Bundesbank using accounting identities. In contrast to the direct employment data, the payroll data is generally considered of high quality. Therefore, we exploit this data to construct a proxy measure for (log) employment $n_{i, t}$ as follows (with a slight abuse of notation, we use $n_{i, t}$ here for log employment).

The idea behind our proxy measure is that we can determine sectoral average wages even though firm level employment is measured with error. Since wage bargaining in Germany is highly centralized, the sectoral average wage is all we need then, since it is a good proxy for firm level wages. Therefore, dividing firm level payroll by the sectoral average wage recovers true firm level employment.

Specifically, we assume that the measurement error in reported log employment, $n_{i, t}^{*},{ }^{42}$ is classical and additive:

$$
n_{i, t}^{*}=n_{i, t}+\varepsilon_{i, t}
$$

Then we decompose the wage per employee, $\omega_{i, t}$, of firm $i$ at time $t$ into two effects. One is determined by a firm-time-specific wage component $w_{i, t}$, and the other one being region-, $r(i, t)$, sector-, $j(i, t)$, and size-class-specific, $s(i, t)$, where $j(i, t), r(i, t)$ and $s(i, t)$ denote that firm $i$ belongs to sector $j$, region $r$ and size-class $s$ at time $t$, respectively. ${ }^{43}$ Thus, we write

$$
\omega_{i, t}=\bar{w}_{j(i, t), r(i, t), s(i, t), t}+w_{i, t}
$$

We denote all firms that belong to sector $j$, region $r$ and size-class $s$ at time $t$ by $I(j, r, s, t)$. Then

\footnotetext{
${ }^{42}$ We use item ap34, Beschaeftigtenzahl im Durchschnitt des Geschaeftsjahres, to measure $n_{i, t}^{*}$, where available.

${ }^{43}$ Specifically, for sectors we use the 2-digit classification in Table 24 in Appendix A.1. For size classes we use terciles of the capital distribution in each year. For the region-specific wage component we proceed as follows: we divide West Germany into three regions, according to zip codes: South with zip codes starting with 7,8,9, except for 98 and 99; Middle with zip codes starting with 4,5,6, except for 48 and 59; North with zip codes starting with 2,3 as well as 48 and 59. However, not all balance sheets feature zip code information, which is why we compute $\widehat{\bar{w}}_{j, r, s, t}$ with and without a region component. For those firms that do not have zip code information or for those firms that are in sector-region-size bins with fewer than 50 observations in a given year, we take the estimate without the region component.
} 
we can estimate a sector-region-size wage component, $\bar{w}_{j, r, s, t}$, as: ${ }^{44}$

$$
\widehat{\bar{w}}_{j, r, s, t}=\frac{1}{\# I(j, r, s, t)} \sum_{i \in I(j, r, s, t)}\left[\log \left(\text { wagebill }_{i, t}\right)-n_{i, t}^{*}\right] .
$$

We then use this estimate of the average wage rate to estimate employment on the basis of the firm's wage bill:

$$
\begin{aligned}
\hat{n}_{i t} & =\log \text { wagebill } i t-\widehat{\bar{w}}_{j, r, s, t} \\
& =n_{i t}+\omega_{i t}-\frac{1}{\# I(j, r, s, t)} \sum_{h \in I(j, r, s, t)}\left(n_{h, t}+\omega_{h, t}-\left(n_{h, t}+\varepsilon_{h, t}\right)\right) \\
& =n_{i t}+w_{i t}-\frac{1}{\# I(j, r, s, t)} \sum_{h \in I(j, r, s, t)}\left(w_{h, t}-\varepsilon_{h, t}\right) \\
& =n_{i t}+w_{i t}+\frac{1}{\# I(j, r, s, t)} \sum_{h \in I(j, r, s, t)} \varepsilon_{h, t .} .
\end{aligned}
$$

The second equality stems from using (18). The next to last equality holds, because one can replace $\omega_{i t}$ by (19), realizing that the $\bar{w}$, which do not depend on a specific firm, cancel. The last equality holds, because, by construction, the average firm-level deviation from a sectorregion-size bin is zero in every year. For \#I $(j, r, s, t)$ large, the average measurement error term $\left(\frac{1}{\# I(j, r, s, t)} \sum_{h \in I(j, r, s, t)} \varepsilon_{h, t}\right)$ is negligible. In addition, since wage bargaining is highly centralized in Germany, also the firm specific wage component, $w_{i t}$, can be expected to be of lesser importance, i.e. the variance $\sigma_{w}^{2}$ is small. In particular it can be expected to be smaller than the initial measurement error in employment stocks. Therefore our measure of employment, $\hat{n}_{i, t}$, should follow real employment, $n_{i, t}$, more closely than $n_{i, t}^{*}$.

To corroborate this claim, we checked our procedure using data from the German social security records at the Institut fuer Arbeitsmarkt- und Berufsforschung (IAB), which provide information on the wage bill and employment at the establishment level. There we observe true employment and wage bills for all plants and the time 1975-2006. Constraining ourselves to the sample period 1975-1998 and to plants with more than 12 employees, i.e. to data comparable to the one of the USTAN data, we find the correlation between $\hat{n}_{i, t}$ and $n_{i, t}$ as well as between $\Delta \hat{n}_{i, t}$ and $\Delta n_{i, t}$ to be fairly high ( $98 \%$ and $94 \%$, respectively). This means that the cross-sectional variance of the firm specific wage innovations $\sigma_{\Delta w}^{2}$ is small (0.0026) compared to the cross-sectional variance of employment changes $\left(\sigma_{\Delta n}^{2}=0.0163, \sigma_{\Delta \hat{n}}^{2}=0.0162\right)$. Finally, a correlation coefficient between mean $\left(\Delta n_{i, t}\right)$ in the USTAN data and the log-change in aggregate NFPBS employment of 0.653 shows also the quality of our employment measure.

\footnotetext{
${ }^{44}$ To estimate $\widehat{\bar{w}}_{j, r, s, t}$ we of course use only those observations, where $n_{i, t}^{*}$, i.e. item ap34, Beschaeftigtenzahl im Durchschnitt des Geschaeftsjahres, is available.
} 


\section{A.4 Solow Residual Calculation}

With the estimated firm-level capital stocks and employment levels we can now compute firmlevel Solow residuals from the logged production function (1). In our baseline specification we estimate the factor elasticities, $v$ and $\theta$, as 1 -digit sector-specific median, pooled over all firmyear observations in a sector, expenditure shares. ${ }^{45}$ Table 27 displays the estimated elasticities. Notice that for the aggregate Solow residual calculation for the baseline simulations, for which we use the data sources specified in Footnote 38 in Appendix A.1, we simply use the expenditure shares from manufacturing, as manufacturing is still the largest sector within NFPBS (had we used any weighted median of expenditure shares the result would have been the same).

Table 27: SECTOR-SPECIFIC EXPENDITURE SHARES

\begin{tabular}{rlrr}
\hline \hline ID & Sector & labor share $v$ & capital share $\theta$ \\
\hline 1 & Agriculture & 0.2182 & 0.7310 \\
2 & Energy \& Mining & 0.3557 & 0.5491 \\
3 & Manufacturing & 0.5565 & 0.2075 \\
4 & Construction & 0.6552 & 0.1771 \\
6 & Trade & 0.4536 & 0.2204 \\
7 & Transport \& Communication & 0.4205 & 0.2896 \\
\hline
\end{tabular}

To check the robustness of our results, we also try alternative specifications with predefined elasticities common across sectors. We first try a combination of $v$ and $\theta, \operatorname{SR}(2)$, such that a one third share of capital in a CRTS production function and a reduced form revenue elasticity of capital of 0.5 are compatible. This implies an implicit markup of 1.33 , if one were to rationalize DRTS with a CRTS production function and monopolistic competition. We then either fix the revenue elasticity of capital (SR5, SR3) or fix the one third share of capital in a CRTS production function (SR6, SR4) and lower the markup. Table 28 summarizes the scenarios.

\footnotetext{
${ }^{45}$ We use profit and loss account item ap 153 , Rohergebnis, for firm-level value added and deflate it in the baseline scenario with the aggregate value added deflator, but experiment also with sector-specific value added deflators, see Footnote 38 in Appendix A.1 for details. To compute firm-level expenditure shares, we proceed as follows: the labor share is simply total payroll divided by value added (ap154/ap153); capital expenditures, which are then again divided by value added, are the sum of the PIM capital stock and the net present value of renting and leasing expenditures multiplied by the user cost of capital as specified in Footnote 41 in Appendix A.2. For firm-level sales we use profit and loss account item ap144, Umsatzerloese, and deflate it with the aggregate value added deflator. For firm-level sales we use profit and loss account item ap151, Aufwendungen fuer Roh-, Hilfs-, und Betriebsstoffe und fuer bezogene Waren, and deflate it again with the aggregate value added deflator.
} 
Table 28: Overview Over the DifFerent Solow Residual Specifications

\begin{tabular}{|c|c|c|c|c|c|}
\hline Specification & $\begin{array}{c}\text { labor share } \\
v\end{array}$ & $\begin{array}{c}\text { capital share } \\
\theta\end{array}$ & $\begin{array}{c}\text { CRTS capital share } \\
\frac{\theta}{\theta+v}\end{array}$ & $\begin{array}{c}\text { markup } \\
\frac{1}{\theta+v}\end{array}$ & $\begin{array}{c}\text { revenue elasticity } \\
\frac{\theta}{1-v}\end{array}$ \\
\hline Baseline & 0.5565 & 0.2075 & 0.31 & 1.32 & 0.47 \\
\hline SR2 & 0.5 & 0.25 & 0.33 & 1.33 & 0.5 \\
\hline SR3 & 0.6667 & 0.1667 & 0.2 & 1.20 & 0.5 \\
\hline SR4 & 0.5556 & 0.2778 & 0.33 & 1.20 & 0.63 \\
\hline SR5 & 0.6 & 0.2 & 0.25 & 1.25 & 0.5 \\
\hline SR6 & 0.5333 & 0.2667 & 0.33 & 1.25 & 0.57 \\
\hline
\end{tabular}

\section{A.5 Cross-sectional Dispersion Data}

Table 29: Cross-sectional Dispersion Data For the Log-Changes in Solow Residuals,

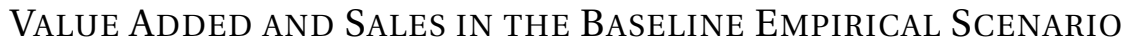

\begin{tabular}{rrrr}
\hline \hline Year & $s t d\left(\Delta \log \epsilon_{i, t}\right)$ & $s t d\left(\Delta \log y_{i, t}\right)$ & $s t d\left(\Delta \log\right.$ sales $\left._{i, t}\right)$ \\
\hline 1973 & 0.12204 & 0.14743 & 0.17619 \\
1974 & 0.12784 & 0.15719 & 0.20029 \\
1975 & 0.13017 & 0.16057 & 0.20948 \\
1976 & 0.12285 & 0.14851 & 0.2013 \\
1977 & 0.11902 & 0.14056 & 0.18989 \\
1978 & 0.1182 & 0.13888 & 0.19715 \\
1979 & 0.11875 & 0.13843 & 0.18751 \\
1980 & 0.11945 & 0.13881 & 0.18311 \\
1981 & 0.12397 & 0.14369 & 0.18629 \\
1982 & 0.12395 & 0.14519 & 0.18548 \\
1983 & 0.12137 & 0.14378 & 0.18798 \\
1984 & 0.12086 & 0.14251 & 0.18383 \\
1985 & 0.12065 & 0.14491 & 0.18567 \\
1986 & 0.1212 & 0.14179 & 0.1901 \\
1987 & 0.12028 & 0.14024 & 0.18593 \\
1988 & 0.11673 & 0.13571 & 0.18348 \\
1989 & 0.1143 & 0.1328 & 0.17782 \\
1990 & 0.11868 & 0.1401 & 0.18643 \\
1991 & 0.12155 & 0.14548 & 0.18557 \\
1992 & 0.12014 & 0.14218 & 0.18209 \\
1993 & 0.12166 & 0.14537 & 0.19942 \\
1994 & 0.12075 & 0.1408 & 0.18527 \\
1995 & 0.1184 & 0.13602 & 0.18021 \\
1996 & 0.11722 & 0.13396 & 0.17517 \\
1997 & 0.11203 & 0.12965 & 0.176 \\
1998 & 0.11017 & 0.13004 & 0.17971
\end{tabular}

Notes: std: cross-sectional standard deviation of the within-transformed data. No detrending. 


\section{B Appendix B - Robustness}

\section{B.1 Further Robustness on the Empirical Results}

Table 30: Robustness For DifFEREnt Solow Residual SPECIFICATIONS

\begin{tabular}{lccc}
\hline \hline Cross-sectional Moment & $c v(\cdot)$ & $\rho(\cdot, H P(100)-Y)$ & $\mu(\cdot)$ \\
\hline$s t d\left(\Delta \log \epsilon_{i, t}\right)_{\text {Baseline }}$ & $2.67 \%$ & -0.481 & 0.120 \\
\hline $\operatorname{std}\left(\Delta \log \epsilon_{i, t}\right)_{\text {SR2 }}$ & $2.71 \%$ & -0.491 & 0.122 \\
$\operatorname{std}\left(\Delta \log \epsilon_{i, t}\right)_{\text {SR3 }}$ & $2.39 \%$ & -0.517 & 0.120 \\
$\operatorname{std}\left(\Delta \log \epsilon_{i, t}\right)_{\text {SR4 }}$ & $2.56 \%$ & -0.481 & 0.123 \\
$\operatorname{std}\left(\Delta \log \epsilon_{i, t}\right)_{\text {SR5 }}$ & $2.51 \%$ & -0.510 & 0.120 \\
$\operatorname{std}\left(\Delta \log \epsilon_{i, t}\right)_{\text {SR6 }}$ & $2.62 \%$ & -0.486 & 0.122 \\
\hline $\operatorname{std}\left(\Delta \log \epsilon_{i, t}\right)_{\text {Baselinevar1 }}$ & $3.64 \%$ & -0.591 & 0.154 \\
$\operatorname{std}\left(\Delta \log \epsilon_{i, t}\right)_{\text {Baselinevar2 }}$ & $2.63 \%$ & -0.501 & 0.117 \\
\hline
\end{tabular}

Notes: $s t d$ : cross-sectional standard deviation, linearly detrended. $c v$ : time series coefficient of variation. $\rho$ : time series correlation coefficient.

$\mu$ : time series average. $H P(\lambda)-Y$ : Cyclical component of GDP after HP-filtering using smoothing parameter $\lambda$.

Table 30 shows that the three main empirical findings of this paper - high idiosyncratic uncertainty and countercyclicality as well as small volatility of idiosyncratic uncertainty - are robust to both different pre-specified and uniform-across-sectors factor elasticities in the production function as well as different lag structures in the production factors: Baselinevar1 assumes predetermined labor in addition to predetermined capital, whereas Baselinevar2 has both labor and capital productive instantaneously. Tables 31 to 36 show the analogous results of Tables 5 to 10 in Section 2.3 for $s t d\left(\Delta \log y_{i, t}\right)$ and $s t d\left(\Delta \log s_{l} e_{e}, t\right)$, respectively. 
Table 31: COUNTERCYCLICALITY OF IDIOSYNCRATIC UNCERTAINTY - ROBUSTNESS TO CYCLICAL INDICATOR

\begin{tabular}{lc}
\hline \hline Cyclical Indicator & $\rho\left(\operatorname{std}\left(\Delta \log y_{i, t}\right), \cdot\right)$ \\
\hline Baseline: $H P(100)-Y$ & -0.450 \\
\hline HP $(6.25)-Y$ & -0.474 \\
Log-diff-Y & -0.482 \\
mean $\left(\Delta \log y_{i, t}\right)$ & -0.490 \\
Log-diff-N & -0.548 \\
Log-diff-Solow Residual & -0.337 \\
\hline \hline Cyclical Indicator & $\rho\left(\right.$ std $\left(\Delta \log\right.$ sales $\left.\left._{i, t}\right), \cdot\right)$ \\
\hline Baseline: $H P(100)-Y$ & -0.405 \\
\hline HP $(6.25)-Y$ & -0.563 \\
Log-diff-Y & -0.375 \\
mean $\left(\Delta \log\right.$ sales $\left._{i, t}\right)$ & -0.410 \\
Log-diff-N & -0.436 \\
Log-diff-Solow Residual & -0.228 \\
\hline
\end{tabular}

Notes: See notes to Table 30. $N$ refers to aggregate employment.

Table 32: More RoBUstness

\begin{tabular}{lccc}
\hline \hline Cross-sectional Moment & $c v(\cdot)$ & $\rho(\cdot, H P(100)-Y)$ & $\mu(\cdot)$ \\
\hline iqr $\left(\Delta \log y_{i, t}\right)$ & $6.13 \%$ & -0.413 & 0.150 \\
std $\left(\Delta \log y_{i, t}\right)_{\text {raw }}$ & $3.95 \%$ & -0.394 & 0.153 \\
std $\left(\Delta \log y_{i, t}\right)_{1973-1990}$ & $3.63 \%$ & -0.675 & 0.143 \\
std $\left(\Delta \log y_{i, t}\right)_{1977-1998}$ & $3.06 \%$ & -0.235 & 0.140 \\
\hline \hline iqr $\left(\Delta \log\right.$ sales $\left._{i, t}\right)$ & $8.22 \%$ & -0.343 & 0.162 \\
std $\left(\Delta \log \text { sales }_{i, t}\right)_{\text {raw }}$ & $4.05 \%$ & -0.306 & 0.199 \\
std $\left(\Delta \log \text { sales }_{i, t}\right)_{1973-1990}$ & $3.86 \%$ & -0.440 & 0.189 \\
std $\left(\Delta \log \text { sales }_{i, t}\right)_{1977-1998}$ & $2.73 \%$ & -0.094 & 0.185 \\
\hline
\end{tabular}

Notes: See notes to Table 30. iqr stands for interquartile range, which is linearly detrended.

Table 33: Results By MATERIAL UsAGE

\begin{tabular}{lccc}
\hline \hline Cross-sectional Moment & $c \nu(\cdot)$ & $\rho(\cdot, H P(100)-Y)$ & $\mu(\cdot)$ \\
\hline$s t d\left(\Delta \log y_{i, t}\right)_{\text {Aggregate }}$ & $3.73 \%$ & -0.450 & 0.142 \\
\hline$s t d\left(\Delta \log y_{i, t}\right)_{\text {Material Intensity const. }}$ & $5.94 \%$ & -0.270 & 0.117 \\
\hline \hline $\operatorname{std}\left(\Delta \log \text { sales }_{i, t}\right)_{\text {Aggregate }}$ & $3.82 \%$ & -0.405 & 0.187 \\
\hline std $\left(\Delta \log \text { sales }_{i, t}\right)_{\text {Material Intensity const. }}$ & $6.64 \%$ & -0.277 & 0.124 \\
\hline
\end{tabular}

Notes: See notes to Table 30. Material Intensity const. refers to firms whose material expenditures over sales $\frac{m_{i, t}}{\text { sales } s_{i, t}}$ have changed by less then one percentage point in absolute terms. 
Table 34: Results By SeCtOR

\begin{tabular}{lccc}
\hline \hline Cross-sectional Moment & $c v(\cdot)$ & $\rho(\cdot, H P(100)-Y)$ & $\mu(\cdot)$ \\
\hline$s t d\left(\Delta \log y_{i, t}\right)_{\text {Aggregate }}$ & $3.73 \%$ & -0.450 & 0.142 \\
\hline$s t d\left(\Delta \log y_{i, t}\right)_{\mathrm{AGR}}$ & $4.24 \%$ & 0.044 & 0.176 \\
std $\left(\Delta \log y_{i, t}\right)_{\mathrm{MIN} / \mathrm{ENE}}$ & $11.39 \%$ & -0.221 & 0.116 \\
std $\left(\Delta \log y_{i, t}\right)_{\mathrm{MAN}}$ & $5.03 \%$ & -0.579 & 0.140 \\
std $\left(\Delta \log y_{i, t}\right)_{\mathrm{CON}}$ & $4.77 \%$ & -0.614 & 0.150 \\
std $\left(\Delta \log y_{i, t}\right)_{\mathrm{TRD}}$ & $3.48 \%$ & -0.057 & 0.141 \\
std $\left(\Delta \log y_{i, t}\right)_{\mathrm{TRA} / \mathrm{COM}}$ & $4.30 \%$ & 0.116 & 0.151 \\
\hline \hline std $\left(\Delta \log \text { sales }_{i, t}\right)_{\mathrm{Aggregate}}$ & $3.82 \%$ & -0.405 & 0.187 \\
\hline std $\left(\Delta \log \text { sales }_{i, t}\right)_{\mathrm{AGR}}$ & $10.14 \%$ & -0.060 & 0.217 \\
std $\left(\Delta \log \text { sales }_{i, t}\right)_{\mathrm{MIN} / \mathrm{ENE}}$ & $18.12 \%$ & 0.047 & 0.118 \\
std $\left(\Delta \log \text { sales }_{i, t}\right)_{\mathrm{MAN}}$ & $4.66 \%$ & -0.506 & 0.170 \\
std $\left(\Delta \log \text { sales }_{i, t}\right)_{\mathrm{CON}}$ & $6.99 \%$ & -0.064 & 0.328 \\
std $\left(\Delta \log \text { sales }_{i, t}\right)_{\mathrm{TRD}}$ & $5.93 \%$ & -0.267 & 0.176 \\
std $\left(\Delta \log \text { sales }_{i, t}\right)_{\mathrm{TRA} / \mathrm{COM}}$ & $8.06 \%$ & -0.27 & 0.174 \\
\hline
\end{tabular}

Notes: See notes to Table 30. AGR: Agriculture; MIN/ENE: Mining \& Energy; MAN: Manufacturing; CON: Construction; TRD: Trade (Retail \& Wholesale); TRA/COM: Transportation \& Communication.

Table 35: Results By Firm Size

\begin{tabular}{lccc}
\hline \hline Cross-sectional Moment & $c v(\cdot)$ & $\rho(\cdot, H P(100)-Y)$ & $\mu(\cdot)$ \\
\hline$s t d\left(\Delta \log \epsilon_{i, t}\right)_{\text {Aggregate }}$ & $2.67 \%$ & -0.481 & 0.120 \\
\hline Capital & & & \\
\hline$s t d\left(\Delta \log \epsilon_{i, t}\right)_{\text {SMALL33 }}$ & $1.95 \%$ & -0.401 & 0.131 \\
$\operatorname{std}\left(\Delta \log \epsilon_{i, t}\right)_{\text {SMALL75 }}$ & $2.44 \%$ & -0.456 & 0.124 \\
$\operatorname{std}\left(\Delta \log \epsilon_{i, t}\right)_{\text {SMALL95 }}$ & $2.66 \%$ & -0.472 & 0.121 \\
$\operatorname{std}\left(\Delta \log \epsilon_{i, t}\right)_{\text {LARGE05 }}$ & $4.71 \%$ & -0.464 & 0.106 \\
\hline \hline Value Added & & & \\
\hline $\operatorname{std}\left(\Delta \log \epsilon_{i, t}\right)_{\text {SMALL33 }}$ & $1.99 \%$ & -0.482 & 0.134 \\
$\operatorname{std}\left(\Delta \log \epsilon_{i, t}\right)_{\text {SMALL75 }}$ & $2.41 \%$ & -0.478 & 0.124 \\
$\operatorname{std}\left(\Delta \log \epsilon_{i, t}\right)_{\text {SMALL95 }}$ & $2.63 \%$ & -0.478 & 0.121 \\
$\operatorname{std}\left(\Delta \log \epsilon_{i, t}\right)_{\text {LARGE05 }}$ & $4.90 \%$ & -0.436 & 0.100 \\
\hline
\end{tabular}

Notes: See notes to Table 30. SMALL33 refers to the smallest 33\% firms in a given year, SMALL75 to the smallest $75 \%$, etc. if size is measured in capital stock and real value added, respectively. 
Table 36: Results By Firm Productivity

\begin{tabular}{lccc}
\hline \hline Cross-sectional Moment & $c v(\cdot)$ & $\rho(\cdot, H P(100)-Y)$ & $\mu(\cdot)$ \\
\hline$s t d\left(\Delta \log y_{i, t}\right)_{\text {Aggregate }}$ & $3.73 \%$ & -0.450 & 0.142 \\
\hline$s t d\left(\Delta \log y_{i, t}\right)_{\text {First Quartile }}$ & $3.00 \%$ & -0.743 & 0.150 \\
std $\left(\Delta \log y_{i, t}\right)_{\text {Second Quartile }}$ & $3.58 \%$ & -0.479 & 0.136 \\
std $\left(\Delta \log y_{i, t}\right)_{\text {Third Quartile }}$ & $4.77 \%$ & -0.381 & 0.135 \\
std $\left(\Delta \log y_{i, t}\right)_{\text {Fourth Quartile }}$ & $4.55 \%$ & -0.211 & 0.142 \\
\hline \hline std $\left(\Delta \log \text { sales }_{i, t}\right)_{\text {Aggregate }}$ & $3.82 \%$ & -0.405 & 0.187 \\
\hline std $\left(\Delta \log \text { sales }_{i, t}\right)_{\text {First Quartile }}$ & $4.80 \%$ & -0.297 & 0.206 \\
std $\left(\Delta \log \text { sales }_{i, t}\right)_{\text {Second Quartile }}$ & $4.65 \%$ & -0.225 & 0.193 \\
std $\left(\Delta \log \text { sales }_{i, t}\right)_{\text {Third Quartile }}$ & $6.35 \%$ & -0.357 & 0.175 \\
std $\left(\Delta \log \text { sales }_{i, t}\right)_{\text {Fourth Quartile }}$ & $4.88 \%$ & -0.349 & 0.168 \\
\hline
\end{tabular}

Notes: See notes to Table 30. First Quartile refers to the $25 \%$ least productive firms in a given year, when measured in firm-level Solow residuals, Second Quartile to the firms with productivity in the $25 \%-50 \%$ range, etc.

We next provide further evidence for the robustness of the three empirical findings of this paper to sample selection and variable construction. First, we use sector-specific price deflators for value added instead of the aggregate one (for sources see Footnote 38 in Appendix A.1). Second, we use an aggregate price deflator for investment goods (see Footnote 38 in Appendix A.1 for details) in the perpetual inventory method instead of sectoral deflators separately for equipment and structures. Third, we employ a stricter outlier removal criterion of 2.5 standard deviations around the firm- and year-specific mean in Solow residual and value added innovations, as well as investment rates and employment changes. Fourth, we use a more liberal outlier criterion using 5 standard deviations instead of $3 .^{46}$ Fifth, we employ a specification, where we assume that an outlier above 3 standard deviations means a merger and, subsequently, treat these firms as new firms in addition to removing them in the year, where the outlier occurs. Sixth, we use all the firms that we observe at least twice with first differences. ${ }^{47}$ Finally, we carry out a more standard perpetual inventory method that simply uses the reported capital stocks in the first year of observation for a firm, instead of solving a fixed point problem in correction factors (see Appendix A.2 for details). As one can see from Table 37, the results are robust to all these alternative sampling procedures.

\footnotetext{
${ }^{46}$ This lowers the number of dropped firm-year observations due to outliers in factor and value added changes from 41,453 to 17,205 , and the ones due to outliers in Solow residual changes from 18,978 to 5,526. This leaves the total number of firm-year observations at 908,476 and the total number of firms in the sample at 76,464.

${ }^{47}$ This lowers the number of dropped firm-year observations due to not satisfying the minimum observation requirement from 417,550 to 158,950 . This leaves the total number of firm-year observations at 971,308 and the total number of firms in the sample at 114,528.
} 
Table 37: More RoBUstness

\begin{tabular}{lccc}
\hline \hline Cross-sectional Moment & $c v(\cdot)$ & $\rho(\cdot, H P(100)-Y)$ & $\mu(\cdot)$ \\
\hline$s t d\left(\Delta \log \epsilon_{i, t}\right)_{\text {Baseline }}$ & $2.67 \%$ & -0.481 & 0.120 \\
\hline std $\left(\Delta \log \epsilon_{i, t}\right)_{\text {Sectoral Deflators for VA }}$ & $2.66 \%$ & -0.483 & 0.120 \\
$\operatorname{std}\left(\Delta \log \epsilon_{i, t}\right)_{\text {Uniform price index for I-goods }}$ & $2.68 \%$ & -0.480 & 0.120 \\
$\operatorname{std}\left(\Delta \log \epsilon_{i, t}\right)_{\text {Stricter outlier removal }}$ & $2.51 \%$ & -0.499 & 0.109 \\
$\operatorname{std}\left(\Delta \log \epsilon_{i, t}\right)_{\text {Looser outlier removal }}$ & $2.88 \%$ & -0.476 & 0.150 \\
$\operatorname{std}\left(\Delta \log \epsilon_{i, t}\right)_{\text {Stricter Merger Criterion }}$ & $2.69 \%$ & -0.485 & 0.118 \\
$\operatorname{std}\left(\Delta \log \epsilon_{i, t}\right)_{\text {Shorter in sample }}$ & $2.46 \%$ & -0.485 & 0.122 \\
$\operatorname{std}\left(\Delta \log \epsilon_{i, t}\right)_{\text {Standard Perpetual Inventory }}$ & $2.64 \%$ & -0.492 & 0.119 \\
\hline
\end{tabular}

Notes: See notes to Table 30.

Figure 11: Time Series of the Dispersions of Firm-Level Value Added and Sales Innovations (Normalized by the Average Dispersion) and the Cyclical Component of GDP
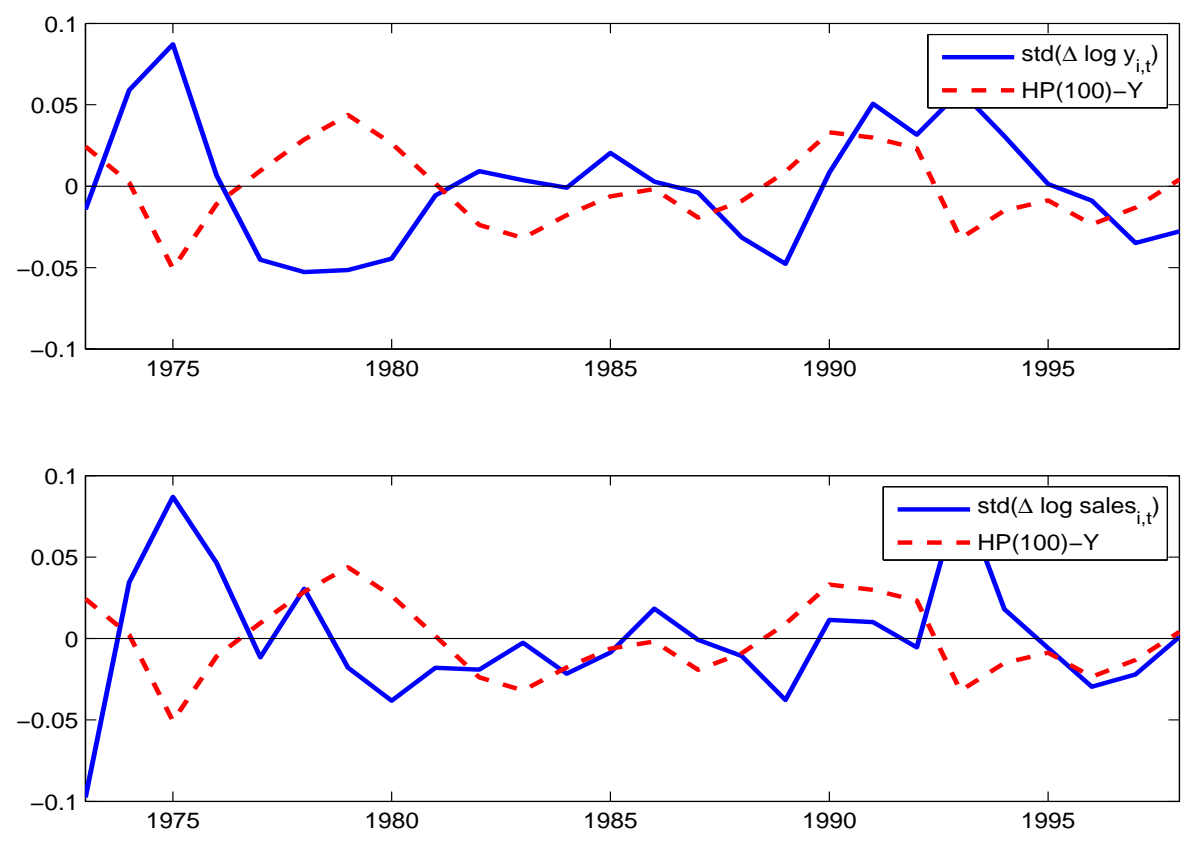

Notes: See notes to Table 30. 
Figure 12: Scatter Plot between the Cross-sectional Dispersion of Firm-Level Solow Residual Innovations and the Cyclical Component of GDP

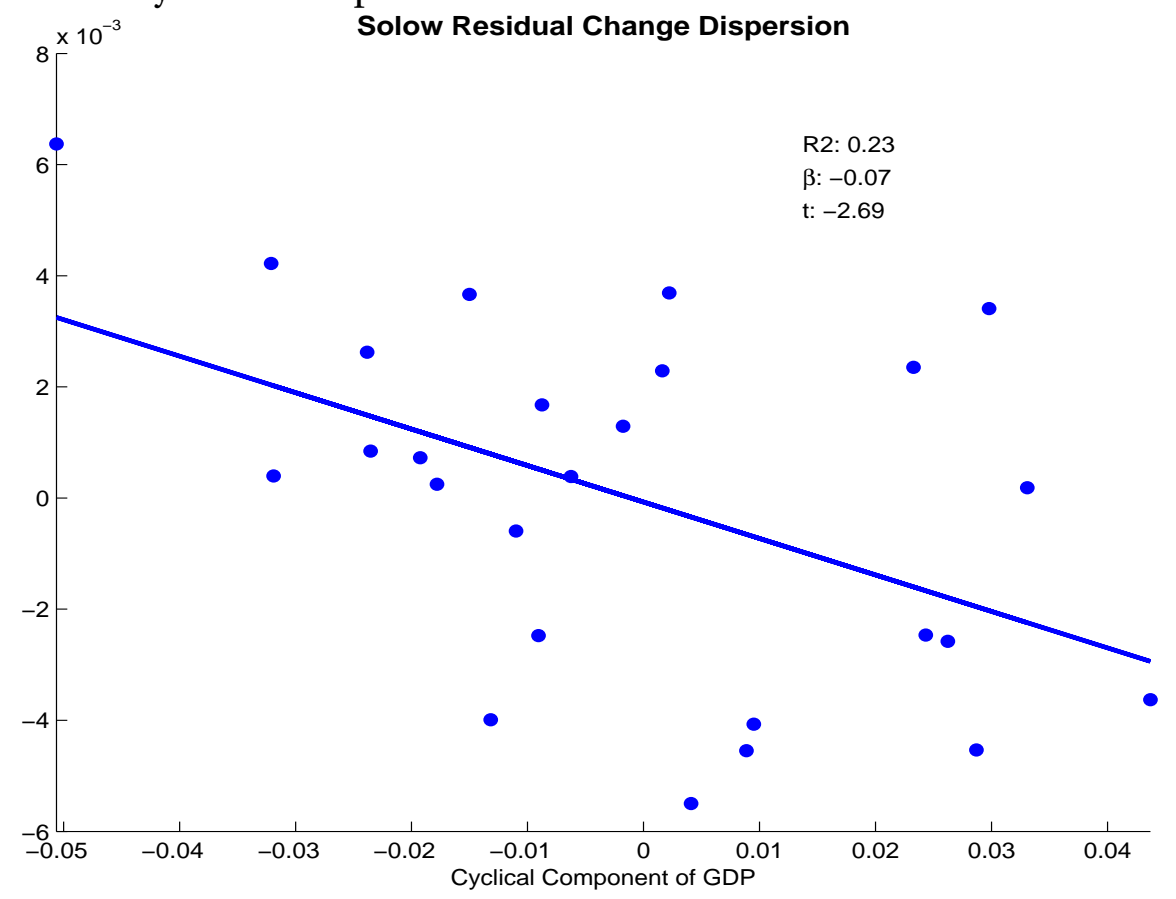

Figure 13: Scatter Plots between the Cross-sectional Dispersion of Firm-Level Value Added/Sales Innovations and the Cyclical Component of GDP
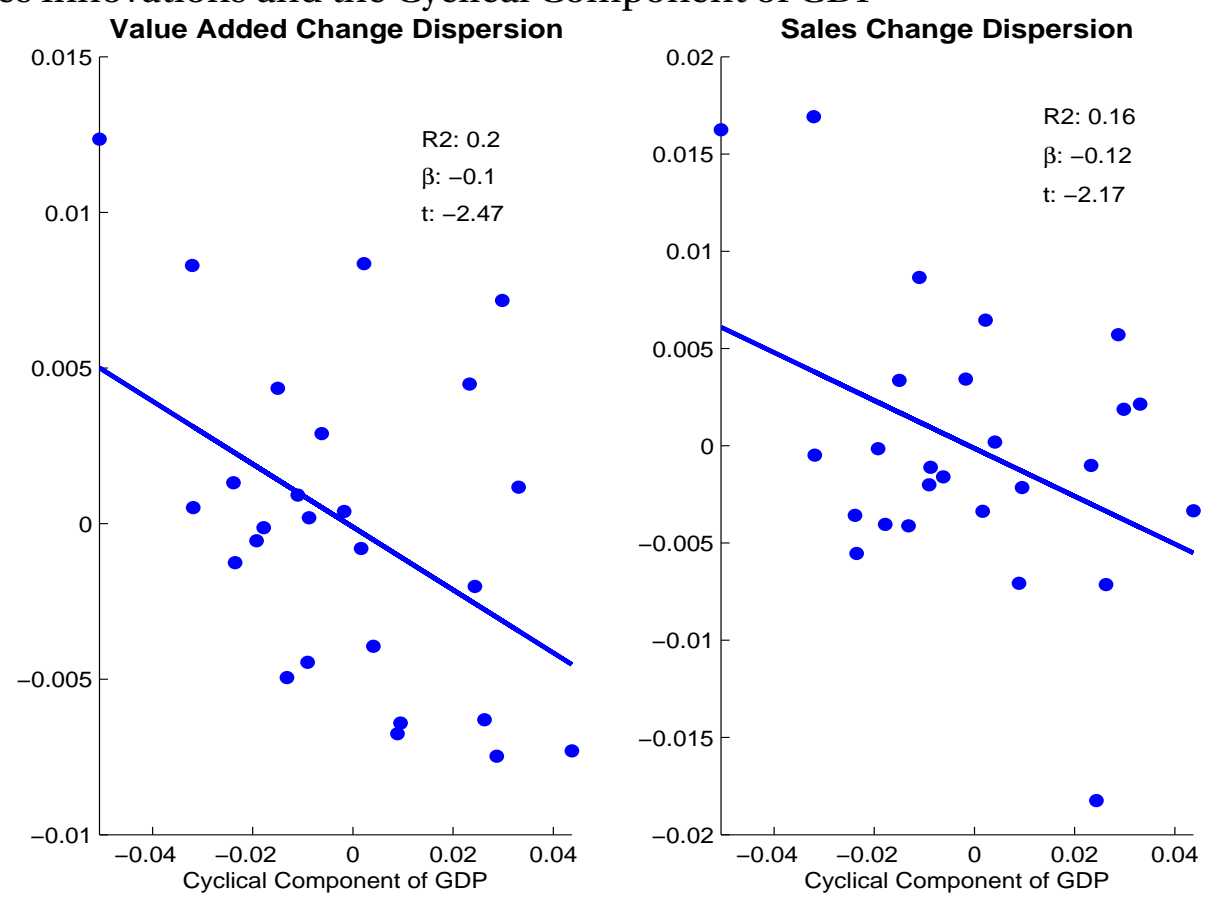


\section{B.2 Further Robustness on the Simulation Results}

In this subsection, we provide further robustness on our three quantitative results: the inability of the pure 'Risk Model' to produce realistic business cycles; the small changes in the second moment analysis that adding uncertainty shocks to a standard first moment shock 'RBC Model' brings; and the interpretation of these changes as largely due to a bad news effect that uncertainty shocks entail. We start by increasing the risk aversion parameter from one to three (Table 38). Technically, with the separable felicity specification in (6) there is no balanced growth path with CRRA=3. The model remains, however, consistent with balanced growth, if the disutility of leisure grows with the steady state growth rate, $\gamma$, and the fundamental discount rate is accordingly adjusted. Second (Table 39), we cut the steady state firm-level uncertainty, $\bar{\sigma}(\epsilon)$, by half, from 0.1201 to 0.06 . This scenario is relevant, if one were to attribute some part of the measured $\bar{\sigma}(\epsilon)$ to measurement error in firm-level Solow residuals. Notice that we leave the volatility of the uncertainty process unchanged. Third (Table 40), we increase the persistence of the firm-level Solow residual process from 0.95 to 0.98 , bringing it closer to a random walk. Fourth (Table 41), we experiment also with weighted average expenditure shares instead of using the ones from the manufacturing sector, both weighted with value added and with employment/capital and using USTAN and NFPBS weights. To come up with a single number for each factor elasticity, we simply take the median of these four weighted averages and end up using $v=0.5229$ and $\theta=0.2352$. In this scenario, we re-estimate the aggregate driving force (2) and also recalibrate the adjustment costs factor, $\bar{\xi}$, to 0.3 . Fifth (Table 42), we lower the implied mark-up (to 1.20) - or equivalently increase the capital elasticity of the revenue function (to 0.63 ) - , and set $v=0.5556, \theta=0.2778$ for all sectors both in the calculation of the firm-level and aggregate Solow residuals as well as in the model simulations. We again reestimate the aggregate driving force (2) and also recalibrate the adjustment costs factor, $\bar{\xi}$, to 0.3. Sixth (Table 43), we compare the baseline results with the ones from a seemingly unrelated regressions (SUR) specification for the aggregate driving force, (2), i.e. a specification, where the off-diagonal elements of $\varrho_{A}$ are restricted to zero. This is interesting for two reasons: first, this specification mitigates somewhat the obvious problems with estimating a bivariate VAR with 7 independent parameters from $2 \times 26$ data points. We show that both the actual estimates of the remaining VAR parameters as well as the implications for our simulation results are remarkably robust. Secondly, Table 43 shows that most of the changes between the 'RBC Model' and the 'Full/News Model' are mainly due to the interaction effect between aggregate Solow residuals and firm-level uncertainty, that in the unrestricted baseline specification is embodied in the negative VAR coefficient of tomorrow's (but known today) firm-level uncertainty on tomorrow's aggregate Solow residual, an effect that we identified as a bad news effect. 
Table 38: Aggregate Business CyCle Statistics - CRRA=3

\begin{tabular}{|c|c|c|c|c|}
\hline & $\begin{array}{c}\text { Full } \\
\text { Model }\end{array}$ & $\begin{array}{l}\text { News } \\
\text { Model }\end{array}$ & $\begin{array}{l}\text { RBC- } \\
\text { Model }\end{array}$ & $\begin{array}{c}\text { Risk } \\
\text { Model }\end{array}$ \\
\hline $\begin{array}{l}\text { Volatility } \\
\text { of Output }\end{array}$ & $3.73 \%$ & $3.93 \%$ & $2.71 \%$ & $0.30 \%$ \\
\hline \multicolumn{5}{|c|}{ Volatility of aggregate variables relative to output volatility } \\
\hline Consumption & 0.14 & 0.13 & 0.20 & 0.35 \\
\hline Investment & 5.46 & 5.51 & 5.10 & 6.47 \\
\hline Employment & 0.72 & 0.73 & 0.60 & 1.77 \\
\hline \multicolumn{5}{|l|}{ Persistence } \\
\hline Output & 0.39 & 0.44 & 0.29 & 0.27 \\
\hline Consumption & 0.66 & 0.64 & 0.52 & 0.44 \\
\hline Investment & 0.35 & 0.41 & 0.26 & 0.17 \\
\hline Employment & 0.28 & 0.36 & 0.31 & 0.14 \\
\hline \multicolumn{5}{|c|}{ Contemporaneous Correlation with Aggregate Output } \\
\hline Consumption & 0.77 & 0.79 & 0.83 & -0.31 \\
\hline Investment & 0.99 & 0.99 & 0.99 & 0.97 \\
\hline Employment & 0.93 & 0.95 & 0.84 & 0.82 \\
\hline
\end{tabular}

Notes:

Business cycle statistics of aggregate output, consumption, investment and employment. Employment in the model includes the amount of labor used to adjust the firms' capital stocks. All variables are logged and then HP-filtered with a smoothing parameter of 100 . The numbers come from a simulation of the model over $T=1500$ periods. Volatility is percentage standard deviation. Persistence refers to the first order autocorrelation. 
Table 39: Aggregate Business Cycle Statistics - Half $\bar{\sigma}(\epsilon)$

\begin{tabular}{|c|c|c|c|c|}
\hline & $\begin{array}{c}\text { Full } \\
\text { Model }\end{array}$ & $\begin{array}{l}\text { News } \\
\text { Model }\end{array}$ & $\begin{array}{l}\text { RBC- } \\
\text { Model }\end{array}$ & $\begin{array}{c}\text { Risk } \\
\text { Model }\end{array}$ \\
\hline $\begin{array}{l}\text { Volatility } \\
\text { of Output }\end{array}$ & $3.88 \%$ & $4.02 \%$ & $3.03 \%$ & $0.21 \%$ \\
\hline \multicolumn{5}{|c|}{ Volatility of aggregate variables relative to output volatility } \\
\hline Consumption & 0.36 & 0.34 & 0.41 & 0.78 \\
\hline Investment & 4.35 & 4.47 & 4.10 & 7.89 \\
\hline Employment & 0.72 & 0.74 & 0.67 & 1.56 \\
\hline \multicolumn{5}{|l|}{ Persistence } \\
\hline Output & 0.44 & 0.46 & 0.31 & 0.44 \\
\hline Consumption & 0.61 & 0.60 & 0.48 & 0.37 \\
\hline Investment & 0.38 & 0.42 & 0.27 & 0.23 \\
\hline Employment & 0.37 & 0.41 & 0.26 & 0.22 \\
\hline \multicolumn{5}{|c|}{ Contemporaneous Correlation with Aggregate Output } \\
\hline Consumption & 0.92 & 0.91 & 0.92 & -0.35 \\
\hline Investment & 0.99 & 0.99 & 0.98 & 0.90 \\
\hline Employment & 0.98 & 0.98 & 0.97 & 0.87 \\
\hline
\end{tabular}

Notes: See notes to Table 38. $\bar{\sigma}(\epsilon)$ is 0.0600 , instead of 0.1201 as in the baseline calibration. 
Table 40: Aggregate Business CyCle Statistics $-\rho_{I}=0.98$

\begin{tabular}{|c|c|c|c|c|}
\hline & $\begin{array}{c}\text { Full } \\
\text { Model }\end{array}$ & $\begin{array}{l}\text { News } \\
\text { Model }\end{array}$ & $\begin{array}{l}\text { RBC- } \\
\text { Model }\end{array}$ & $\begin{array}{c}\text { Risk } \\
\text { Model }\end{array}$ \\
\hline $\begin{array}{l}\text { Volatility } \\
\text { of Output }\end{array}$ & $4.23 \%$ & $4.32 \%$ & $3.22 \%$ & $0.18 \%$ \\
\hline \multicolumn{5}{|c|}{ Volatility of aggregate variables relative to output volatility } \\
\hline Consumption & 0.29 & 0.28 & 0.36 & 0.92 \\
\hline Investment & 4.87 & 4.92 & 4.49 & 7.16 \\
\hline Employment & 0.77 & 0.78 & 0.72 & 1.50 \\
\hline \multicolumn{5}{|l|}{ Persistence } \\
\hline Output & 0.43 & 0.46 & 0.31 & 0.56 \\
\hline Consumption & 0.68 & 0.67 & 0.55 & 0.42 \\
\hline Investment & 0.37 & 0.41 & 0.26 & 0.26 \\
\hline Employment & 0.36 & 0.40 & 0.26 & 0.24 \\
\hline \multicolumn{5}{|c|}{ Contemporaneous Correlation with Aggregate Output } \\
\hline Consumption & 0.81 & 0.82 & 0.84 & 0.02 \\
\hline Investment & 0.98 & 0.98 & 0.97 & 0.79 \\
\hline Employment & 0.98 & 0.98 & 0.96 & 0.72 \\
\hline
\end{tabular}

Notes: See notes to Table 38. 
Table 41: Aggregate Business Cycle Statistics $-v=0.5229$ and $\theta=0.2352$

\begin{tabular}{|c|c|c|c|c|}
\hline & $\begin{array}{c}\text { Full } \\
\text { Model }\end{array}$ & $\begin{array}{l}\text { News } \\
\text { Model }\end{array}$ & $\begin{array}{l}\text { RBC- } \\
\text { Model }\end{array}$ & $\begin{array}{c}\text { Risk } \\
\text { Model }\end{array}$ \\
\hline $\begin{array}{l}\text { Volatility } \\
\text { of Output }\end{array}$ & $3.91 \%$ & $4.08 \%$ & $3.15 \%$ & $0.28 \%$ \\
\hline \multicolumn{5}{|c|}{ Volatility of aggregate variables relative to output volatility } \\
\hline Consumption & 0.30 & 0.29 & 0.36 & 0.78 \\
\hline Investment & 4.25 & 4.29 & 3.97 & 5.86 \\
\hline Employment & 0.77 & 0.78 & 0.72 & 1.38 \\
\hline \multicolumn{5}{|l|}{ Persistence } \\
\hline Output & 0.39 & 0.43 & 0.32 & 0.62 \\
\hline Consumption & 0.66 & 0.65 & 0.56 & 0.56 \\
\hline Investment & 0.32 & 0.38 & 0.27 & 0.39 \\
\hline Employment & 0.30 & 0.37 & 0.27 & 0.35 \\
\hline \multicolumn{5}{|c|}{ Contemporaneous Correlation with Aggregate Output } \\
\hline Consumption & 0.82 & 0.83 & 0.85 & 0.05 \\
\hline Investment & 0.98 & 0.98 & 0.98 & 0.84 \\
\hline Employment & 0.97 & 0.98 & 0.96 & 0.77 \\
\hline
\end{tabular}

Notes: See notes to Table 38. $v=0.5229$ and $\theta=0.2352$ are used for computing aggregate Solow residuals and in the model simulations (firm-level Solow residuals are unchanged compared to the baseline empirical results). The aggregate driving force is re-estimated: $\varrho_{A}=\left(\begin{array}{cc}0.467 & -3.828 \\ 0.0581 & 0.6855\end{array}\right)$ and $\Omega=\left(\begin{array}{ll}0.0149 & 0.1740 \\ 0.1740 & 0.0023\end{array}\right)$. The univariate AR(1)processes for the 'RBC Model' and the 'Risk Model', respectively, are: autocorrelation: 0.5283 and 0.5685; standard deviation of the innovation: 0.0186 and 0.0028 . The adjustment costs factor, $\bar{\xi}$, is re-calibrated to 0.3 . 
Table 42: Aggregate Business Cycle Statistics - Lower Markup, Lower Curvature

\begin{tabular}{|c|c|c|c|c|}
\hline & $\begin{array}{c}\text { Full } \\
\text { Model }\end{array}$ & $\begin{array}{l}\text { News } \\
\text { Model }\end{array}$ & $\begin{array}{l}\text { RBC- } \\
\text { Model }\end{array}$ & $\begin{array}{c}\text { Risk } \\
\text { Model }\end{array}$ \\
\hline $\begin{array}{l}\text { Volatility } \\
\text { of Output }\end{array}$ & $4.54 \%$ & $4.75 \%$ & $3.42 \%$ & $0.38 \%$ \\
\hline \multicolumn{5}{|c|}{ Volatility of aggregate variables relative to output volatility } \\
\hline Consumption & 0.26 & 0.24 & 0.32 & 0.72 \\
\hline Investment & 3.81 & 3.82 & 3.55 & 4.74 \\
\hline Employment & 0.80 & 0.81 & 0.75 & 1.29 \\
\hline \multicolumn{5}{|l|}{ Persistence } \\
\hline Output & 0.40 & 0.45 & 0.31 & 0.66 \\
\hline Consumption & 0.69 & 0.67 & 0.59 & 0.63 \\
\hline Investment & 0.34 & 0.41 & 0.27 & 0.52 \\
\hline Employment & 0.33 & 0.41 & 0.27 & 0.48 \\
\hline \multicolumn{5}{|c|}{ Contemporaneous Correlation with Aggregate Output } \\
\hline Consumption & 0.75 & 0.78 & 0.80 & 0.08 \\
\hline Investment & 0.98 & 0.99 & 0.98 & 0.87 \\
\hline Employment & 0.98 & 0.98 & 0.97 & 0.78 \\
\hline
\end{tabular}

Notes: See notes to Table 38. $v=0.5556$ and $\theta=0.2778$ are set for all sectors. The mark up is now 1.20 , the capital elasticity of the revenue function 0.63. Both firm-level and aggregate Solow residuals are recomputed and the aggregate driving force re-estimated: $\varrho_{A}=\left(\begin{array}{cc}0.4522 & -4.0152 \\ 0.0597 & 0.7096\end{array}\right)$ and $\Omega=\left(\begin{array}{cc}0.0148 & 0.1581 \\ 0.1581 & 0.0022\end{array}\right)$. The univariate AR(1)processes for the 'RBC Model' and the 'Risk Model', respectively, are: autocorrelation: 0.5267 and 0.5762; standard deviation of the innovation: 0.0186 and 0.0027 . The adjustment costs factor, $\bar{\xi}$, is re-calibrated to 0.3 . 
Table 43: Aggregate Business CyCle Statistics - SUR

\begin{tabular}{|c|c|c|c|c|c|}
\hline & $\begin{array}{c}\text { Full } \\
\text { Model }\end{array}$ & $\begin{array}{c}\text { Full } \\
\text { Model } \\
\text { SUR }\end{array}$ & $\begin{array}{l}\text { News } \\
\text { Model }\end{array}$ & $\begin{array}{c}\text { News } \\
\text { Model } \\
\text { SUR }\end{array}$ & $\begin{array}{c}\text { RBC } \\
\text { Model }\end{array}$ \\
\hline $\begin{array}{l}\text { Volatility } \\
\text { of Output }\end{array}$ & $4.05 \%$ & $3.12 \%$ & $4.25 \%$ & $3.19 \%$ & $3.18 \%$ \\
\hline \multicolumn{6}{|c|}{ Volatility of aggregate variables relative to output volatility } \\
\hline Consumption & 0.31 & 0.43 & 0.30 & 0.37 & 0.38 \\
\hline Investment & 4.74 & 4.42 & 4.79 & 4.48 & 4.39 \\
\hline Employment & 0.75 & 0.71 & 0.76 & 0.71 & 0.70 \\
\hline \multicolumn{6}{|l|}{ Persistence } \\
\hline Output & 0.42 & 0.20 & 0.46 & 0.23 & 0.31 \\
\hline Consumption & 0.67 & 0.58 & 0.66 & 0.54 & 0.54 \\
\hline Investment & 0.34 & 0.11 & 0.41 & 0.17 & 0.25 \\
\hline Employment & 0.33 & 0.10 & 0.40 & 0.17 & 0.25 \\
\hline \multicolumn{6}{|c|}{ Contemporaneous Correlation with Aggregate Output } \\
\hline Consumption & 0.83 & 0.80 & 0.85 & 0.85 & 0.86 \\
\hline Investment & 0.98 & 0.95 & 0.98 & 0.95 & 0.97 \\
\hline Employment & 0.97 & 0.93 & 0.98 & 0.96 & 0.96 \\
\hline
\end{tabular}

Notes: See notes to Table 38. SUR means a specification of the aggregate driving force, where the off-diagonal elements of $\varrho_{A}$ in (2) are restricted to zero. $\varrho_{A}=\left(\begin{array}{cc}0.4717 & 0 \\ 0 & 0.7335\end{array}\right)$ and $\Omega=\left(\begin{array}{ll}0.0186 & 0.1707 \\ 0.1707 & 0.0026\end{array}\right)$. Recall that the autocorrelation for the 'RBC Model' is 0.5259 , and the standard deviation of the innovation is 0.0182 . 
This section concludes by displaying the impulse responses - both for the data and 'Full Model' as well as 'News Model' - with respect to a first moment shock, i.e. an innovation to aggregate Solow residuals, in the same SVARs that we estimated and discussed in Section 5.1. Specifically, we show the impulse responses for aggregate output, consumption, the aggregate investment rate, aggregate employment, total hours and the real wage. Except for the general excess volatility that our baseline calibration suffers from, data and model impulse responses are very similar and theoretically reasonable.

Figure 14: Impulse Responses to a Shock in the Aggregate Solow Residual

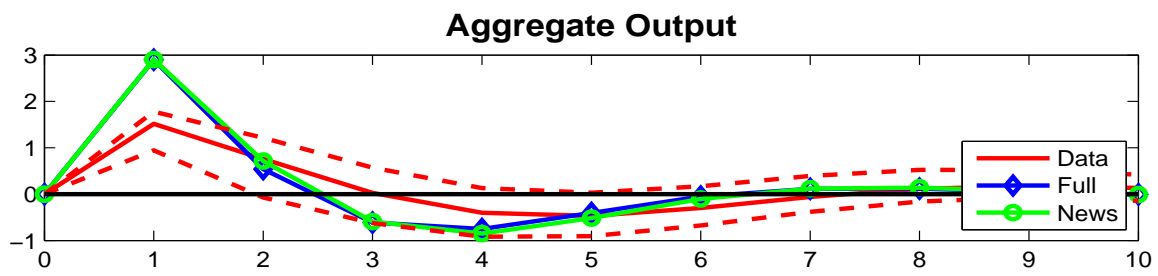

Aggregate Investment Rate

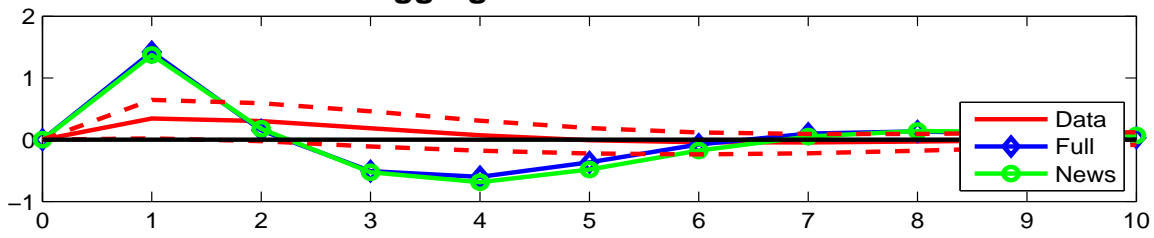

Aggregate Consumption

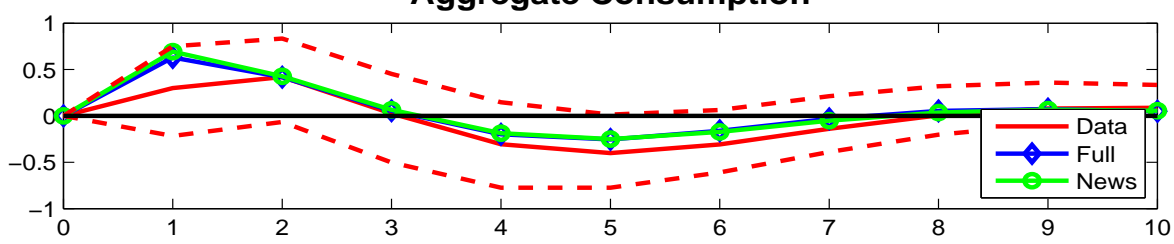

Notes: Impulse response functions from SVAR estimations of the linearly detrended aggregate Solow residual (ordered first), the linearly detrended idiosyncratic uncertainty (ordered second) and some other HP(100)-filtered aggregate variable, such as output, consumption, etc. (ordered third). The aggregate investment rate is linearly detrended. The dotted lines reflect $95 \%$ confidence bounds for the estimates from the data from 10,000 bootstrap replications. Estimates from data are in red, estimates from simulated data in blue ('Full Model') and green ('News Model'), respectively. Estimates from simulated data are the average of 60 impulse response functions estimated on 60 independent time series of $T=26$, the length of our sample. 
Figure 15: Impulse Responses to a Shock in the Aggregate Solow Residual

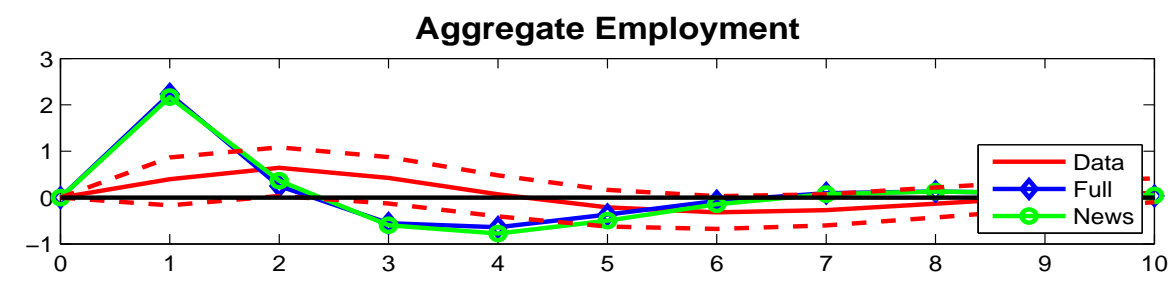

Aggregate Hours

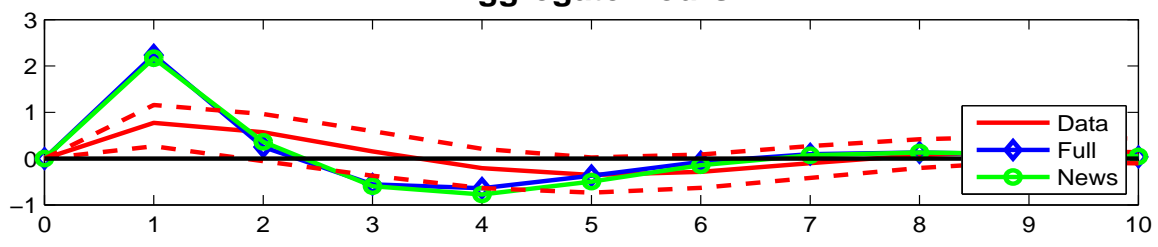

Real Wage

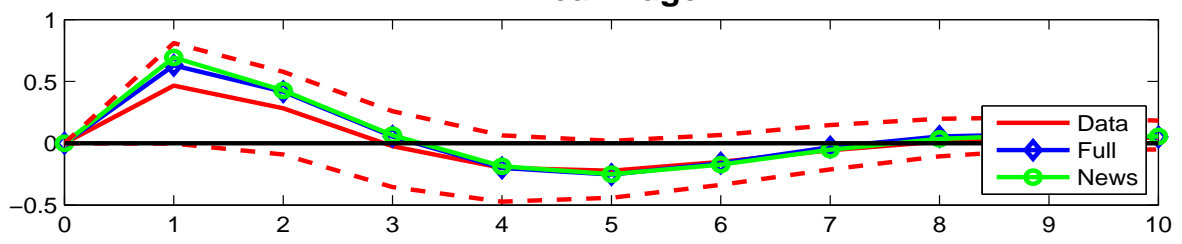

Notes: See notes to Figure 14. 